\title{
Mine reclamation using biofuel crops: Insights into the microbial ecology of the switchgrass (Panicum virgatum) microbiome
}

\author{
Brianna L. Mayfield \\ West Virginia University, blm0021@mix.wvu.edu
}

Follow this and additional works at: https://researchrepository.wvu.edu/etd

Part of the Environmental Microbiology and Microbial Ecology Commons

\author{
Recommended Citation \\ Mayfield, Brianna L., "Mine reclamation using biofuel crops: Insights into the microbial ecology of the \\ switchgrass (Panicum virgatum) microbiome" (2019). Graduate Theses, Dissertations, and Problem \\ Reports. 3808. \\ https://researchrepository.wvu.edu/etd/3808
}

This Thesis is protected by copyright and/or related rights. It has been brought to you by the The Research Repository @ WVU with permission from the rights-holder(s). You are free to use this Thesis in any way that is permitted by the copyright and related rights legislation that applies to your use. For other uses you must obtain permission from the rights-holder(s) directly, unless additional rights are indicated by a Creative Commons license in the record and/ or on the work itself. This Thesis has been accepted for inclusion in WVU Graduate Theses, Dissertations, and Problem Reports collection by an authorized administrator of The Research Repository @ WVU. For more information, please contact researchrepository@mail.wvu.edu. 
Mine reclamation using biofuel crops: Insights into the microbial ecology of the switchgrass (Panicum virgatum) microbiome

\author{
Brianna Mayfield
}

Thesis submitted to the Davis College of Agriculture, Natural Resources and Design at West Virginia University in partial fulfillment of the requirements for the degree of

\author{
Master of Science in \\ Applied and Environmental Microbiology
}

Zachary Freedman, Ph.D., Chair

Jeffrey Skousen, Ph.D.

Edward Brzostek, Ph.D.

Division of Plant and Soil Sciences

Morgantown, West Virginia

2019

Keywords: surface mine reclamation, bioenergy crops, microbial ecology, soil enzymes, soil metagenomics 


\begin{abstract}
Mine reclamation using biofuel crops: Insights into the microbial ecology of the switchgrass (Panicum virgatum) microbiome

Brianna Mayfield
\end{abstract}

Bioenergy crop production has steadily increased due to growing political support for renewable energy, thus initiating a demand to find alternative agricultural land. An innovative option is the use of marginal soils, such as reclaimed mine lands, to produce bioenergy crops. Switchgrass (Panicum virgatum) is a promising bioenergy crop that can be grown on marginal lands due to its robust growth in various soil types and climates. However, little is known regarding plantmicrobe interactions among switchgrass systems within reclaimed mine lands. A study conducted in 2008 grew switchgrass on high- and low- quality reclaimed mine sites (Hampshire and Hobet, respectively) in West Virginia to examine the resilience of switchgrass as a reclamation-friendly bioenergy crop. Switchgrass yields at Hampshire were nearly an order of magnitude higher than Hobet (8.4 Mg ha-1 vs $1.0 \mathrm{Mg}$ ha-1). Within Hampshire, the Cave-inRock cultivar yield was approximately 2-fold greater than that of Shawnee (12.9 $\mathrm{Mg} \mathrm{ha}^{-1}$ vs. 7.6 $\left.\mathrm{Mg} \mathrm{ha}^{-1}\right)$. Here, I sought to illuminate plant-microbial interactions that may account for this drastic shift in cultivar yield by assessing the soil microbial community's function and composition. I tested two hypotheses: i) that the microbial community's ability to acquire $\mathrm{C}, \mathrm{N}$, and $\mathrm{P}$ will be greatest in Hampshire soils compared to that of Hobet and ii) that there will be a cultivar-specific root-associated microbiome that may drive previously observed greater, but differential yields across switchgrass cultivars at Hampshire. I found that reclamation strategy substantially impacts the switchgrass microbiome's composition as well as its ability to acquire critical nutrients like carbon, nitrogen, and phosphorus. I also found that a functionally, but not necessarily compositionally, unique microbiome exists in the root-associated soils compared to that of the bulk soil. Additionally, there were indicators that organic amendments to the topsoil may induce cultivar-specific soil microbiomes that mediate or facilitate differential yields within Hampshire. Taken together, I suggest that organic amendments to the topsoil during reclamation selects for a cultivar-specific microbiome more adept to acquiring critical nutrients and thus, increases aboveground productivity. 


\section{Acknowledgements}

I would like to thank the members of the Freedman lab: Greg Martin, Jenni Kane, Elisabeth Six, and Kinsey Reed for their insight and assistance. I thank my undergraduate research assistant, Taylor Paeth, for assisting in data acquisition and analysis. I thank Michael Gates for the unwavering moral support throughout my coursework and research. Finally, I thank my advisor, Dr. Freedman, for his continuing dedication and encouragement as I work towards becoming a successful researcher. Without you all, this work would not be possible. 


\section{Table of Contents}

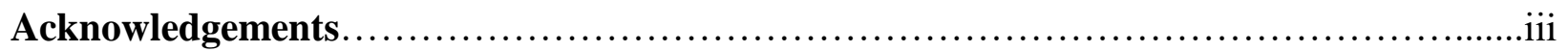

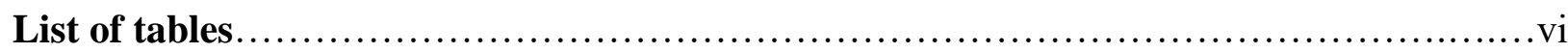

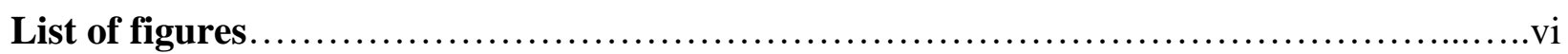

Chapter 1: Surface mine reclamation strategy alters the microbial community function and composition in switchgrass (Panicum virgatum) soils...............................

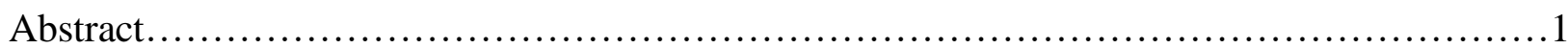

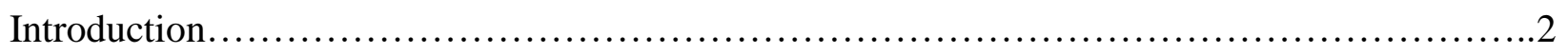

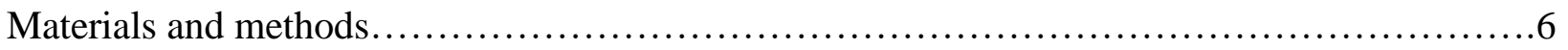

Site Locations.........................................................6

Soil Properties $\quad$ …....................................................

Extracellular Enzyme Activity..............................................

DNA Extraction and Sequencing ............................................

Bacterial and Fungal Community Composition...................................

Functional Gene Identification............................................ 10

Statistical Analyses....................................................... 12

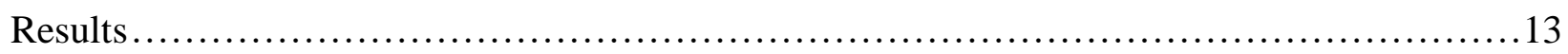

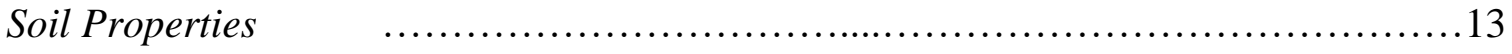

Switchgrass microbiome extracellular enzyme activity .............................14

Bacterial and fungal taxonomy and composition .................................. 14

Metagenomic assessment of the switchgrass microbiome ...............................16

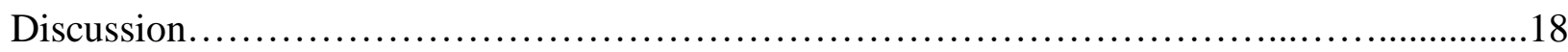

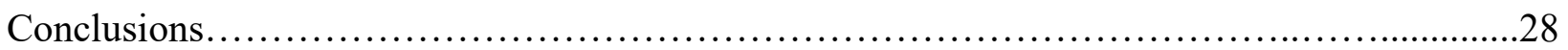


Chapter 2: cultivar-specific microbiomes may modulate switchgrass (Panicum virgatum) biomass yields on reclaimed mine sites in West Virginia ..............................29

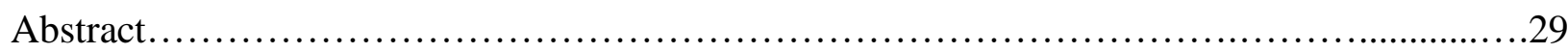

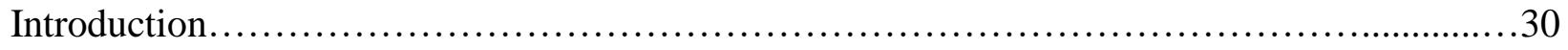

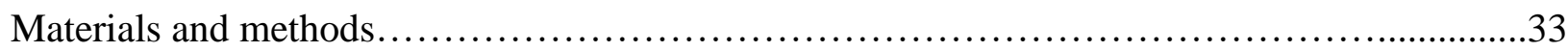

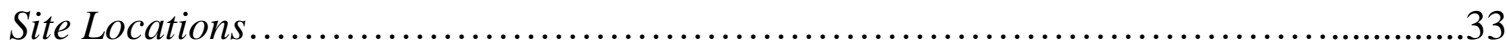

Soil Properties............................................................ 34

Extracellular Enzyme Activity.................................................35

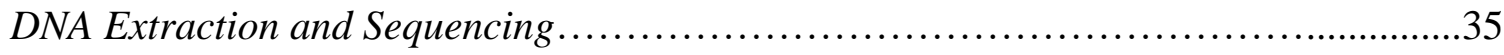

Bacterial and Fungal Community Composition .....................................36

Statistical Analyses......................................................... 36

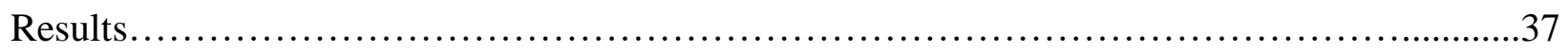

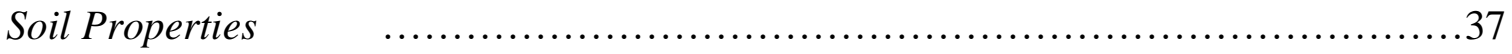

Switchgrass microbiome extracellular enzyme activity................................38

Bacterial and fungal taxonomy and composition ...................................38

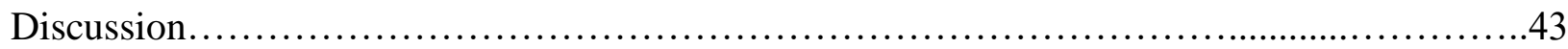

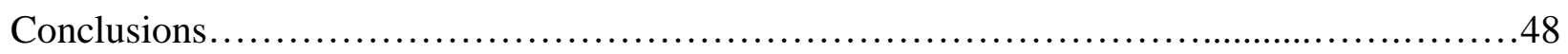

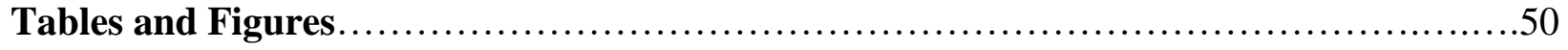

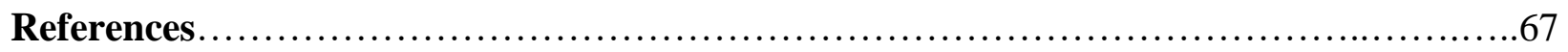




\section{List of Tables}

\section{Chapter 1}

Table 1: Site characteristics and soil chemical/physical properties at Hampshire and Hobet......48

Table 2: Summary of functional genes used in metagenomic analyses......................49

\section{Chapter 2}

Table 3: Site characteristics and soil chemical/physical properties among switchgrass cultivars

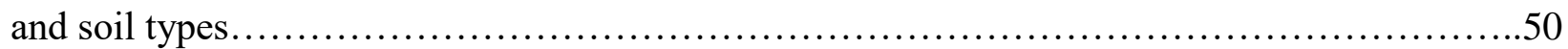

Table 4: The relative abundance of bacterial taxa-associated P-values from a 3-way ANOVA...51

Table 5: The relative abundance of fungal taxa-associated P-values from a 3-way ANOVA......52

\section{List of Figures}

\section{Chapter 1}

Figure 1: Extracellular enzyme activity responses of $\beta$-glucosidase, $\mathrm{N}$-acetyl-glucosaminidase (NAGase), and acid phosphatase to differing reclamation techniques.......................53

Figure 2: The effect of reclamation strategy on the bacterial and fungal richness of the switchgrass microbiome.

Figure 3: The effect of reclamation strategy on the bacterial and fungal community composition of the switchgrass microbiome .55

Figure 4: The effect of reclamation strategy on selected bacterial taxa.....................56

Figure 5: The effect of reclamation strategy on selected fungal taxa......................57 
Figure 6: The effect of reclamation technique on the relative abundance of $\mathrm{C}-, \mathrm{N}-$, and $\mathrm{P}-$

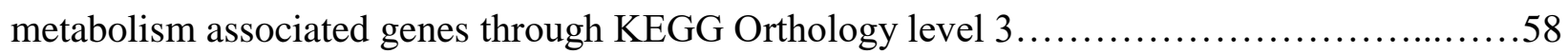

Figure 7: The effect of reclamation strategy on the relative abundances of C-, N-, and P-

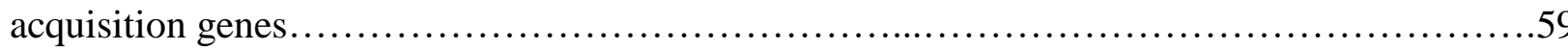

\section{Chapter 2}

Figure 8: Extracellular enzyme activity responses of $\beta$-glucosidase, $\mathrm{N}$-acetyl-glucosaminidase (NAGase), and acid phosphatase across switchgrass cultivars and soil types.................60

Figure 9: The effect of reclamation strategy on the bacterial and fungal richness of the switchgrass microbiome

Figure 10: The effect of reclamation strategy on the bacterial and fungal community composition of the switchgrass microbiome

Figure 11: The effect of reclamation strategy on the relative abundance of bacterial taxa.......63

Figure 12: The effect of reclamation strategy on the relative abundance of fungal taxa..........64 


\title{
Chapter 1: Surface mine reclamation strategy alters the microbial community function and composition in switchgrass (Panicum virgatum) soils.
}

\begin{abstract}
Since the 1970's, bioenergy crop production has steadily increased, initiating demand to find alternative growing land. An innovative option is the use of marginal lands, such as reclaimed mine lands, for bioenergy crop agriculture. Switchgrass (Panicum virgatum) is a promising bioenergy crop that can be grown on marginal lands due to its robust growth in various soil types and climates. However, little is known regarding plant-microbe interactions among switchgrass systems within reclaimed mine lands. A study conducted in 2008 grew switchgrass on high- and low- quality reclaimed mine sites (Hampshire and Hobet, respectively) in West Virginia to examine the feasibility of switchgrass as a reclamation-friendly bioenergy crop. Switchgrass yields at Hampshire were nearly an order of magnitude higher than Hobet $\left(8.4 \mathrm{Mg} \mathrm{ha}^{-1}\right.$ vs 1.0 $\mathrm{Mg} \mathrm{ha}^{-1}$ ). Within Hampshire, the Cave-in-Rock cultivar yield was approximately 2-fold greater than that of Shawnee (12.9 $\mathrm{Mg} \mathrm{ha}^{-1}$ vs. $\left.7.6 \mathrm{Mg} \mathrm{ha}^{-1}\right)$. Here, I sought to identify plant-microbial interactions that may account for this shift in cultivar yield by combining enzymatic activity analyses with shotgun metagenomics. I tested two hypotheses: i) that the microbial community's ability to acquire $\mathrm{C}, \mathrm{N}$, and $\mathrm{P}$ as well as the abundance of functional genes encoding enzymes associated with $\mathrm{C}, \mathrm{N}$, and $\mathrm{P}$ acquisition will be greatest in Hampshire soils compared to that of Hobet and ii) that there will be a cultivar-specific microbiome that may drive previously observed greater, but differential yields across switchgrass cultivars at Hampshire. Hampshire soils showed significant increases in extracellular enzyme activities associated with the mineralization and acquisition of $\mathrm{C}$ and $\mathrm{N}$ compared to Hobet, whereas the activity of an enzyme associated with $\mathrm{P}$ acquisition was variable across sites and cultivars. Metagenomic analyses revealed significant increases in carbon, nitrogen, and phosphorus metabolism-associated gene abundances within Hampshire's microbiome, but showed no differences in housekeeping genes across sites. Further, a taxonomically-unique bacterial community was found between sites but not cultivars, with Hampshire soils having a greater abundance of copiotrophic bacteria while Hobet soils had a greater abundance of oligotrophic bacteria. Similarly, a taxonomically-unique fungal community was found between sites but not cultivars, with Hampshire soils having a greater abundance of fungi that preferentially degrade labile $\mathrm{C}$ compounds while Hobet soils had a greater abundance of fungi that preferentially degrade recalcitrant $\mathrm{C}$ compounds. Throughout, there were no cultivar-specific microbiome differences observed. Together, these data suggest that differences in soil quality due to different reclamation strategies foster a compositionally and functionally unique soil microbiome but they do not suggest microbiome-influenced differences in yield across cultivars.
\end{abstract}




\section{Introduction}

In an effort to reduce the dependence, acquisition costs, and environmental implications of fossil fuel use, renewable energy production (i.e., bioenergy, solar, etc.) has gained substantial momentum in the past 30 years. To date, renewable energy sources comprise approximately $12 \%$ of the United States energy consumption market, with $44 \%$ sourced from plant biomass (U.S. Energy Information Administration 2019). With a forecasted 30\% increase in global population (United Nations Department of Economic and Social Affairs 2017) and a 110\% increase in global food and biomass crop production estimated by 2050 (Tilman et al. 2011), increased demands for productive growing land are inevitable. However, the environmental and economic sustainability of planting cellulosic or non-feedstock crops on agricultural land has been a highly debated matter in recent years (Koh and Ghazoul 2008; Rajagopal et al. 2007).

One possible means of producing biofuel crops is using marginal lands, that is, lands that have soils that harbor undesirable characteristics or are of little agricultural value. One type of marginal land that is particularly promising for the production of bioenergy crops are reclaimed mine lands (Skousen et al. 2013; Varvel et al. 2008). The Surface Mining and Reclamation Act (SMCRA) of 1977 requires that these lands be reclaimed to equal or better condition once mining ceases (U.S. Department of the Interior 1977), which can plausibly be achieved by productively farming marginal lands for bioenergy crops. One particularly favorable bioenergy crop is switchgrass (Panicum virgatum): a low-input high-yield bioenergy crop that can be grown in marginal soils due to its commercial scale growth in various soil types and climates as well as its ability to increase soil productivity and nutrient (namely carbon $(\mathrm{C})$ and nitrogen $(\mathrm{N})$ ) cycling (McLaughlin and Adams Kszos 2005). More specifically, the large roots systems of switchgrass have been found to stabilize soil and aid in soil organic carbon (SOC) sequestration, 
both of which are important for successful mine land reclamation (Liebig et al. 2005). While promising, several questions persist such as how to grow dedicated bioenergy crops like switchgrass on marginal lands, and whether these sites can produce abundant biomass while maintaining or improving ecosystem services (Blanco-Canqui 2016). Further, switchgrass cultivars have been found to respond to their environment differently (Casler and Boe 2003), making it imperative to gain insight into switchgrass cultivar-specific responses across sites of different soil qualities.

Microorganisms inhabiting the soil (i.e., soil microbiome) can associate with plants to confer various ecosystem services and are key components in establishing and maintaining soil fertility. For example, the soil microbiome is largely responsible for the mineralization and acquisition of critical nutrients, such as $\mathrm{C}, \mathrm{N}$, and P-containing compounds, that are needed for both plant and microbial success (Chapman et al. 2005; Fierer et al. 2012). Associations with beneficial soil bacteria and fungi, termed plant growth-promoting microbes, have been found to enhance switchgrass aboveground biomass yields (Kim-Dura et al. 2016; Xia et al. 2013; Xia, Amna, and Opiyo 2018). Notably, switchgrass form associations with endophytic fungi called arbuscular mycorrhizal (AM) fungi, which are responsible for converting soil P into plantavailable forms (Clark et al. 1999; George et al. 1995) as well as enhancing aboveground biomass (Brejda, Moser, and Vogel 1998).

The diversity and functionality of the soil microbiome is largely shaped by the site's soil properties, such as moisture, $\mathrm{pH}$, and C:N ratios (Van Horn et al. 2014; Rousk et al. 2010; Heuck et al. 2015). Nutrient availability, in particular, selects for a microbiome that exploits the resources available within the environment, a phenomenon called the copiotroph-oligotroph framework that aims to classify microorganisms based upon microbial life strategies (Fierer, 
Bradford, and Jackson 2007; Ho et al. 2017). Within this framework, copiotrophic microorganisms are considered fast-growing taxa that thrive in environments with readilyavailable C compounds (Fierer et al. 2007). In contrast, oligotrophic microorganisms are considered slower-growing taxa that thrive under low C conditions (Ishida and Kadota 1981; Kuznetsov, Dubinina, and Lapteva 1979). The copiotroph-oligotroph framework has been utilized as a soil fertility indicator (Swedrzyńska et al. 2013), and may be a valuable tool for assessing the disturbance impacts and reclamation initiatives on reclaimed surface mines (Wolna-Maruwka et al. 2007).

Although land disturbance, such as surface mine reclamation, fundamentally alters both the physicochemical properties of soil and the soil microbiome, recent insights into productive farming potential on reclaimed lands have yielded promising results, especially for switchgrass (Mummeyet al. 2002; Tang et al. 2010; Marra et al. 2013). Within the past decade, studies have described the soil microbiome of switchgrass grown on dedicated cropland (Bahulikar et al. 2014; Chaudhary et al. 2012; Jesus et al. 2016), but little is known regarding the cultivar-specific nutrient cycling and genomic capacities of the switchgrass microbiome on reclaimed mine lands. An improved understanding of the switchgrass microbiome will provide insight into bioenergy crop management strategies as well as reclamation impacts on critical soil biogeochemical processes in marginal soils.

In 2008, a field study was developed to quantify the aboveground productivity of three switchgrass cultivars on two surface mines, Hampshire Hill mine and Hobet 21 mine, that were experimentally reclaimed in different manners (Brown et al. 2016). Hampshire was reclaimed with topsoil and organic amendments; a technique historically found to promote aboveground biomass yields and increase soil productivity (Larney and Angers 2012). Hobet was reclaimed 
without topsoil or any amendments; a technique historically found to limit productivity due to unfavorable changes to soil physicochemical properties (Haering, Daniels, and Roberts 1993). Ultimately, Hampshire's reclamation technique led to switchgrass yields 13 times higher compared to yields at Hobet. Further, yield of the Cave-in-Rock cultivar was 70\% greater than that of the Shawnee cultivar at Hampshire, but similar differences between cultivar yield were not observed at Hobet (Brown et al. 2016). While this study quantified yield differences across two sites with different reclamation strategies, the potential influence of belowground microbial dynamics that may result in differential productivity between cultivars at Hampshire, and not at Hobet, are unknown.

Here, I assessed the function, composition, and metagenomic capacity of the soil microbiome beneath the two highest yielding cultivars of switchgrass, Cave-in-Rock and Shawnee, in long-term switchgrass plots. To do so, extracellular enzyme assays were performed in parallel with high-throughput ribosomal rRNA gene sequencing and shotgun metagenomics. Specifically, I tested two hypotheses: i) that the microbial community's ability to acquire C, N, and $\mathrm{P}$ as well as the abundance of functional genes encoding enzymes associated with $\mathrm{C}, \mathrm{N}$, and P acquisition will be greatest in Hampshire soils compared to that of Hobet and ii) that there will be a cultivar-specific microbiome that may drive previously observed greater, but differential yields across switchgrass cultivars at Hampshire. In this way, I obtained insight into the marginal land switchgrass microbiome, leading to a better understanding of the functional and genomic capacity attributable to differential reclamation strategies and yield response at Hampshire and Hobet. 


\section{Materials and Methods}

\section{Site Locations}

To investigate the influence of mine reclamation strategy and switchgrass cultivar on the composition and metagenomic capacity of the soil microbiome, soils were sampled from long term switchgrass plots on reclaimed mine sites in West Virginia, USA (Table 1.). Experimental plots within each site were laid out in a completely randomized block design in 2008. Each site was reclaimed using a different reclamation strategy. Briefly, the Hampshire Hill mine, hereafter referred to as Hampshire, was reclaimed using topsoil amended with municipal sewage waste and paper pulp spread over the existing overburden. The Hobet 21 mine, hereafter referred to as Hobet, was reclaimed using crushed, unweathered overburden that was regraded to approximate original contour. Once reclaimed, three replicate $4,000 \mathrm{~m}^{2}$ plots of each switchgrass cultivar (Cave-in-Rock and Shawnee) were broadcast seeded across each plot. Further detail regarding reclamation strategy can be found in Brown et al. (2016).

Soil sampling occurred in late May 2017, during a time at which ample moisture favored high rates of microbial activity and 9 years after the switchgrass stands were seeded. Within each plot, 10 soil cores were randomly collected at the base of a switchgrass plant to a depth of $15 \mathrm{~cm}$ (A horizon). Soil cores were homogenized and composited to yield one sample per plot. All samples were placed on ice and transported to West Virginia University where the soil was immediately passed through a $2 \mathrm{~mm}$ sieve to remove roots and rocks. A portion of each homogenized and sieved soil sample was stored at $-4^{\circ} \mathrm{C}$ for enzyme and soil chemical analysis and the remainder was stored at $-80^{\circ} \mathrm{C}$ for DNA extraction. 


\section{Soil Properties}

Soil $\mathrm{pH}$ was determined using a 1:5 soil: $0.01 \mathrm{M} \mathrm{CaCl}_{2}$ suspension with samples shaking at $60 \mathrm{rpm}$ for 30 minutes (Rayment and Higginson 1992). Soil moisture was determined gravimetrically by drying soil samples at $105^{\circ} \mathrm{C}$ for 24 hours. Using this dried soil, organic matter content was assessed by combustion at $505^{\circ} \mathrm{C}$ for 6 hours via loss on ignition. To assess soil texture, soil samples were placed in a muffle furnace for 5 hours to remove organic matter at which point a hydrometer was used to quantify sand, silt, and clay proportions (American Society for Testing and Materials 1985). Microbial biomass was estimated by substrate-induced respiration (SIR), which measures induced microbial respiration when presented a labile carbon source (West and Sparling 1986). The average microbiome respiration rate $\left(\mathrm{mg} \mathrm{C}-\mathrm{CO}_{2} \mathrm{~g} \mathrm{soil}^{-1} \mathrm{~h}^{-}\right.$

${ }^{1}$ ) was quantified by implementing adaptations to the West and Sparling protocol as described by Fierer, Schimel and Holden (2003). Soil total C, total N, and C:N ratios were determined by combusting approximately $250 \mathrm{mg}$ air-dried, milled soils using a vario MAX cube (Elementar, Langenselbold, Germany).

\section{Extracellular Enzyme Activity}

To determine the microbial potential to mineralize $\mathrm{C}, \mathrm{N}$ and $\mathrm{P}$ from organic matter, extracellular enzymatic activities associated with $\mathrm{C}-, \mathrm{N}-$, and $\mathrm{P}$ - acquisition were assessed, namely $\beta$-glucosidase (BG; EC 3.2.1.21), N-acetyl-glucosaminidase (NAGase; EC 3.2.1.50), and acid phosphatase (ACP; EC 3.1.3.2), respectively. Enzyme assays were performed according to the fluorometric protocol from Saiya-Cork, Sinsabaugh and Zak (2002) and read at $365 \mathrm{~nm}$ excitation and $450 \mathrm{~nm}$ emission on a Synergy HTX plate reader (Biotek, Winooski, VT). Enzymatic activity was expressed as $\mu \mathrm{mol} \mathrm{h} \mathrm{h}^{-1}$ of oxidized substrate per gram soil. 


\section{DNA Extraction and Sequencing}

DNA was extracted in triplicate from $1.5 \mathrm{~g}$ total of each soil sample within 72 hours of sample collection. A PowerLyzer PowerSoil DNA isolation kit (Qiagen, Valencia, CA) was used following manufacturer's instructions in conjunction with a PowerLyzer 24 homogenizer (MoBio Laboratories, Carlsbad, CA). Purified DNA was quality checked on a ND8000 Nanodrop (Thermo Scientific, Waltham, MA) and quantified using a Qubit 4 Fluorometer (Thermo Scientific, Waltham, MA). Quantified DNA was submitted for high throughput sequencing of the bacterial 16S rRNA gene and the fungal internal transcribed spacer (ITS) region, as well as for the generation of shotgun metagenomes from total extracted DNA through the U.S. Department of Energy Joint Genome Institute (JGI) sequencing facility (JGI Project ID \#1159680). Briefly, $10 \mathrm{ng}$ of extracted DNA was used as template to amplify the V4-V5 region of the 16S rRNA gene using universal bacterial primers 515F (Parada, Needham, and Fuhrman 2016) and 805R (Apprill et al. 2015).The fungal ITS2 region was amplified using ITS9F and ITS4R universal fungal primers (Menkis et al. 2012; White et al. 1990). Unique i7 index barcode identifiers were included in the reverse primer. PCR reactions were performed in triplicate using the 5PRIME HotMasterMix (QuantaBio, Beverly, MA) under the following thermalcycling conditions: an initial 3 minutes at $94{ }^{\circ} \mathrm{C}, 30$ cycles of 45 seconds at $94{ }^{\circ} \mathrm{C}, 60$ seconds at $50{ }^{\circ} \mathrm{C}$, and 90 seconds at $72{ }^{\circ} \mathrm{C}$, a final 10 minutes at $72{ }^{\circ} \mathrm{C}$ once cycles were complete, then held at 4 ${ }^{\circ} \mathrm{C}$. Reactions were pooled to yield a single $16 \mathrm{~S}$ rRNA and ITS product per sample. Pooled amplicons were purified using 1.2X AMPure XP beads (Beckman Coulter, Brea, CA) prior sequencing. Purified barcoded amplicons were composited in equimolar concentrations for sequencing using an Illumina MiSeq 2x300 base read platform (Illumina, San Diego, CA). For 
shotgun metagenome generation, total extracted DNA was barcoded by plot and composited in equimolar concentrations for sequencing using an Illumina HiSeq 2000 2x151 base read platform (Illumina, San Diego, CA). Ribosomal rRNA gene sequences are publicly available through the NCBI Sequence Read Archive (accession PRJNA533292) and metagenomic sequence data is publicly available on the Metagenomic Rapid Annotations using Subsystems Technology (MGRAST) server (Meyer et al. 2008) under ID number mgm4776043.3.

\section{Bacterial and Fungal Community Composition}

For both 16S rRNA gene and ITS analyses, forward and reverse reads were joined using USEARCH (Edgar 2010) and the paired sequences were further processed in QIIME (version 1.9.1; Caporaso et al. 2010). Sequences were quality controlled by removing OTUs that were observed fewer than 5 times. Open reference operational taxonomic units (OTU) were picked using default parameters and the UCLUST (Edgar 2010) algorithm in QIIME. Sequences were rarified to 2,500 16S rRNA sequences per plot and 40,000 ITS sequences per plot. After rarifying, taxonomic assignments were performed at $90 \%$ similarity by comparing $16 \mathrm{~S}$ rRNA OTUs against the Greengenes reference database (version 13.8; Mcdonald et al. 2012) using UCLUST and by comparing ITS OTUs against the UNITE reference database (version 8.0; UNITE Community 2019) using BLAST (Altschul et al. 1990). Initial ITS taxonomic assignments yielded a high proportion (41-66\%) of "unassigned" phyla across all samples, so ITS taxonomic assignments were presented as the total hits of all identified phyla per sample and used for all subsequent taxonomic analyses (McGuire et al. 2013; Saravesi et al. 2015). Changes in bacterial and fungal taxonomy across sites and switchgrass cultivars were assessed at the phylum, order, and class level, with unassigned taxa or those under $3 \%$ in all samples binned as “other". Fungal OTUs were classified into ecological guilds at the genus level using FUNGuild 
(Nguyen et al. 2016a). After classification, any observation with a total of less than 3 hits were removed, binned into their primary functional guild, and summed by sample. Microbial community $\alpha$ - and $\beta$-diversity metrics were also calculated in QIIME using Chaol richness (Chao 1984) and Bray-Curtis dissimilarity indices (Bray and Curtis 1957), respectively.

\section{Functional Gene Identification}

Metagenomic libraries were constructed, assembled, and annotated using the JGI's MAP v.4 sequencing pipeline, where adapter sequences were removed and contigs were assembled for each sample ( $n=12$ metagenomes; Huntemann et al. 2016). First, raw sequences were trimmed, contaminants were removed, and reads containing 4 or more ambiguous bases, had an average quality score less than 3 , or had a minimum length of $<=51$ basepairs were removed using BBDuk within the BBTools software package (Bushnell n.d.). Reads were corrected for sequencing errors using BFC (version r181; Li 2015), dereplicated, and unassembled, quality controlled paired-end reads were saved in fasta format for analysis. Additionally, contigs were assembled from quality-controlled (QC) paired-end reads using the SPAdes assembler (version 3.1.1; Nurk et al. 2017) under the following options: -m 2000 --only-assembler -k $33,55,77,99,127$--meta $-t$ 32. All filtered reads were mapped to the final contig assembly using default parameters, with addition of "ambiguous=random" switch, in bbmap (version 37.62) within the BBTools package. Protein-coding genes were identified using a combination of four ab initio gene prediction tools: prokaryotic GeneMark.hmm (version 2.8; Lukashin and Borodovsky 1998), MetaGeneAnnotator (version Aug 2008; Noguchi et al. 2008), Prodigal (version 2.6.2; Hyatt et al. 2010), and FragGeneScan (version 1.16; Rho et al. 2010), and final gene callers were determined on a majority-rule basis. 
The genetic potential of the soil microbial community was assessed using two complimentary approaches: i) by comparing post-QC metagenomic contigs for homology to the Kyoto Encyclopedia of Genes and Genomes (KEGG; Kanehisa and Goto 2000) pathways in MG-RAST and ii) by comparing post-QC metagenomic short reads to locally constructed functional gene databases using DIAMOND (Buchfink, Xie, and Huson 2014) and the blastn and blastx functions within BLAST (Altschul et al. 1990). For KEGG pathway classification, metagenome contigs were assigned to functional pathways using KEGG orthology (KO) under the "representative-hit classification" using the following default cutoffs: a maximum e-value of $10^{-5}$, minimum percent identity of $60 \%$, and a minimum alignment length of $15 \mathrm{bp}$. Homology to KEGG orthologous groups was assessed on level three classifications (herein termed functional pathways) that are associated with C-, N- and P-metabolism, namely starch and sucrose metabolism (herein referred to as C- metabolism; 29 genes included; PATH:ko00500), nitrogen metabolism (27 genes; PATH:ko00910), and phosphonate and phosphinate metabolismassociated (herein referred to as P-metabolism; 5 genes; PATH:ko00440) gene pathways, respectively. The effect of site and switchgrass cultivar on the abundance of functional pathways was assessed after summing the abundances of each gene within the gene pathway and normalizing the number of hits to the total number of predicted protein features for each sample. After classification, any pathway with a total of less than 3 hits were removed prior to analysis.

To delineate fungal from bacterial functional genes, local databases for functional genes associated with C-, N-, and P- acquisition were individually curated using the Carbohydrate Active Enzyme database (CAZy; Lombard et al. 2014) and the Functional Gene Repository (FunGene; Fish et al. 2013) sensu Freedman et al. (2016). Two bacterial reference genes (i.e., "housekeeping genes"), RNA polymerase (rpoB) and DNA recombinase (recA), and one fungal 
reference gene, RNA polymerase II ( $r p b 2)$, were included in the analysis to determine if site differences altered basic metabolic function in addition to $\mathrm{C}$-, $\mathrm{N}$ - and $\mathrm{P}$-associated functional genes. With the exception of the bacterial lignin decay-associated nucleotide-curated database, bacterial gene abundances were determined by comparing post-QC metagenomic short reads using DIAMOND’s blastx function against each local functional gene database. To examine fungal functional genes, fungal-specific nucleotide functional gene databases were individually curated using the CAZy database, Peroxibase (Fawal et al. 2012), FunGene, and NCBI reference sequences (RefSeq; O’Leary et al. 2016) sensu Cline and Zak (2015). Databases for fungal functional genes and bacterial lignin-decay were determined by comparing filtered metagenomic short reads using NCBI's Magic-BLAST tool against each local functional gene database (version 1.4.0; Boratyn et al. 2018). Genes included in the functional databases are further detailed in Table 2.

\section{Statistical Analyses}

The effect of site, cultivar, and their interaction on soil physicochemical properties, microbial biomass, extracellular enzyme activities, richness, as well as the relative abundances of microbial taxa were determined using a two-way analysis of variance (ANOVA) using the integrated stats package in $\mathrm{R}$ (version 3.5.2; R Core Team 2013). $\beta$-diversity was determined using a Bray-Curtis distance matrix based on OTU abundance and analyzed through a two-way permutational multivariate analysis of variance (PerMANOVA; Anderson 2001), with site, cultivar, and their interaction as factors through the vegan package (version 2.5-4; Oksanen et al. 2019) in R. Significance was accepted at $\alpha=0.05$ and marginal significance was accepted at $\alpha=0.10$. Where applicable, means were compared using Tukey’s Honestly Significant Difference post-hoc test (Tukey HSD; Tukey 1949). 
Prior to analysis, each metagenome's functional gene assignments were normalized to the number of total predicted proteins for each sample (Glass et al. 2015; Warren et al. 2017). The impact of site and switchgrass cultivar on the relative abundance of KEGG pathways or functional genes were determined using a two-way ANOVA $(\mathrm{P}<0.05)$ with site, cultivar, and their interaction as factors. When appropriate, means were compared by a Tukey HSD. The Benjamini \& Hochberg false discovery rate correction (Benjamini and Hochberg 1995) was implemented to account for multiple comparisons; in this instance, an "adjusted P" value is listed.

\section{Results}

\section{Soil Properties}

The soil physical and chemical properties were distinctly different between Hampshire and Hobet (Table 1). Soil pH and moisture content at Hampshire were $23 \%$ and $135 \%$ greater than that at Hobet, respectively (site effect $\mathrm{P}<0.01$ ). Further, soils at Hampshire had greater soil organic matter (SOM) content $(+149 \%)$ and microbial biomass $(+55 \%)$ than Hobet soils (site effect $\mathrm{P}<0.01)$. Soil texture was significantly different between sites; silt content was approximately double in Hampshire soils whereas clay content was over an order of magnitude higher in Hobet soils (site effect $\mathrm{P}<0.01$ ). Sand content was only marginally greater in Hobet soils compared to Hampshire (+29\%; $\mathrm{P}=0.08)$. Total soil $\mathrm{C}$ and $\mathrm{N}$ contents were both approximately three times higher in Hampshire soils compared to Hobet soils, respectively (site effect $\mathrm{P}<0.01$ ). Soil $\mathrm{C}: \mathrm{N}$ ratios were $19 \%$ higher in Hampshire soils compared to Hobet soils (site effect $\mathrm{P}=0.03$ ). There were no differences in soil physical or chemical properties between cultivars. 


\section{Switchgrass microbiome extracellular enzyme activity}

The activity of three extracellular enzymes associated with soil C-, N- and P-acquisition were assessed, namely $\beta$-glucosidase (cellobiose hydrolysis), $\mathrm{N}$-acetyl-glucosaminidase (NAGase; chitin hydrolysis), and acid phosphatase (ACP; organic phosphate hydrolysis), respectively. $\beta$-glucosidase and NAGase enzymatic activities were both approximately triple in Hampshire compared to Hobet, respectively (Figure 1; site effect $\mathrm{P}<0.01$ ). No differences in $\beta$ glucosidase nor NAGase activity were observed across cultivars. Acid phosphatase activity was variable across sites and cultivars (Figure 1 ; site $\times$ cultivar $\mathrm{P}=0.05$ ). Post-hoc tests revealed acid phosphatase activity to be $78 \%$ higher in Hobet's Shawnee soils compared to Hobet's Cave-inRock soils as well as $274 \%$ and $96 \%$ higher than the Cave-in-Rock and Shawnee soils at Hampshire, respectively. No significant differences in enzymatic activity were observed across cultivars.

Bacterial and fungal taxonomy and composition

Sequencing of bacterial 16S rRNA gene amplicons yielded 3,616,272 post-QC sequences and prior to analysis, each sample was rarified to the sample with the lowest coverage $(2,500$ sequences). Bacterial richness, as estimated by Chao1, was $49 \%$ greater at Hobet compared to Hampshire (Figure 2A; site effect $\mathrm{P}=0.04$ ) and no cultivar effect was found. Similarly, the composition of the bacterial community differed across sites (Figure 3A; PerMANOVA site effect; $\mathrm{F}=3.38, \mathrm{P}=0.001$ ), but not across cultivars. Across sites, the most abundant bacterial phyla were Proteobacteria (42-43\% relative abundance), Bacteroidetes (13-19\%), and Acidobacteria (11-12\%; Figure 4). Within the Proteobacteria, classes Alphaproteobacteria (11-18\%) and Betaproteobacteria (11-15\%) were most abundant across the two sites. The relative abundance of multiple bacterial taxa were different across sites. For example, Hobet's microbiome harbored a 
greater relative abundance of Actinobacteria (+170\%), Chloroflexi (+60\%), and Alphaproteobacteria (+60\%) as compared to Hampshire, while Hampshire's microbiome harbored a greater relative abundance of Firmicutes $(+653 \%)$, Nitrospirae $(+2,050 \%)$, Betaproteobacteria $(+33 \%)$, and Gammaproteobacteria $(+120 \%$; site effect $\mathrm{P}<0.05)$ as compared to Hobet. However, the relative abundance of these taxa did not change across cultivars. The relative abundance of Bacteroidetes was variable across sites and cultivars (site $\times$ cultivar $\mathrm{P}<0.05)$. Post-hoc tests revealed that within Hampshire, the Shawnee cultivar harbored 25\% greater relative abundance of Bacteroidetes compared to the Cave-in-Rock microbiome whereas the trend was reversed at Hobet, with the Cave-in-Rock cultivar harboring 25\% greater relative abundance of Bacteroidetes compared to the Shawnee microbiome.

Sequencing of the fungal ITS region yielded 2,312,954 post-QC reads and prior to analysis, each sample was rarified to the sample with the lowest coverage (40,000 sequences). Fungal richness was 95\% greater in Hobet as compared to Hampshire (Figure 2B; site effect $\mathrm{P}<0.01$ ), but there was no difference in richness across cultivars. Further, fungal composition also differed across sites (Figure 3B; PerMANOVA site effect; F=5.51, P=0.001), and no compositional differences between cultivars was observed. Initial fungal taxonomic assignments resulted in $42-66 \%$ of OTUs unassigned at the phylum level. For this reason, subsequent fungal taxonomic analyses were conducted by normalizing to the total classified to any given phylum. Of the 7 identified phyla, Ascomycota (53-67\%) and Basidiomycota (16-35\%) were most dominant across sites and cultivars. However, only members of the Basidiomycota were significantly different in abundance across sites, with the Hobet microbiome harboring $85 \%$ greater relative abundance of Basidiomycota compared to that of Hampshire (site effect $\mathrm{P}=0.04$ ). To consider the fungal community at a more resolved taxonomic level, fungal classes were 
assessed as well. Of the 16 identified fungal classes, Agaricomycetes (9-28\%), Dothideomycetes (11-18\%), and Sordariomycetes (9-14\%) dominated across sites and cultivars. Hampshire harbored a greater relative abundance of Microbotryomycetes (+1,505\%), Chytridiomycetes $(+709 \%)$, and Saccharomycetes $(+4,414 \%)$ while Hobet harbored a greater relative abundance of Agaricomycetes (+246\%) and Lecanoromycetes (Figure 5; +817\%; site effect $\mathrm{P}<0.05$ ). Eurotiomycetes were variably affected across sites and cultivars (site $\times$ cultivar effect $\mathrm{P}=0.01$ ). Post-hoc tests revealed that the Shawnee microbiome harbored $63 \%$ and $136 \%$ greater relative abundance of Eurotiomycetes compared to the Cave-in-Rock and Shawnee microbiomes at Hampshire, respectively, but no differences were observed between microbiomes at Hobet. There were no significant differences in the relative abundance of Glomeromycetes across sites or cultivars. To achieve a deeper taxonomic resolution, fungal OTU genus-level classifications were cross-checked against the FUNGuild database to match fungal genera to their associated ecological guilds. Fungal OTUs assigned to the plant pathogen guild were two times greater in abundance at Hampshire compared to Hobet (site effect $\mathrm{P}<0.01$ ). The relative abundance of arbuscular mycorrhizae and saprotrophs were no different between sites or cultivars.

Metagenomic assessment of the switchgrass microbiome

The relative abundance of genes associated with $\mathrm{C}-, \mathrm{N}-$, and $\mathrm{P}$ - cycling were determined from shotgun metagenomes using two complimentary approaches: i) by comparing post-QC metagenomic contigs for homology to the KEGG pathways in MG-RAST and ii) by comparing post-QC metagenomic short reads to locally constructed functional gene databases using DIAMOND and BLAST queries (detailed in Table 2). Across the 12 metagenomes, 551,593 post-QC contigs were obtained (totaling $26.37 \mathrm{Mb}$ ). Contigs ranged from $5.44-66.76 \mathrm{~Kb}$ per contig, with a mean length of $16.14 \mathrm{~Kb}$. The effects of site and switchgrass cultivar on the 
abundance of KEGG-based C-, N- and P-metabolism functional pathways were examined to elucidate potential cultivar-specific differences across the two reclamation strategies. Genes associated with C-metabolism were marginally different in relative abundance across sites, with 19\% greater abundance observed in Hampshire as compared to Hobet (Figure 6; adj $\mathrm{P}=0.09$ ). Further, genes associated with N-metabolism and P-metabolism were $88 \%$ and $165 \%$ more abundant in Hampshire compared to Hobet, respectively (Figure 6; adj $\mathrm{P}<0.01$ ).

To complement the KEGG pathway-based analysis, metagenomic short reads were compared to local functional gene databases curated from the CAZy, Peroxibase, FunGene, and NCBI RefSeq repositories. Across the 12 metagenomes, 296,465,928 post-QC short reads were obtained (totaling $44.3 \mathrm{~Gb}$ ). Local functional gene databases were curated to include only highquality sequences homologous to the functional gene of interest. In this way, local gene databases were built for both bacterial and fungal functional genes associated with $\mathrm{C}_{-}, \mathrm{N}-$, and $\mathrm{P}-$ acquisition processes (summarized in Table 2). Bacterial genes associated with cellulose decay were marginally variably abundant across sites and cultivars (site $\times$ cultivar effect adj. $\mathrm{P}=0.066$ ). Post-hoc tests revealed that Hobet's Cave-in-Rock and Shawnee microbiomes harbored 57\% and $59 \%$ greater abundance of bacterial genes associated with cellulose decay compared to Hampshire's Shawnee microbiome, respectively, but Hampshire's Cave-in-Rock microbiome was not different between sites or cultivars. Hampshire soils harbored a greater relative abundance of bacterial phosphate mineralization-associated genes compared to Hobet soils (Figure $7 ;+18 \%$, site effect adj. $\mathrm{P}=0.001$ ). Bacterial genes associated with lignin and chitin decay were not significantly between sites (Figure 7; site effect adj. P>0.05). However, the abundance of bacterial genes associated with chitin decay were different across cultivars, with the Cave-in-Rock microbiome harboring a greater abundance of genes compared to that of Hobet 
( $+6 \%$, cultivar effect adj. $\mathrm{P}=0.02)$. While there were significant differences in functional gene relative abundances, no differences were found in bacterial housekeeping genes associated with basic metabolic functions across sites (Figure 7; site effect adj. $\mathrm{P}=0.7$ ).

Overall, the relative abundances of queried fungal functional genes were higher in Hobet compared to Hampshire. Fungal genes associated with cellulose and lignin decay were 663 and $21 \%$ higher in Hobet as compared to Hampshire (Figure 7; site effect adj. $\mathrm{P}<0.001$ ). Similarly, fungal genes associated with chitin decay were $28 \%$ higher in Hobet compared to Hampshire (Figure 7; site effect $\mathrm{P}<0.001$ ). Additionally, the fungal housekeeping gene was significantly greater in Hobet soils compared to Hampshire soils (Figure $7 ;+9 \%$, site effect adj. $\mathrm{P}<0.001$ ). There were no differences in the abundance of functional genes across cultivars.

\section{Discussion}

The enzymatic, taxonomic composition and metagenomic potential of the switchgrass soil microbiome was significantly different across sites, suggesting that the mine reclamation strategy employed at each site shaped both a functionally and taxonomically unique soil microbiome. However, I did not observe a functionally or compositionally unique microbiome across switchgrass cultivars. Soil physicochemical properties as well as microbial biomass, enzymatic, taxonomic, and metagenomic assessments were used to evaluate switchgrass soil microbiomes within two reclaimed mine sites. While I found that Hampshire's soil microbiome had a greater functional and genetic capacity to acquire critical nutrients than Hobet's microbiome, there was no indication that the microbiome influences differential yields between switchgrass cultivars at Hampshire. 
Soil properties influence switchgrass microbiome activity across sites but not cultivars

It has been well established that soil properties (such as moisture, $\mathrm{pH}$, and $\mathrm{C}: \mathrm{N}$ ratios) play a substantial role in shaping the soil microbiome (Van Horn et al. 2014; Rousk et al. 2010; Heuck et al. 2015). Due to the drastically different reclamation strategies employed at Hampshire and Hobet, it can be postulated that soil enzymatic activity would be largely governed by the differences in soil properties between sites. Indeed, the differences in soil properties associated with distinct surface mine reclamation strategies significantly influenced the enzymatic capacity of the switchgrass microbiome to cycle critical nutrients like carbon, nitrogen, and phosphorus. Soil moisture has been positively linked to microbial respiration and activity (Barros et al. 1995; Greaves and Carter 1920). Low soil moisture levels disturb the physiological and metabolic integrity of microorganisms (Schimel, Balser, and Wallenstein 2007), which may have functional consequences (Manzoni, Schimel, and Porporato 2012; Stark and Firestone 1995). Foreseeably, the low soil moisture content in Hobet may have impeded microbial activity compared to that of Hampshire, which may elude to the substantial differences in enzymatic activity between sites.

Hampshire, the surface mine with a circumneutral $\mathrm{pH}$ and greater organic matter content as compared to Hobet, had higher activities of microbial $\beta$-glucosidase and NAGase (Fig 1). $\beta$ glucosidase catalyzes cellulose hydrolysis and in turn produces glucose, an important $\mathrm{C}$ source for the soil microbiome (Merino, Godoy, and Matus 2016). $\beta$-glucosidase activity is often positively related to SOM content (Stott et al. 2010; Zhang et al. 2011), similar to my findings. Additionally, NAGase impacts both C- and N-cycling due to its role in hydrolyzing the degradation of chitin into glucosamine. $\beta$-glucosidase and NAGase activities are positively linked to soil $\mathrm{C}$ and $\mathrm{N}$ contents, respectively (Cenini et al. 2016), which further supports the observation of higher $\mathrm{C}$ - and $\mathrm{N}$-acquiring enzymatic activities at Hampshire compared to Hobet. 
In contrast to $\beta$-glucosidase and NAGase activity increases observed at Hampshire, Hobet's microbiome exhibited overall greater acid phosphatase activity, an enzyme responsible for P-mineralization, with the greatest acid phosphatase activity seen in the Shawnee cultivar (Fig. 1). Hobet's soil was more acidic than that of Hampshire. Acid phosphatase activity is generally greater and the enzyme is more stable in acidic environments (Nguyen et al. 2016b; Tabatabai 1994), supporting the acid phosphatase response at Hobet. Further, plants require bioavailable P for the production of critical macromolecules like ATP and nucleic acids in order to grow (Schachtman et al. 1998). In particular, switchgrass yields have been found to increase as a function of $\mathrm{P}$ amendments to the soil (Kering et al. 2013; Sawyer et al. 2019). Under Preplete conditions, acid phosphatase activities are typically increased to mineralize organic $\mathrm{P}$ into inorganic, bioavailable forms (Ndakidemi 2006; R. and J. 2001; Tarafdar and Claassen 1988), which may elude to a bioavailable P-deficiency that is plausibly responsible for the low switchgrass yields at Hobet. This may be further substantiated by the 10-fold increase in clay content in Hobet, as phosphate ions have been found to adsorb to clay particles due to their differential charges (Edzwald et al. 1976; Anjembe et al. 2016).

Switchgrass plants form associations with arbuscular mycorrhizal fungi (Clark 2002; Jesus et al. 2016), which play a role in P acquisition (Smith et al. 2011). Glomeromycota, an exclusively arbuscular mycorrhizal fungal phylum (Helgason and Fitter 2009), harbors genes encoding acid phosphatase (Eivazi and Tabatabai 1976; Sato et al. 2015). It is possible that this mycorrhizal association may account for the observed increase in acid phosphatase activity at Hobet. While we found no differences in Glomeromycota between sites, it is possible that since this study assessed the bulk soil, differences in root-associated fungi such as Glomeromycota 
(Treseder and Cross 2006) were less resolved. A more targeted analysis of the fungal community is required to ascertain differences in root-associated microbiota.

\section{Reclamation strategy creates a unique soil microbiome across sites}

Due to the differences in nutrient availability at each site, I expected that switchgrass plots at Hampshire would support a more diverse microbiome than the plots at Hobet, as soil $\mathrm{pH}$ and nutrient availability (namely $\mathrm{C}$ and $\mathrm{N}$ ) largely shape microbial richness and diversity (Fierer and Jackson 2006; Rousk et al. 2010; Siciliano et al. 2014; Zhang et al. 2016). Counter to our predictions, the switchgrass soil-associated bacterial and fungal communities were 55 and 100\% more rich in Hobet as compared to Hampshire (Fig. 2). While unexpected, one plausible explanation for these results could be explained by the intermediate disturbance hypothesis, which postulates that at intermediate levels of disturbance (i.e., heavy metal contamination in soils or surface mining), richness is highest due to the reduction of competitive exclusion for niche spaces (Connell 1978). Disturbance events, especially as a result of mining, have been found to increase species richness and diversity in both macro- and micro-environments (Armesto and Pickett 1985; Engelmann and Weaks 1985; Galand et al. 2016; Hong et al. 2015). My findings of increased microbial richness at Hobet, the poor-quality mine site, may suggest that disturbance effects continue to affect the microbiome at Hobet.

Switchgrass biomass yields across cultivars can be variable under different soil physicochemical conditions, which has been reported in these plots (Brown et al. 2016) as well as other studies (Casler et al. 2017; Fike et al. 2006). For this reason, I hypothesized that distinct microbiomes would exist across cultivars that may contributable to differences in crop yield at Hampshire. In this study, the diversity of the switchgrass soil microbiome differed across sites, but surprisingly no cultivar-specific differences were observed (Fig 3). Moreover, multiple 
bacterial and fungal taxa were significantly different in abundance across sites (Fig. 4,5). I expected a greater abundance of copiotrophic microbial taxa, or taxa that thrive in environments with readily-available $\mathrm{C}$ compounds (Fierer et al. 2007) within Hampshire due to the increased amount of soil $\mathrm{C}$ and $\mathrm{N}$ compared to Hobet. Indeed, greater abundances of the bacterial phyla Bacteroidetes, Betaproteobacteria, and Firmicutes, all of which are typically considered copiotrophic due to their nutrient acquisition strategies (Fierer et al. 2007; Ho et al. 2017; De León-Lorenzana et al. 2018; Mueller, Belnap, and Kuske 2015) were observed at Hampshire compared to Hobet. In contrast, Hobet's reclamation technique involved the application of crushed overburden with no topsoil amendment; thus I expected to observe a greater abundance of oligotrophic taxa, or taxa that thrive under low C conditions (Ishida and Kadota 1981; Kuznetsov et al. 1979). Again, similar to my expectations, abundances of Actinobacteria, Alphaproteobacteria, and Chloroflexi, all of which are considered oligotrophic taxa (Fierer et al. 2007; Ho et al. 2017; De León-Lorenzana et al. 2018; Mueller et al. 2015), were of greater abundance in Hobet as compared to Hampshire. These results suggest that each sites' soil microbiome is selected for based upon the sites nutrient availability and the propensity of microbial taxa to exploit available nutrients.

When discussing microbial life strategies, soil fungi are considered generally more oligotrophic compared to bacteria due to their ability to acquire nutrients in more recalcitrant $\mathrm{C}$ environments (Hammer et al. 2011; Rinnan and Baath 2009). However, there were differences within the fungal community that also align with the copiotroph and oligotroph framework among sites. I found greater abundances of Saccharomycetes and Microbotryomycetes, or yeasts that readily degrade labile substrates like cellulose (i.e., a copiotrophic life strategy), in Hampshire compared to Hobet, (van der Klei et al. 2011; van der Wal et al. 2013). While the 
fungal class Agaricomycetes are broad in their substrate usage, they are primarily considered wood-decay fungi that degrade recalcitrant substrates like lignin (Lundell et al. 2014). In congruency with previous research, the Hobet soil microbiome harbored a significantly greater abundance of Agaricomycetes compared to that of Hobet, further substantiating that the employed reclamation strategy selects for a compositionally unique microbiome.

By classifying the fungal community into functional guilds using FUNGuild, I found no significant differences in arbuscular mycorrhizal fungi or saprotrophs between sites, but there was a greater relative abundance of plant pathogen-associated fungi at Hampshire compared to Hobet. These results were surprising, as organic amendments such as paper pulp and municipal waste have been historically found to suppress soil-borne plant pathogens (Abawi and Widmer 2000; Lazarovits 2001; Stone et al. 2003). However, an interesting dichotomy existed where the relative abundances of Firmicutes and Gammaproteobacteria, which include many bacterial taxa accountable to plant disease suppression (Köberl et al. 2017; Mendes et al. 2011), were also greater in Hampshire. Regardless, these results suggest that the reclamation strategy impacts soil microbiome composition, and is largely modulated by nutrient availability.

\section{Functional genes associated with nutrient cycling differ across reclamation strategies}

Previous studies on reclaimed mine sites have found that the organic amendments increase soil nutrient availability and cycling (Bendfeldt, Burger, and Daniels 2001; Shrestha, Lal, and Jacinthe 2009), so I hypothesized that Hampshire would have a greater genomic capacity to cycle $\mathrm{C}, \mathrm{N}$, and $\mathrm{P}$ compared to Hobet. The response of both functional gene pathways and selected functional genes associated with critical nutrient cycling differed across sites, suggesting that reclamation technique impacts the genomic capacity for the soil microbiome to cycle $\mathrm{C}, \mathrm{N}$ and $\mathrm{P}$ (Fig. 6,7). The relative abundances of fungal cellulose, lignin, and chitin decay- 
associated genes as well as overall DNA metabolism-associated genes were greater in Hobet compared to Hampshire, likely due to their increased ability to scavenge $\mathrm{N}$ and $\mathrm{P}$ in nutrientlimiting and recalcitrant $\mathrm{C}$ environments (Behie and Bidochka 2014; Ho et al. 2017). KEGG orthology genes associated with C-metabolism were marginally more abundant in Hampshire, but the relative abundances of genes associated with bacterial and fungal cellulose decay were both significantly greater in Hobet's microbiome compared to Hampshire. While it was expected that Hobet's microbiome would have a greater abundance of fungal-associated functional genes for aforementioned reasons, a greater abundance of bacterial cellulose decay-associated genes was unexpected. However, while the KEGG functional pathway for C metabolism included genes involved in cellulose decay (i.e., cellobiosidase and $\beta$-glucosidase), there are multiple genes not directly related to cellulose decay, such as maltose phosphatase and trehalose synthase. Additionally, an increase in bacterial cellulose decay-associated genes at Hobet may be modulated by an increase in plant root exudation of labile C compounds (Rovira 1969), a phenomenon found to increase as nutrient (namely $\mathrm{N}$ and $\mathrm{P}$ ) availability decreases (Carvalhais et al. 2011; Edayilam et al. 2018). However, a more thorough analysis of switchgrass metabolites on reclaimed mine lands is warranted to further elucidate the influence of root exudation in shaping the microbiome composition.

Bacterial genes associated with chitin decay were not different across sites, but fungal genes associated with chitin decay were $22 \%$ greater in Hobet compared to Hampshire. Chitin is the second most abundant polysaccharide in nature, and is primarily derived from fungal cell walls that are especially chitin-rich (Bowman and Free 2006; Tharanathan and Kittur 2003). Thus, the increase in chitin decay-associated genes may suggest greater amounts of fungal necromass at Hobet (Freedman et al. 2016). With this knowledge, it is to be expected that there 
was an increase in fungal chitin decay-associated genes at Hobet, as soil fungi are able to degrade complex compounds such as chitin (Dighton 2016) and the abundance of fungal chitin decay-associated genes have been found to increase in chitin-rich environments (Deng et al. 2007).

Bacterial genes associated with lignin decay were not significantly different across sites, but fungal genes associated with lignin decay were $17 \%$ greater in Hobet compared to Hampshire. Decomposition has been well documented to be rate-limited by lignin decay (Fog 1988; Meentemeyer 1978), and lignin decay-associated enzymes have been found to be constrained by lower soil pH (Sinsabaugh et al. 2008). While I did not assess lignin decayassociated enzymes in this study, lignin decay-associated enzymes can be positively correlated to lignin decay-associated genes (Chen et al. 2018). Surprisingly, Hobet, the site with the lower $\mathrm{pH}$, had a greater relative abundance of lignin decay-associated genes. However, labile $\mathrm{C}$ sources are primarily preferentially degraded before recalcitrant compounds, such as lignin, in soils (Berg 2000; Rinkes et al. 2011), and fungi are able to more readily degrade recalcitrant compounds than most bacteria (Boer et al. 2005; Ho et al. 2017), so it is to be expected to observe a greater abundance of fungal lignin decay-associated genes within Hobet. With this knowledge, these results suggest that different reclamation strategies select for a functionally unique microbiome that is influenced by nutrient availability, particularly $\mathrm{C}$.

The relative abundance of genes associated with $\mathrm{N}$-metabolism was $61 \%$ greater in Hampshire compared to Hobet, respectively. This was to be expected, as municipal waste and paper pulp amendments are typically N-rich (Abdullah et al. 2015; Wolkowski 2003), and N-rich amendments can increase the abundance of genes involved in $\mathrm{N}$ cycling (i.e., nirK, nirS, nosZ; Ouyang et al. 2018; Wang et al. 2018). Indeed, I found that Hampshire had 195\% higher total 
soil N compared to Hobet. Previous studies have found that organic amendments increased plant N uptake between 30-60\% (Ma, Dwyer, and Gregorich 1999). Switchgrass yield is N-limited (Hong et al. 2014; Owens et al. 2013) and responds positively to $\mathrm{N}$ amendments in otherwise low $\mathrm{N}$ conditions (Kering et al. 2013; Pedroso et al. 2013). Taken together, this may suggest that Hampshire has a greater functional capacity to cycle N compared to Hobet, which plausibly modulated higher yields in Hampshire that were reported by Brown et al. (2016).

A similar effect was found for genes associated with P-cycling, where Hampshire's soil microbiome harbored $90 \%$ greater relative abundance of genes associated with P-metabolism via the KEGG pathway and $18 \%$ greater relative abundance of genes associated with bacterial phosphate mineralization. Organic amendments such as municipal waste and paper pulp typically have higher $\mathrm{P}$ due to the treatment processes employed (Abdullah et al. 2015; Sokka, Antikainen, and Kauppi 2004), and an increase in soil P has been found to increase the abundance of genes associated with P acquisition (Fraser et al. 2015; Xue et al. 2018). With this knowledge, it was to be expected that Hampshire had greater abundances of genes associated with P-metabolism and phosphate mineralization. In addition, phosphatases are primarily excreted by root-associated mycorrhizal fungi (Sato et al. 2015; Smith et al. 2011). Unfortunately, this study was unable to assess fungal phosphate mineralization-associated genes due to currently unresolved records of fungal genes regulating $\mathrm{P}$ acquisition. However, further characterization of fungal $\mathrm{P}$ acquisition in a switchgrass system is warranted, as switchgrass closely associate with arbuscular mycorrhizal fungi for P acquisition (Clark, Baligar, and Zobel 2005; Kering et al. 2012). Arbuscular mycorrhizal fungi can secret organic acids to solubilize P from rock phosphate (Antunes et al. 2007; Javaid 2009), so it is possible that further studies could incorporate an 
assessment of fungal organic acid-associated genes to elucidate differences in fungal $\mathrm{P}$ acquisition across sites.

\section{Potential contributors influencing differential yield responses}

It has been well established that switchgrass cultivars are genetically and morphologically unique, even within upland and lowland ecotypes, and that these differences cause differential yield responses (Boe and Casler 2005; Casler and Boe 2003; Lemus et al. 2002; Ma, Wood, and Bransby 2000). For this reason, I hypothesized that there will also be a functionally and compositionally unique microbiome amongst switchgrass cultivars, specifically within Hampshire. Counter to my predictions, there were no strong indicators of Cave-in-Rock or Shawnee cultivar-specific microbiomes. While this is the only known study examining the switchgrass cultivar-specific microbiome on reclaimed mine soils, multiple studies have reported differences in the soil microbiome across switchgrass cultivars, potentially due to reported differences in root exudation strategies across cultivars (de Graaff et al. 2014; Mao et al. 2014; Roosendaal et al. 2016; Sawyer et al. 2019). Studies across a myriad of plants have concluded that root exudates shape the root-associated microbiome (Hu et al. 2018; Huang et al. 2014; Walker et al. 2003). It is possible that the bulk microbial community may not be modulating the differential yield response seen at Hampshire, but rather cultivar-unique secondary metabolites may increase productivity and nutrient cycling efficiency via the root-associated microbiome (Chomel et al. 2016). Regardless, additional analyses are required to understand the extent of the plant-microbial dynamics associated with switchgrass cultivars. 


\section{Conclusions}

Here, I determined that the switchgrass microbiome does not exhibit cultivar-specificity, but does change based on differences in soil chemical and physical properties across two reclaimed mine lands in WV, USA. These data suggest that amended topsoil reclamation increases the propensity for a functionally unique soil microbial community compared to nonamended overburden, wherein Hampshire's microbiome acquires $\mathrm{C}$ and $\mathrm{N}$ more readily than Hobet's microbiome. Although I am currently unable to determine if the switchgrass soil microbiome mediated differential yield responses seen at Hampshire, further examination into switchgrass cultivar-specific metabolites and the root-associated microbiome is warranted. Together, results presented in this study suggest that reclamation technique alters the microbial potential to acquire $\mathrm{C}, \mathrm{N}$, and $\mathrm{P}$ in a marginal switchgrass agroecosystem, which occurred in parallel with differences in the abundance of functionally important bacterial and fungal taxa as well as the abundance of functional genes associated with $\mathrm{C}, \mathrm{N}$, and $\mathrm{P}$ cycling. As such, differences in the bulk soil microbiome may not influence differential switchgrass yield across sites, but further study is necessary to draw a causative link between soil microbiome dynamics and switchgrass yield. 


\title{
Chapter 2: Cultivar-specific microbiomes may modulate switchgrass (Panicum virgatum) biomass yields on reclaimed mine sites in West Virginia.
}

\begin{abstract}
Switchgrass (Panicum virgatum) has been supported by the U.S. Department of Energy as a "model bioenergy crop" due to its well-characterized growth in various soil types and climates. Its ability to withstand harsh environmental conditions and increase soil stability has incentivized the use of switchgrass as a reclamation crop in recent years as well. However, little is known regarding plant-microbe interactions among switchgrass systems within reclaimed mine lands. A study conducted in 2008 grew switchgrass on high- and low- quality reclaimed mine sites (Hampshire and Hobet, respectively) in West Virginia to examine the resilience of switchgrass as a reclamation-friendly bioenergy crop. Switchgrass yields at Hampshire were nearly an order of magnitude higher than Hobet (8.4 $\mathrm{Mg} \mathrm{ha}^{-1}$ vs $\left.1.0 \mathrm{Mg} \mathrm{ha}^{-1}\right)$. Within Hampshire, the Cave-inRock cultivar yield was $70 \%$ greater than that of Shawnee $\left(12.9 \mathrm{Mg} \mathrm{ha}^{-1}\right.$ vs. $\left.7.6 \mathrm{Mg} \mathrm{ha}^{-1}\right)$ and $187 \%$ greater than that of Carthage (12.9 Mg ha-1 vs. $\left.4.5 \mathrm{Mg} \mathrm{ha}^{-1}\right)$. Here, I sought to illuminate plant-microbial interactions that may account for this drastic shift in cultivar yield by examining the root-associated and bulk soils underneath three switchgrass cultivars using enzymatic activity analyses and microbiome taxonomic identification. Specifically, I tested two hypotheses: (i) that the root-associated microbiome will have a functionally and compositionally unique microbiome compared to that of the bulk soil and (ii) that there will be a cultivar-specific root-associated microbiome that may drive previously observed greater, but differential yields across switchgrass cultivars at Hampshire. Hampshire soils showed significant increases in extracellular enzymes associated with the acquisition of $\mathrm{C}, \mathrm{N}$, and $\mathrm{P}$ compared to Hobet. Additionally, the rootassociated microbiome had a greater activities associated with the acquisition of $\mathrm{C}, \mathrm{N}$, and $\mathrm{P}$ compared to the bulk soil. Further, diverse and taxonomically-unique microbiomes were found between sites and cultivars. While Together, this data suggests that the root-microbiome may contribute to overall aboveground biomass yields between sites, and cultivar-specific microbiomes were observed that may substantiate differential yield responses within Hampshire.
\end{abstract}




\section{Introduction}

Plant productivity responds to a diverse array of environmental, biochemical, and microbial stimuli in the soil; many processes of which are still not well characterized. With a rapidly increasing global population and a comparable demand for food (United Nations Department of Economic and Social Affairs 2017), understanding plant-soil dynamics that lead to productivity is of utmost importance to an agriculturally sustainable future. Additionally, to reduce our dependence on fossil fuels, obtaining renewable energy sourced from plant biomass (i.e., cellulosic biofuel) has been nationally supported through the Energy Policy Act of 1992, the Renewable Fuel Standard of 2007, among other environmental statutes (Environmental Protection Agency 2007; United States 102d Congress 1992). In 1991, the United States Department of Energy deemed switchgrass (Panicum virgatum) a "model" bioenergy crop due to its ability to withstand nutrient-poor soil and unfavorable climates as well as its ability to increase soil productivity and nutrient (namely carbon and nitrogen) cycling (McLaughlin and Adams Kszos 2005). Moreover, switchgrass' large roots systems have been found to stabilize soil and aid in soil organic carbon (SOC) sequestration, both of which are important in marginal soil environments (Liebig et al. 2005).

Since switchgrass has been found to not only survive in marginal lands, but actually promote healthy soils, substantial interest has advocated for farming switchgrass in marginal soils, like reclaimed surface mines (Skousen et al. 2013; Varvel et al. 2008). The Surface Mining and Reclamation Act (SMCRA) of 1977 requires that these lands be reclaimed to equal or better condition once mining ceases (U.S. Department of the Interior 1977), which switchgrass could plausibly help achieve. Despite this growing interest in farming switchgrass on reclaimed mine 
lands, little is known about above- and belowground dynamics leading to productive yields on marginal soils.

Many root-associated bacterial and fungal taxa (i.e., plant growth-promoting bacteria and fungi) play an important role in the mineralization and immobilization of nutrients required for both plant and microbial growth (Badalucco and Kuikman 2001; Darrah 1993; Mendes et al. 2013). Previous studies in agricultural lands have found that the switchgrass soil microbiome may mediate aboveground productivity, especially within root-associated soils (Brejda et al. 1998; de Graaff et al. 2014; Roosendaal et al. 2016). Root-associated plant growth-promoting bacteria (PGPB) have been linked to upwards of $17 \%$ increased biomass in potato plants (Kloepper 1980) and 18\% in alfalfa (Liu et al. 2019). The switchgrass rhizosphere has also been found to play a crucial role in promoting aboveground productivity, with studies observing 4049\% greater yields with the colonization of PGPBs (Ker et al. 2012; Kim et al. 2012). In addition, switchgrass form associations with arbuscular mycorrhizal (AM) fungi, which are responsible for converting soil P into bioavailable forms (Clark et al. 1999; George et al. 1995) and enhancing aboveground biomass (Brejda et al. 1998).

Switchgrass cultivars have been found to respond to their environment differently (Casler and Boe 2003), as in the case of differences in root structures and biomass yields documented between switchgrass cultivars (Brown et al. 2016; de Graaff et al. 2013). Switchgrass cultivars also secrete unique labile organic compounds from the roots to act on the root-associated microbiome (de Graaff et al. 2014), a process termed priming (Dalenberg and Jager 1989). Foreseeably, these differences in switchgrass cultivars may select for a unique microbiome that facilitate yield responses on reclaimed mine lands. However, there are currently no known 
studies that have examined the influence of the switchgrass root-associated microbiome on aboveground productivity in reclaimed mine lands.

In 2008, a field study was developed to quantify the aboveground productivity of three switchgrass cultivars on two surface mines, Hampshire Hill mine and Hobet 21 mine, that were experimentally reclaimed in different manners (Brown et al. 2016). Hampshire's reclamation strategy that employed topsoil and organic amendments has historically been found to promote aboveground biomass yields and increase soil productivity (Larney and Angers 2012). In contrast, Hobet's reclamation strategy that employed no topsoil or amendments has been historically linked to reduced productivity due to unfavorable changes to soil physicochemical properties (Haering et al. 1993). Ultimately, Hampshire's reclamation technique led to switchgrass yields 13 times higher compared to yields at Hobet. Further, yield of the Cave-inRock cultivar was $+70 \%$ greater than that of the Shawnee cultivar and $187 \%$ greater than that of the Carthage cultivar at Hampshire, but similar differences between cultivar yield were not observed at Hobet (Brown et al. 2016). While this study quantified yield differences across two sites with different reclamation strategies, the potential influence of belowground microbial dynamics that may result in differential productivity between cultivars at Hampshire, and not at Hobet, are unknown.

Here, I assessed the function and composition of the soil microbiome beneath three cultivars of switchgrass, Carthage, Cave-in-Rock, and Shawnee, in long-term switchgrass plots. Additionally, I sought to identify unique differences in the root-associated microbiome that may account for differential yield responses. To do so, extracellular enzyme assays were performed in parallel with high-throughput ribosomal rRNA gene sequencing. Specifically, I tested two hypotheses: (i) that the root-associated microbiome will have a functionally and compositionally 
unique microbiome compared to that of the bulk soil and (ii) that there will be a cultivar-specific root-associated microbiome that may drive previously observed greater, but differential yields across switchgrass cultivars at Hampshire. In this way, I obtained insight into the root-associated switchgrass microbiome in marginal lands, leading to a better understanding of the functional capacity attributable to differential reclamation strategies and yield response at Hampshire and Hobet.

\section{Materials and Methods}

\section{Site Locations}

To investigate the influence of mine reclamation strategy, switchgrass cultivar, and soil type on the function and composition of the soil microbiome, soils were sampled from long term switchgrass plots on reclaimed mine sites in West Virginia, USA (Table 3.). Experimental plots within each site were laid out in a completely randomized block design in 2008. Each site was reclaimed using a different reclamation strategy. Briefly, the Hampshire Hill mine (herein referred to as Hampshire) was reclaimed using topsoil amended with municipal sewage waste and paper pulp spread over the existing overburden. The Hobet 21 mine, hereafter referred to as Hobet, was reclaimed using crushed, unweathered overburden that was regraded to approximate original contour. Once reclaimed, three replicate 4,000 $\mathrm{m}^{2}$ plots of each switchgrass cultivar (Carthage, Cave-in-Rock, and Shawnee) were broadcast seeded across each plot. Further detail regarding reclamation strategy can be found in Brown et al. (2016). A particularly noteworthy difference in site management occurred in 2018, when Hampshire was amended with municipal sewage waste and paper pulp prior to sampling while Hobet remained unamended. 
Soil sampling occurred in late May 2018, during a time at which ample moisture favored high rates of microbial activity and 10 years after the switchgrass stands were seeded. Within each plot, 10 soil cores were randomly collected at the base of a switchgrass plant to a depth of $15 \mathrm{~cm}$ (A horizon) and further referred to as bulk soil samples. Root-associated soil samples were obtained via removing a portion of the switchgrass roots and manually collecting the soil within the root system. Soil samples were homogenized and composited to yield one bulk soil and one root-associated sample per plot. All samples were placed on ice and transported to West Virginia University where the soil was immediately passed through a $0.2 \mathrm{~mm}$ sieve to remove roots and rocks. A portion of each homogenized and sieved soil sample was stored at $-4^{\circ} \mathrm{C}$ for enzyme and soil chemical analysis and the remainder was stored at $-80^{\circ} \mathrm{C}$ for DNA extraction.

\section{Soil Properties}

Soil $\mathrm{pH}$ was determined using a 1:5 soil:0.01 $\mathrm{M} \mathrm{CaCl}_{2}$ suspension with samples shaking at $60 \mathrm{rpm}$ for 30 minutes (Rayment and Higginson 1992). Soil moisture was determined gravimetrically by drying soil samples at $105^{\circ} \mathrm{C}$ for 24 hours. Using this dried soil, organic matter content was assessed by combustion at $505^{\circ} \mathrm{C}$ for 6 hours via loss on ignition. Microbial biomass was estimated by substrate-induced respiration (SIR), which measures induced microbial respiration when presented a labile carbon source (West and Sparling 1986). The average microbiome respiration rate $\left(\mathrm{mg} \mathrm{C}-\mathrm{CO}_{2} \mathrm{~g} \mathrm{soil}^{-1} \mathrm{~h}^{-1}\right)$ was quantified by implementing adaptations to the West and Sparling protocol as described by Fierer, Schimel and Holden (2003). 


\section{Extracellular Enzyme Activity}

To determine the microbial potential within switchgrass root-associated and bulk soils to mineralize critical soil nutrients from organic matter, extracellular enzymatic activities associated with C-, N-, and P- acquisition were conducted as described in Chapter 1 (page 6).

\section{DNA Extraction and Sequencing}

DNA was extracted in triplicate from $1.5 \mathrm{~g}$ total of each soil sample within 72 hours of sample collection. A PowerLyzer PowerSoil DNA isolation kit (Qiagen, Valencia, CA) was used following manufacturer's instructions in conjunction with a PowerLyzer 24 homogenizer (MoBio Laboratories, Carlsbad, CA). Purified DNA was quality checked on a ND8000 Nanodrop (Thermo Scientific, Waltham, MA) and quantified using a Qubit 4 Fluorometer (Thermo Scientific, Waltham, MA). Quantified DNA was submitted to the University of Minnesota Genomics Center for high throughput sequencing of the bacterial 16S rRNA gene and the fungal internal transcribed spacer (ITS) region. Briefly, $10 \mathrm{ng}$ of extracted DNA was used as template to amplify the V4-V5 region of the $16 \mathrm{~S}$ rRNA gene using universal bacterial primers 515F (Parada et al. 2016) and 805R (Apprill et al. 2015).The fungal ITS2 region was amplified using ITS9F and ITS4R universal fungal primers (Menkis et al. 2012; White et al. 1990). Unique i7 index barcode identifiers were included in the reverse primer. PCR reactions were performed in triplicate under the following thermalcycling conditions: an initial 3 minutes at $94{ }^{\circ} \mathrm{C}, 30$ cycles of 45 seconds at $94{ }^{\circ} \mathrm{C}, 60$ seconds at $50{ }^{\circ} \mathrm{C}$, and 90 seconds at $72{ }^{\circ} \mathrm{C}$, a final 10 minutes at $72{ }^{\circ} \mathrm{C}$ once cycles were complete, then held at $4{ }^{\circ} \mathrm{C}$. Reactions were pooled to yield a single 16S rRNA and ITS product per sample. Pooled amplicons were purified using 1.2X AMPure XP beads (Beckman Coulter, Brea, CA) prior sequencing. Purified barcoded amplicons were 
composited in equimolar concentrations for sequencing using an Illumina MiSeq 2x300 base read platform (Illumina, San Diego, CA) and a dual-indexing approach (Gohl et al. 2016). Ribosomal rRNA gene sequences are publicly available through the NCBI Sequence Read Archive (accession PRJNA533308).

\section{Bacterial and Fungal Community Composition}

For both 16S rRNA gene and ITS analyses, forward and reverse reads were joined using USEARCH (Edgar 2010) and the paired sequences were further processed in QIIME (version 1.9.1; Caporaso et al. 2010). Sequences were quality controlled by removing OTUs that were observed fewer than 5 times. Open reference operational taxonomic units (OTU) were picked using default parameters and the UCLUST (Edgar 2010) algorithm in QIIME. Sequences were rarified to 8,000 16S rRNA sequences per plot and 5,500 ITS sequences per plot. After rarifying, taxonomic assignments were performed at $90 \%$ similarity by comparing $16 \mathrm{~S}$ rRNA OTUs against the Greengenes reference database (version 13.8; Mcdonald et al. 2012) using UCLUST and by comparing ITS OTUs against the UNITE reference database (version 8.0; UNITE Community 2019) using BLAST (Altschul et al. 1990). Changes in bacterial and fungal taxonomy across sites, switchgrass cultivars, and soil types were assessed at the phylum, order, and class level, with unassigned taxa or those under 3\% in all samples binned as "other". Microbial community $\alpha$ - and $\beta$-diversity metrics were also calculated in QIIME using Chao1 richness (Chao 1984) and Bray-Curtis dissimilarity indices (Bray and Curtis 1957), respectively.

\section{Statistical Analyses}

The effect of site, cultivar, soil type, and their interaction on soil physicochemical properties, microbial biomass, extracellular enzyme activities, richness, as well as the relative 
abundances of microbial taxa were determined using a 3-way analysis of variance (ANOVA) using the integrated stats package in $\mathrm{R}$ (version 3.5.2; R Core Team 2013). $\beta$-diversity was determined using a Bray-Curtis distance matrix based on OTU abundance and analyzed through a three-way permutational multivariate analysis of variance (PerMANOVA; Anderson 2001), with site, cultivar, soil type, and their interaction as factors in PRIMER (version 7; Primer-E Ltd., Plymouth, UK; Clarke and Gorley 2015). Where interactions were observed for multivariate analyses, a pairwise PerMANOVA was conducted in PRIMER to parse statistical dissimilarities. Significance was accepted at $\alpha=0.05$ and marginal significance was accepted at $\alpha=0.10$. Where applicable, means were compared using Tukey's Honestly Significant Difference post-hoc test (Tukey HSD; Tukey 1949).

\section{Results}

\section{Soil Properties}

The soil physical and chemical properties were distinctly different between Hampshire and Hobet (Table 3). Soil pH and moisture content at Hampshire were $10 \%$ and $271 \%$ greater than that at Hobet, respectively (site effect $\mathrm{P}<0.01$ ). A marginal increase in soil $\mathrm{pH}$ was observed in root-associated soils compared to bulk soils $(\mathrm{P}=0.08)$. SOM content was overall approximately 4 times greater in Hampshire soils compared to Hobet soils, but was variable across sites and cultivars ( site $\times$ cultivar effect $\mathrm{P}<0.01$ ). Post-hoc tests revealed that $\mathrm{SOM}$ content within the Carthage and Shawnee cultivar soils were 39 and $44 \%$ higher than that of Cave-in-Rock soils at Hampshire, respectively, while there were no differences observed between cultivars at Hobet. Overall, Hampshire soils had approximately 5 times greater microbial biomass than Hobet soils. Though, microbial biomass was marginally variable across sites and cultivars ( ite $\times$ cultivar $\mathrm{P}=0.06$ ), wherein post-hoc tests revealed that the Shawnee 
cultivar soils exhibited 58\% and 75\% greater microbial biomass that of Cave-in-Rock and Carthage in Hampshire, respectively. There were no differences in microbial biomass observed between cultivars at Hobet.

Switchgrass microbiome extracellular enzyme activity

The activity of three extracellular enzymes associated with soil C-, N- and P- acquisition were assessed, namely $\beta$-glucosidase (cellobiose hydrolysis), $\mathrm{N}$-acetyl-glucosaminidase (NAGase; chitin hydrolysis), and acid phosphatase (organic phosphate hydrolysis), respectively. $\beta$-glucosidase and NAGase enzymatic activities were both approximately an order of magnitude higher in Hampshire compared to Hobet (Figure 8; site effect $\mathrm{P}<0.01$ ). In addition to site differences, $\beta$-glucosidase and NAGase activities were higher in root-associated soils, although NAGase was only marginally higher $(+27 \%$, soil type effect $\mathrm{P}=0.01 ;+27 \%$, soil type effect $\mathrm{P}=0.09)$. Acid phosphatase activity was also higher in Hampshire soils compared to Hobet soils (Figure $8 ;+178 \%$, site effect $\mathrm{P}<0.001$ ). I also found a significant increase in acid phosphatase activity in root-associated soils compared to bulk soils $(+31 \%$, soil effect $\mathrm{P}=0.009)$. For all examined enzyme activities, no differences were observed across cultivars.

\section{Bacterial and fungal taxonomy and composition}

Sequencing of bacterial 16S rRNA gene amplicons yielded 972,904 post-QC sequences and prior to analysis, each sample was rarified to the sample with the lowest coverage $(8,000$ sequences). Bacterial richness, as estimated by Chao1, was not significantly different between sites, cultivars, or soil types (Figure 9A). However, the composition of the bacterial community was variable across sites and cultivars (Figure 10A; site $\times$ cultivar PerMANOVA F=1.43, $\mathrm{P}=0.01$ ). Pairwise tests revealed that the Cave-in-Rock microbiome was dissimilar from the 
Shawnee microbiome $(\mathrm{t}=1.4 ; \mathrm{P}=0.03)$ and marginally dissimilar from the Carthage microbiome within Hampshire $(\mathrm{t}=1.4 ; \mathrm{P}=0.06)$, but no dissimilarities were observed between the Carthage and Shawnee microbiomes at Hampshire or between cultivars at Hobet $(\mathrm{P}>0.05)$.

Across sites, the most abundant bacterial phyla were Proteobacteria (38-39\%), Actinobacteria (12-17\%), and Acidobacteria (12-17\%; Figure 11). Within Proteobacteria, orders Alphaproteobacteria (15-20\%) and Betaproteobacteria (9-10\%) were most abundant across the two sites. There were multiple differences in bacterial taxonomic abundance across sites, detailed in Table 4. The Hampshire microbiome had greater abundances of Firmicutes $(+1,096 \%)$, Nitrospirae (+181\%), Verrucomicrobia $(+10 \%)$, and Deltaproteobacteria $(+34 \%$; site effect $\mathrm{P}<0.01)$. The Hobet microbiome harbored greater abundances of Acidobacteria $(+32 \%)$, Armatimonadetes (+73\%), Chlorobi (+47\%), Cyanobacteria (+74\%), Fibrobacteres (+59\%), and Alphaproteobacteria ( $+28 \%$; site effect $\mathrm{P}<0.01)$.

Significant, but few, differences in bacterial taxonomic abundances were observed between soil types. Specifically, Gemmatimonadetes were $26 \%$ and Nitrospirae were $44 \%$ more abundant in the bulk soil microbiome compared to root-associated microbiome (soil type effect $\mathrm{P}<0.05)$.

There were also cultivar-specific differences in microbiome composition observed for bacteria, namely Acidobacteria and Deltaproteobacteria (cultivar effect $\mathrm{P}<0.05$ ). Post-hoc tests concluded that the Carthage microbiome harbored 25\% greater relative abundance of Acidobacteria compared to the Cave-in-Rock microbiome, but the relative abundance of Acidobacteria in the Shawnee microbiome was not significantly different amongst cultivars. Post-hoc tests also revealed that Deltaproteobacteria were 30 and $31 \%$ greater in the Cave-inRock microbiome compared to that of Carthage and Shawnee, respectively. 
While Actinobacteria and Gammaproteobacteria were more abundant in Hampshire, differential responses across sites and cultivars were observed for both (site $\times$ cultivar $\mathrm{P}<0.05$ ). Post-hoc tests revealed that while there were no differences in Actinobacteria relative abundance between cultivars within sites, the Hampshire Cave-in-Rock microbiome harbored a greater relative abundance of Actinobacteria compared to all cultivars at Hobet (+56-82\%). For Gammaproteobacteria, post-hoc tests revealed that Hampshire's Carthage and Shawnee microbiomes were 85 and $75 \%$ greater in relative abundance compared to Hobet's Carthage and Shawnee microbiomes, respectively, but no differences were observed within the Cave-in-Rock microbiome between sites. While Bacteroidetes was marginally variable across sites and cultivars (site $\times$ cultivar $\mathrm{P}=0.09$ ), post-hoc tests concluded there were only site differences, with the Hampshire microbiome harboring $88 \%$ greater relative abundance of Bacteroidetes compared to Hobet's microbiome.

Two site $\times$ cultivar $\times$ soil type interactions were found for bacterial microbiome composition: Chloroflexi (site $\times$ cultivar $\times$ soil type effect $\mathrm{P}=0.03$ ) and a marginal interaction was observed for Elusimicrobia (site $\times$ cultivar $\times$ soil type effect $\mathrm{P}=0.07$ ). While multiple posthoc differences existed between sites, cultivars, and soil types for Chloroflexi, many comparisons were not significant. However, post-hoc tests did reveal a $64 \%$ increase in Chloroflexi relative abundance in Hobet's Cave-in-Rock microbiome compared to Hampshire's Cave-in-Rock microbiome. Multiple post-hoc differences were also observed for Elusimicrobia, but it was revealed that Hobet's Cave-in-Rock bulk soil microbiome harbored 1,250\% greater relative abundance of Elusimicrobia compared to Hampshire's Cave-in-Rock bulk soil microbiome. 
Sequencing of the fungal ITS region yielded 946,465 post-QC reads, and each sample was rarified to the sample with the lowest coverage (5,500 sequences) prior to analysis. Fungal richness was 34\% greater in Hampshire as compared to Hobet (Figure 9B; site effect; $\mathrm{P}<0.001$ ), but there was no difference in richness across cultivars or soil types. Fungal community composition was variable across sites and cultivars (Figure 10B; site $\times$ cultivar PerMANOVA $\mathrm{F}=1.7, \mathrm{P}<0.01$ ). Pairwise tests revealed that the Cave-in-Rock microbiome was marginally dissimilar from the Shawnee $(\mathrm{t}=1.4 ; \mathrm{P}=0.08)$ and Carthage $(\mathrm{t}=1.4 ; \mathrm{P}=0.07)$ microbiomes at Hampshire, but no dissimilarities were observed between Hampshire's Carthage and Shawnee microbiomes $(\mathrm{t}=1.3 ; \mathrm{P}=0.12)$. Additionally, pairwise tests also revealed that the Cave-in-Rock microbiome was marginally dissimilar from the Shawnee microbiome at Hobet $(\mathrm{t}=1.3 ; \mathrm{P}=0.052)$, but no other dissimilarities were observed at Hobet $(\mathrm{P}>0.05)$.

Of the 21 fungal classes identified, Dothideomycetes (23-27\%), Sordariomycetes (1332\%), and Agaricomycetes (12-32\%) dominated across sites, cultivars, and soil types. There were multiple differences in fungal taxonomic abundance across sites, detailed in Table 5. The Hampshire microbiome had greater abundances of Basidiobolomycetes $(+10,333 \%)$, Leotiomycetes $(+200 \%)$, Olpidiomycetes $(+3,83 \%)$, and Sordariomycetes $(+139 \%$; site effect $\mathrm{P}<0.01)$. The Hobet microbiome harbored greater abundances of Agaricomycetes $(+64 \%)$, Eurotiomycetes (+64\%), Glomeromycetes (+78\%), Kickxellomycetes (+84\%), and Paraglomeromycetes ( $+94 \%$; site effect $\mathrm{P}<0.01)$.

There were also cultivar-specific differences in microbiome composition observed for Eurotiomycetes (cultivar effect $\mathrm{P}=0.06$ ). The Cave-in-Rock and Shawnee microbiomes harbored 45 and 36\% greater relative abundance of Eurotiomycetes compared to the Carthage microbiome, respectively. 
Pezizomycetes and Rhizophydiomycetes relative abundances were variable across sites and cultivars (site $\times$ cultivar $\mathrm{P}<0.05$ ) while the relative abundance of Orbiliomycetes was marginally variable across sites and cultivars (site $\times$ cultivar $\mathrm{P}=0.07$ ). Post-hoc tests revealed that Hampshire's Carthage microbiome harbored \% greater relative abundance of Pezizomycetes compared to Hobet. Post-hoc tests revealed that Hampshire's Carthage microbiome harbored 4,493\% greater relative abundance of Pezizomycetes compared to Hobet's Carthage microbiome, while no differences were observed for the Shawnee or Cave-in-Rock microbiomes across sites. Additionally, post-hoc tests revealed that Hampshire's Cave-in-Rock and Shawnee microbiomes harbored 332 and 537\% greater relative abundance of Rhizophydiomycetes compared to Hampshire's Carthage microbiome, respectively, and no differences were observed between cultivars within Hobet. A marginal site $\times$ cultivar effect was observed for Orbiliomycetes (site $\times$ cultivar $\mathrm{P}=0.07$ ), wherein post-hoc tests revealed that Hobet's Shawnee microbiome had $244 \%$ greater relative abundance of Orbiliomycetes compared to Hampshire's Shawnee microbiome, but no differences were observed for the Cave-in-Rock or Carthage microbiomes across sites.

The relative abundance of Microbotryomycetes was variable across sites and soil types (site $\times$ soil type $\mathrm{P}=0.016$ ) while the relative abundance of Rhizophydiomycetes and Spizellomycetes were marginally variable across sites and soil types (site $\times$ soil types $\mathrm{P}<0.1$ ). Post-hoc test revealed that Hampshire's root-associated microbiome harbored 167\% greater relative abundance of Microbotryomycetes, but there were no differences between soil types within Hobet. While a marginally significant site $\times$ soil type existed for Rhizophydiomycetes (site $\times$ soil type $\mathrm{P}=0.088$ ), post-hoc tests revealed that there were only site differences, with the Hampshire microbiome harboring 573\% greater relative abundance of Rhizophydiomycetes 
compared to Hobet's microbiome. Additionally, post-hoc tests on the relative abundance of Spizellomycetes concluded that there were no significant differences between sites or soil types.

\section{Discussion}

This research highlights that a unique microbiome exists between switchgrass cultivars on two reclaimed mine sites in West Virginia, USA. The results herein are suggestive of a cultivar-specific microbiome that may influence differential plant productivity within Hampshire. Soil physicochemical properties as well as microbial biomass, enzymatic, and taxonomic assessments were used to evaluate switchgrass soil microbiomes grown within the Hampshire and Hobet mines. I found that Hampshire's soil microbiome had an overall greater enzymatic activity associated with $\mathrm{C}, \mathrm{N}$, and P acquisition than Hobet's microbiome. In addition, I found that the root-associated microbiomes have greater enzymatic activity associated with C-, $\mathrm{N}$-, and P-acquisition compared to the bulk soil microbiome across sites, but no compositional differences were observed between soil types. Taken together, a compositionally unique microbiome exists between sites and cultivars, suggestive of a microbial influence on aboveground biomass yields.

\section{Extracellular enzymatic activity is highest in switchgrass root-associated soils}

Similar to Chapter 1, I expected the differences in soil properties to foster a unique microbiome across sites, since soil microbial activity is largely mediated by soil physicochemical properties like soil pH and OM content (Van Horn et al. 2014; Rousk et al. 2010; Xue et al. 2018). For this reason, I also expected that while the Hampshire microbiome would foreseeably have greater enzymatic activities associated with $\mathrm{C}-, \mathrm{N}-$, and P-acquisition compared to Hobet, particularly within the root-associated microbiome. Further supporting the results obtained in 
Chapter 1, differences in the soil physicochemical factors associated with distinct surface mine reclamation strategies significantly influenced the enzymatic capacity of the switchgrass microbiome to cycle critical nutrients such as carbon, nitrogen, and phosphorus (Fig 8). In particular, $\beta$-glucosidase, $\mathrm{N}$-acetyl-glucosaminidase, and phosphatases all have been found to increase with substrate availability, microbial nutrient demand stoichiometry, and soil pH (Sinsabaugh et al. 2008). Indeed, Hampshire, the site with circumneutral $\mathrm{pH}$, had greater enzymatic activities associated with all three enzymes. Together, this knowledge suggests that increased enzymatic activity at Hampshire suggests that Hampshire had greater nutrient availability than that of Hobet.

It has been found that root-associated soils have higher enzymatic activity compared to that of the bulk soil, likely due to the influence of plant root exudates on the microbiome (Dai et al. 2016). For this reason, I hypothesized that the root-associated soils would have greater enzymatic activity associated with $\mathrm{C}, \mathrm{N}$, and $\mathrm{P}$ acquisition in root-associated soils. Indeed, an overall increase in $\beta$-glucosidase and acid phosphatase as well as a marginal increase in NAGase activities were observed within the root-associated soils within both Hampshire and Hobet (Fig 8). A unique difference between these sites recent management strategies is that Hampshire was amended with organic wastes shortly before sampling while Hobet remained unamended. It is likely that the organic amendments at Hampshire further stimulated the root-associated microbiome to cycle C, N, and P, similar to the findings from (Fang et al. 2010). However, it has been well established that plant root exudates stimulate soil enzymatic activity, especially in AM-fungi-associated systems like switchgrass (Brzostek et al. 2013; Egamberdieva et al. 2011), so it is to be expected that the root-associated microbiome had an increased propensity to acquire C, N, and P compared to the bulk soil within Hampshire and Hobet. While there were no 
significant interactions that elude to cultivar-specific enzymatic activity differences, my data does suggest that the root-associated microbiome acquires $\mathrm{C}, \mathrm{N}$, and $\mathrm{P}$ more readily than that of the bulk soil.

While Chapter 1 observed the greatest acid phosphatase activity in Hobet soils, I found that Hampshire had the greatest acid phosphatase activity after the addition of organic wastes. Although acid phosphatase activity is most stable at a lower $\mathrm{pH}$ (Eivazi and Tabatabai 1976), activities increase as a function of P limitation (Bragazza et al. 2006). This study did not quantify $\mathrm{C} / \mathrm{N}$ ratios within Hampshire and Hobet, but the addition of organic amendments has been linked to increased mineralizable $\mathrm{C}$ and N (Goyal et al. 1999; Ryals et al. 2014). While these results may arise as an artifact of one sampling date, it is more likely that the addition of organic amendments caused a stoichiometric nutrient imbalance towards greater amounts of $\mathrm{C}$ and $\mathrm{N}$ which may have limited P acquisition at Hampshire, thus causing an increase in phosphateacquiring enzymes (Chang, Chung, and Tsai 2007).

Organic amendments increase switchgrass soil microbiome diversity between cultivars

In concordance with previous studies that have found that soil $\mathrm{pH}$ and nutrient availability largely shape microbial richness and diversity (Fierer and Jackson 2006; Rousk et al. 2010; Siciliano et al. 2014), I expected that switchgrass plots at Hampshire would support a more diverse microbiome than the plots at Hobet. Additionally, due to plant-influenced selection on the root-associated microbiome, the rhizosphere is typically more biodiverse (Campbell and Greaves 1990; Gilbert et al. 1996). Although I assessed root-associated soils and not the rhizosphere, I expected similar increases in biodiversity to be apparent in the root-associated soils within Hampshire and Hobet. Indeed, I observed greater fungal richness in Hampshire compared to Hobet (Fig. 9). For fungi, richness has been found to increase as a function of 
organic matter content (Siciliano et al. 2014), which is supported here with increased organic matter content in Hampshire compared to Hobet. However, I found no differences in richness between sites, cultivars, or soil types for bacteria. In addition, there were no differences in the root-associated and bulk soil richness for either bacteria or fungi. While these results were surprising, richness metrics may be useful to identify trends on a large scale, while community composition via taxonomic identification may better to elucidate differences on smaller scales (Hartmann et al. 2015; Hartmann and Widmer 2006). Moreover, bacterial richness is largely variable across temporal and spatial scales (Naveed et al. 2016; Terrat et al. 2017), so direct taxonomic and functional assessments may better elude to compositional differences in the microbiome.

While richness examines diversity within a given site, $\beta$-diversity examines the heterogeneity of microbial composition between sites (Barwell, Isaac, and Kunin 2015). $\beta$ diversity indices concluded that the cultivars within Hampshire had greater diversity amongst each other than cultivars within Hobet (Fig. 10). Previous studies have reported that increases in nutrient availability increases the significance of diversity within both bacteria and fungi (Maron et al. 2018), which compliment results found in this study. Interestingly, previous studies have positively linked $\beta$-diversity indices with differences in aboveground plant biomass (Li et al. 2018). Taken together, these results suggest that Hampshire's reclamation strategy of organic amendments foster a unique and biodiverse microbiome across cultivars that may substantiate differential yields within Hampshire.

\section{Cultivar-specific microbiomes may link to aboveground switchgrass productivity}

Similar to the results observed in Chapter 1, reclamation strategy selected for a unique soil microbiome across sites, likely due to differences in nutrient availability. Similar site- 
specific trends existed, where Hampshire harbored generally greater relative abundances of Bacteroidetes, Betaproteobacteria, and Firmicutes, all of which are copiotrophic bacteria that preferentially degrade labile C compounds (Fierer et al. 2007; Ho et al. 2017; De LeónLorenzana et al. 2018; Mueller et al. 2015). Additionally, Hobet harbored generally greater relative abundances of Alphaproteobacteria and Chloroflexi, all of which are oligotrophic bacteria that typically degrade recalcitrant C substances (Ishida and Kadota 1981; Kuznetsov, Dubinina, and Lapteva 1979).

However, in contrast to Chapter 1, I also found multiple interactions between cultivars that may indicate a cultivar-specialized microbiome potentially influencing differential yields observed within Hampshire. A notable site $\times$ cultivar interaction was observed for Actinobacteria where the greatest abundance was found in Hampshire's Cave-in-Rock and Shawnee rootassociated microbiomes (Fig. 11). Interestingly, these two cultivars had the greatest aboveground biomass at Hampshire (Brown et al. 2016). While Actinobacteria are broad in their nutrient acquisition and substrate usage schemes, they have been considered plant growth-promoting bacteria due to their influence in nitrogen fixation, phosphate mineralization, and contribution to plant pathogen suppression via secondary metabolites (Sathya, Vijayabharathi, and Gopalakrishnan 2017). Previous studies have found that increased abundances of Actinobacteria increases plant biomass (Lasudee et al. 2018). Although Actinobacteria alone may not modulate the differential yield response observed at Hampshire, this may be a contributory link to cultivarspecific microbiome-induced aboveground productivity.

Fungal community composition also was substantially different across sites, following similar trends to Chapter 1 with generally greater abundances of copiotrophic taxa (i.e., Microbotryomycetes; van der Klei et al. 2011; van der Wal et al. 2013) observed in Hampshire 
while generally greater abundances of oligotrophic taxa (i.e., Agaricomycetes; Lundell et al. 2014) were observed in Hobet. Notably dissimilar from Chapter 1, I found that Glomeromycetes were significantly greater in Hobet compared to Hampshire. This was expected since Glomeromycetes, an arbuscular mycorrhizal clade, have been seen to promote plant growth under environmentally stressful conditions, such as water and nutrient deficiencies (Hashem et al. 2018). An interesting site $\times$ cultivar was also observed for Rhizophydiomycetes where there was a greater relative abundance within the Cave-in-Rock and Shawnee microbiomes, or the cultivars with the highest reported yields by Brown et al. (2016). Due to their low abundance in soil, this fungal class has been substantially understudied. However, taxa within this class have been identified as saprobes, which may aid in nutrient acquisition within the system (Letcher et al. 2006). It is possible that these bacterial taxa may serve as an indicator species for plant productivity; however, additional research is warranted to support a plant-microbe interaction for Rhizophydiomycetes. To date, this is the only known study that has observed Rhizophydiomycetes differences as a function of plant aboveground productivity.

\section{Conclusions}

Here, I determined that there are switchgrass cultivar-specific microbiomes that may modulate differential aboveground yield responses across two reclaimed mine lands in WV, USA. This data suggests that amended topsoil reclamation increases enzymatic activities associated with $\mathrm{C}, \mathrm{N}$, and $\mathrm{P}$ acquisition in soil microbiome compared to non-amended overburden, wherein Hampshire's microbiome acquires C, N, and P more readily than Hobet's microbiome. Additionally, functionally relevant microbial taxa were positively connected to differential aboveground yields within Hampshire and Hobet. More specifically, Actinobacteria and Rhizophydiomycetes were highest in abundance within the microbiomes of the two highest- 
yielding sites at Hampshire. Together, results presented in this study suggest that reclamation technique alters the microbial potential to acquire $\mathrm{C}, \mathrm{N}$, and $\mathrm{P}$ in a marginal switchgrass agroecosystem, and that cultivar-specific microbiomes may promote aboveground switchgrass yields in marginal soils. However, a more thorough analysis of plant influence via metabolites and root exudates on the microbial community is warranted to foster a causative link between the soil microbiome and switchgrass yields. 


\section{Tables}

Table 1: Site characteristics and soil chemical/physical properties at Hampshire and Hobet.

\begin{tabular}{rcc}
\hline & Site Characteristics \\
\hline Site & Hampshire & Hobet \\
Latitude (N), Longitude (W) & $39.4^{\circ},-79.1^{\circ}$ & $38.1^{\circ},-81.6^{\circ}$ \\
Elevation (m) & 599 & 203 \\
Mean annual temp. $\left({ }^{\circ} \mathrm{C}\right)$ & 11.3 & 13.2 \\
Mean annual precip. $(\mathrm{cm})$ & 101 & 112 \\
\hline
\end{tabular}

Soil Properties $(0-10 \mathrm{~cm})$

\begin{tabular}{|c|c|c|c|c|}
\hline \multirow{2}{*}{$\begin{array}{r}\text { Site } \\
\text { Cultivar }\end{array}$} & \multicolumn{2}{|c|}{ Hampshire } & \multicolumn{2}{|c|}{ Hobet } \\
\hline & Cave-in-Rock & Shawnee & Cave-in-Rock & Shawnee \\
\hline $\mathrm{pH}\left(1: 5\right.$ soil/ $\left./ \mathrm{CaCl}_{2}\right)$ & $7.0(0.1)^{a}$ & $7.2(0.1)^{a}$ & $5.9(0.01)^{b}$ & $5.7(0.2)^{b}$ \\
\hline Gravimetric moisture content & $61.4(3.1)^{\mathrm{a}}$ & $69.2(2.3)^{\text {a }}$ & $17.7(2.8)^{b}$ & $22.9(1.3)^{b}$ \\
\hline Organic matter (\% dry weight) & $15.1(1.7)^{\mathrm{a}}$ & $16.7(0.7)^{a}$ & $6.2(1.9)^{b}$ & $6.6(0.7)^{b}$ \\
\hline Microbial biomass (mg C-CO2 g soil $^{-1} \mathrm{~h}^{-1}$ ) & $72.0(2.0)^{\mathrm{a}}$ & $77.3(3.6)^{a}$ & $43.7(6.9)^{b}$ & $52.8(1.2)^{b}$ \\
\hline Soil C (\%) & $6.7(1.2)^{a}$ & $7.6(0.9)^{a}$ & $2.0(0.5)^{b}$ & $2.1(0.3)^{b}$ \\
\hline Soil N (\%) & $0.37(0.04)^{a}$ & $0.43(0.04)^{a}$ & $0.13(0.02)^{b}$ & $0.15(0.02)^{b}$ \\
\hline C:N Ratio & $17.6(1.3)^{\mathrm{a}}$ & $17.5(0.5)^{\mathrm{a}}$ & $14.8(0.2)^{\mathrm{b}}$ & $14.8(0.2)^{b}$ \\
\hline Soil texture class & sandy loam & silt loam & sandy loam & sandy loam \\
\hline$\%$ sand & $56^{a}$ & $38^{a}$ & $60^{a}$ & $61^{a}$ \\
\hline$\%$ silt & $44^{a}$ & $61^{a}$ & $29^{a}$ & $26^{a}$ \\
\hline$\%$ clay & $0^{a}$ & $1^{a}$ & $11^{b}$ & $12^{b}$ \\
\hline
\end{tabular}

Values represent means \pm SEM $(n=3)$. Different letters indicate significant differences between groups $(P<0.05)$. 
Table 2: Summary of functional genes used in metagenomic analyses.

Bacterial enzyme/gene name

$\beta$-glucosidase

Endocellulase

Alpha-N-acetylglucosaminidase

Chitin deacetylase

Endochitinase

$\beta$-N-acetylhexosaminidase

Laccase

Alkaline phosphatase (ALP)

RNA Polymerase II ( $r p o B)$

Protein recombinase $\mathrm{A}(\mathrm{rec} A)$

Fungal enzyme/gene name

$\beta$-glucosidase

Cellulose 1,4-beta-cellobiosidase ( $c b h 1)$

$\alpha-\mathrm{N}$-acetylglucosaminidase

$\beta$-N-acetylhexosaminidase

Laccase (lcc)

Lignin peroxidase (lip)

Manganese peroxidase (mnp)

Versatile peroxidase (vp)

RNA polymerase II ( $r p b 2)$
EC Number

3.2.1.21

3.2.1.4

3.2 .1 .50

3.5 .1 .41

3.2 .1 .14

3.2.1.52

1.10.3.2

3.1.3.1

2.7.7.6

3.4.99.37

EC Number

3.2.1.21

3.2.1.91

3.2.1.50

3.2.1.52

1.10.3.2

1.11.1.14

1.11.1.13

1.11.1.16

2.7.7.6

\section{Function Category}

Cellulose

Cellulose

Chitin

Chitin

Chitin

Chitin

Lignin

Phosphate

Reference

Reference

Function Category

Cellulose

Cellulose

Chitin

Chitin

Lignin

Lignin

Lignin

Lignin

Reference 


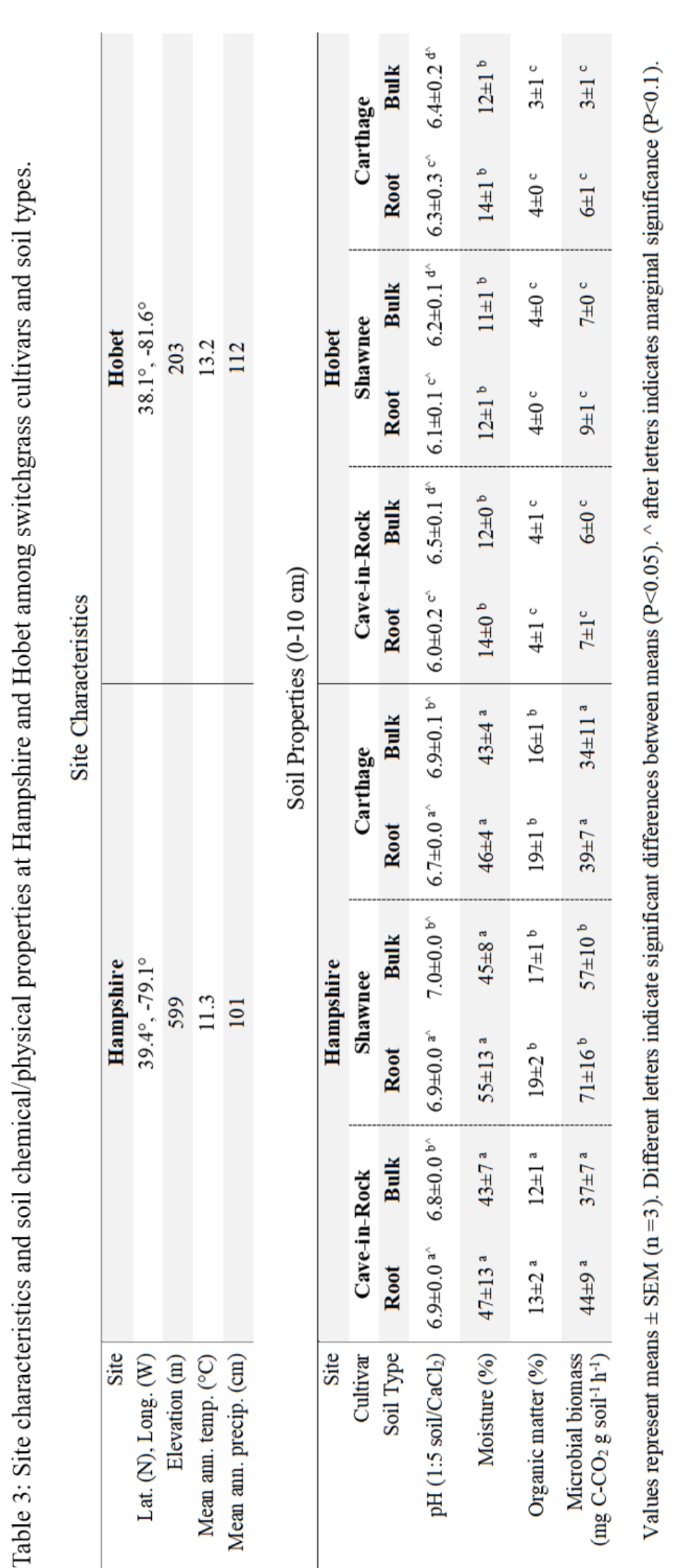


Table 4: The relative abundance of bacterial taxa-associated P-values from a 3-way ANOVA with site, cultivar, and soil type as effects. Yellow highlight indicates significance at $\mathrm{P}<0.05$ and orange highlight indicates marginal significance at $\mathrm{P}<0.1$.

\begin{tabular}{|c|c|c|c|c|c|c|c|}
\hline & Site & Cultivar & Soil & Site $\times$ Cultivar & Cultivar $\times$ Soil & Site $\times$ Soil & 3 Factor \\
\hline Acidobacteria & $<0.01$ & 0.04 & 0.82 & 0.51 & 0.18 & 0.64 & 0.27 \\
\hline Actinobacteria & $<0.01$ & 0.33 & 0.27 & 0.04 & 0.10 & 0.76 & 0.12 \\
\hline Armatimonadetes & $<0.01$ & 0.47 & 0.18 & 0.67 & 0.83 & 0.94 & 0.51 \\
\hline Bacteroidetes & $<0.01$ & 0.11 & 0.85 & 0.09 & 0.50 & 0.74 & 0.60 \\
\hline Chlamydiae & $<0.01$ & 0.60 & 0.05 & 0.35 & 0.17 & 0.07 & 0.78 \\
\hline Chlorobi & $<0.01$ & 0.73 & 0.86 & 0.49 & 0.41 & 0.51 & 0.60 \\
\hline Chloroflexi & $<0.01$ & 0.17 & 0.64 & 0.88 & 0.12 & 0.31 & 0.03 \\
\hline Cyanobacteria & $<0.01$ & 0.64 & 0.68 & 0.11 & 0.44 & 0.83 & 0.65 \\
\hline Elusimicrobia & $<0.01$ & 0.19 & 0.71 & $<0.01$ & 0.05 & 0.09 & 0.07 \\
\hline Fibrobacteres & $<0.01$ & 0.57 & 0.42 & 0.15 & 0.59 & 0.53 & 0.71 \\
\hline Firmicutes & $<0.01$ & 0.14 & 0.31 & 0.12 & 0.26 & 0.20 & 0.26 \\
\hline Gemmatimonadetes & 0.01 & 0.25 & 0.03 & 0.12 & 0.83 & 0.48 & 0.45 \\
\hline Nitrospirae & $<0.01$ & 0.30 & 0.04 & 0.12 & 0.76 & 0.46 & 0.32 \\
\hline Planctomycetes & 0.22 & 0.10 & 0.03 & 0.01 & 0.11 & 0.39 & 0.37 \\
\hline Alphaproteobacteria & $<0.01$ & 0.79 & 0.90 & 0.40 & 0.90 & 0.42 & 0.48 \\
\hline Betaproteobacteria & 0.77 & 0.38 & 0.85 & 0.66 & 0.33 & 0.58 & 0.38 \\
\hline Deltaproteobacteria & $<0.01$ & $<0.01$ & 0.59 & 0.30 & 0.45 & 0.49 & 0.90 \\
\hline Gammaproteobacteria & $<0.01$ & 0.86 & 0.47 & 0.03 & 0.18 & 0.63 & 0.57 \\
\hline Verrucomicrobia & 0.20 & 0.11 & 0.28 & 0.14 & 0.49 & 0.93 & 0.56 \\
\hline
\end{tabular}


Table 5: The relative abundance of fungal taxa-associated P-values from a 3-way ANOVA with site, cultivar, and soil type as effects. Yellow highlight indicates significance at $\mathrm{P}<0.05$ and orange highlight indicates marginal significance at $\mathrm{P}<0.1$.

\begin{tabular}{|cccccccc}
\hline & Site & Cultivar & Soil & Site $\times$ Cultivar Cultivar $\times$ Soil & Site $\times$ Soil & 3 Factor \\
Agaricomycetes & $<0.01$ & 0.34 & 0.868 & 0.942 & 0.469 & 0.985 & 0.877 \\
Archaeorhizomycetes & 0.133 & 0.518 & 0.262 & 0.519 & 0.636 & 0.264 & 0.635 \\
Basidiobolomycetes & $<0.01$ & 0.191 & 0.838 & 0.212 & 0.604 & 0.866 & 0.56 \\
Blastocladiomycetes & 0.316 & 0.39 & 0.316 & 0.39 & 0.385 & 0.323 & 0.385 \\
Dothideomycetes & 0.075 & 0.298 & 0.62 & 0.96 & 0.2 & 0.19 & 0.96 \\
Eurotiomycetes & $<0.01$ & 0.061 & 0.934 & 0.412 & 0.837 & 0.777 & 0.429 \\
Exobasidiomycetes & 0.071 & 0.218 & 0.743 & 0.257 & 0.99 & 0.773 & 0.996 \\
Glomeromycetes & 0.003 & 0.796 & 0.909 & 0.254 & 0.708 & 0.424 & 0.425 \\
Kickxellomycetes & $<0.01$ & 0.176 & 0.502 & 0.718 & 0.553 & 0.902 & 0.924 \\
Lecanoromycetes & 0.063 & 0.596 & 0.898 & 0.235 & 0.275 & 0.259 & 0.495 \\
Leotiomycetes & 0.013 & 0.262 & 0.386 & 0.707 & 0.867 & 0.378 & 0.895 \\
Microbotryomycetes & $<0.01$ & 0.242 & 0.02 & 0.216 & 0.68 & 0.016 & 0.703 \\
Mortierellomycetes & 0.085 & 0.966 & 0.795 & 0.714 & 0.244 & 0.934 & 0.9 \\
Olpidiomycetes & 0.044 & 0.5 & 0.463 & 0.42 & 0.31 & 0.41 & 0.34 \\
Orbiliomycetes & $<0.01$ & $<0.01$ & 0.271 & 0.073 & 0.685 & 0.147 & 0.573 \\
Paraglomeromycetes & $<0.01$ & 0.665 & 0.906 & 0.749 & 0.884 & 0.71 & 0.866 \\
Pezizomycetes & $<0.01$ & 0.258 & 0.659 & 0.027 & 0.64 & 0.766 & 0.62 \\
Rhizophydiomycetes & $<0.01$ & $<0.01$ & 0.134 & $<0.01$ & 0.492 & 0.088 & 0.736 \\
Sordariomycetes & $<0.01$ & 0.179 & 0.276 & 0.288 & 0.527 & 0.633 & 0.338 \\
Spizellomycetes & 0.49 & 0.043 & 0.991 & 0.727 & 0.987 & 0.079 & 0.504 \\
Tremellomycetes & 0.066 & 0.417 & 0.895 & 0.406 & 0.871 & 0.924 & 0.704 \\
\hline
\end{tabular}



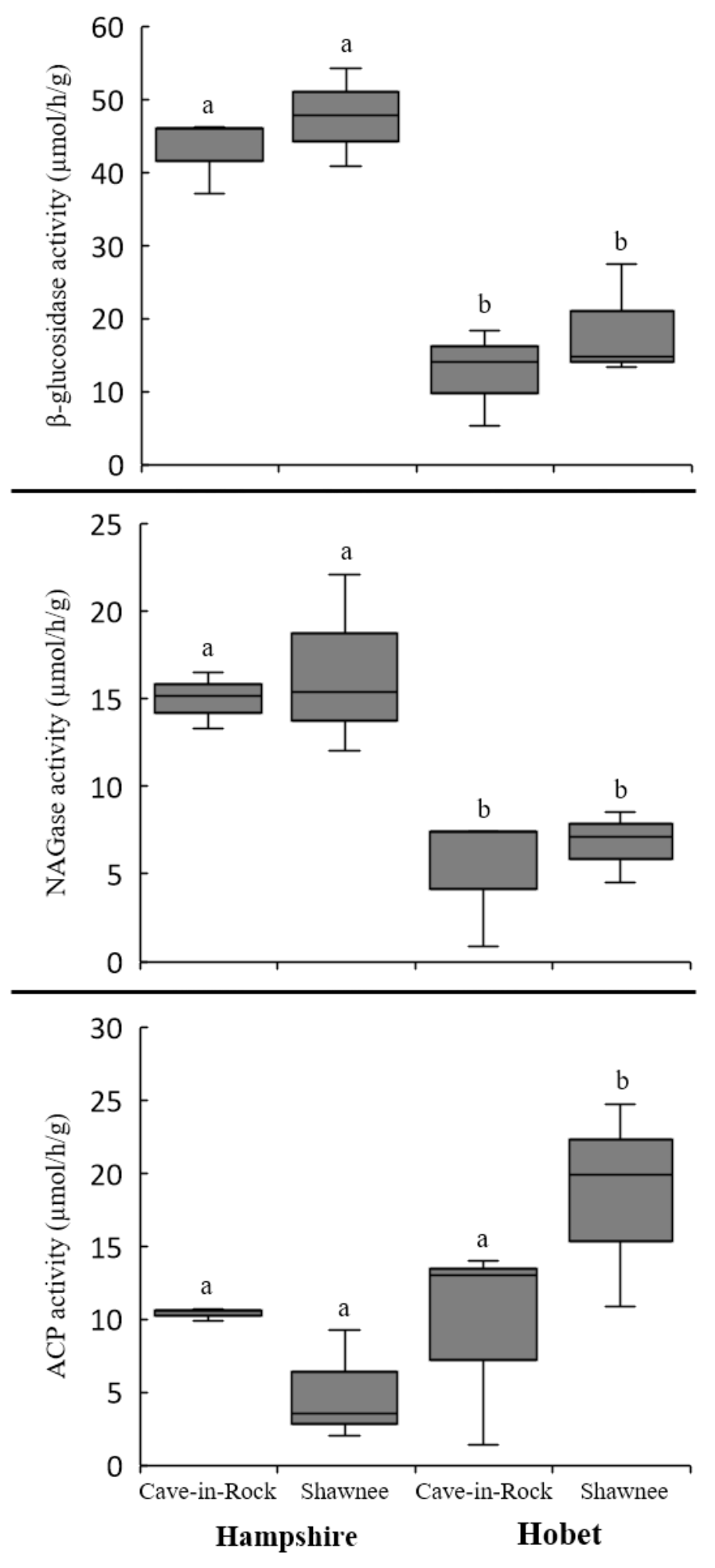

Figure 1: Extracellular enzyme activity responses of $\beta$-glucosidase, $\mathrm{N}$-acetyl-glucosaminidase (NAGase), and acid phosphatase (ACP) to differing reclamation techniques. Values expressed as mean \pm standard error $(n=3)$ with eight analytical replicates. Different letters indicate significant differences in means at $\mathrm{P}=0.05$. 
A

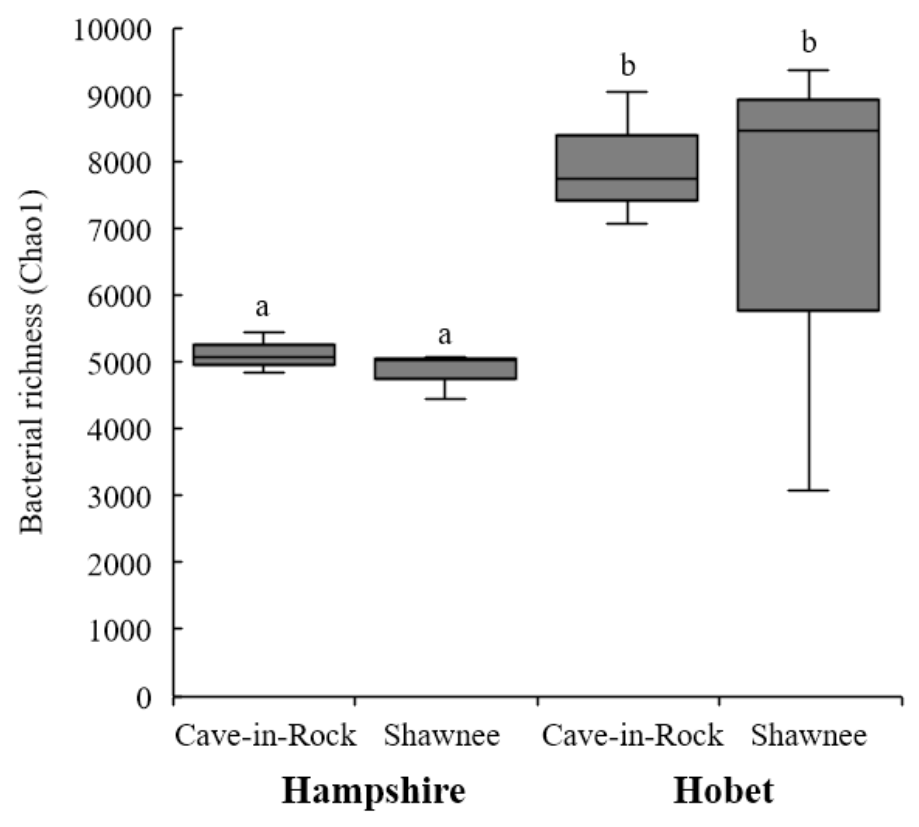

$\mathrm{B}$

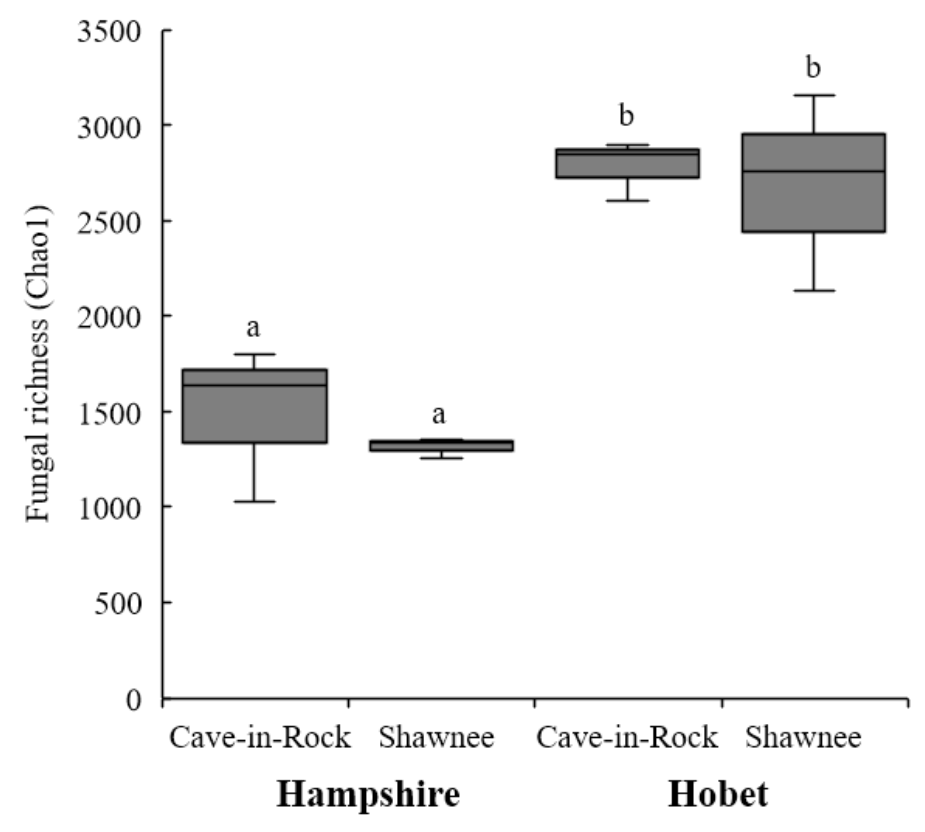

Figure 2: The effect of reclamation strategy on the (A) bacterial and (B) fungal richness of the switchgrass microbiome, as measured by Chaol index. Values expressed as mean \pm standard error $(\mathrm{n}=3)$. Different letters indicate significant differences in means at $\mathrm{P}=0.05$. 


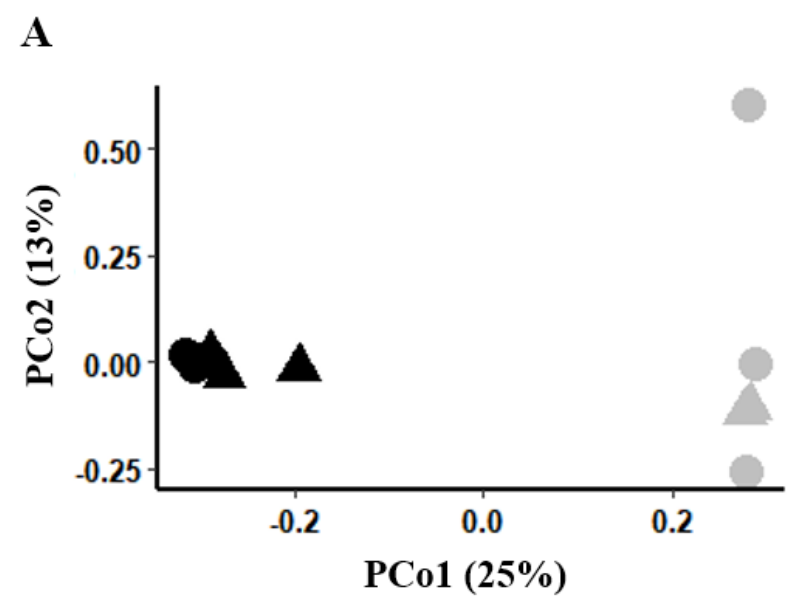

B

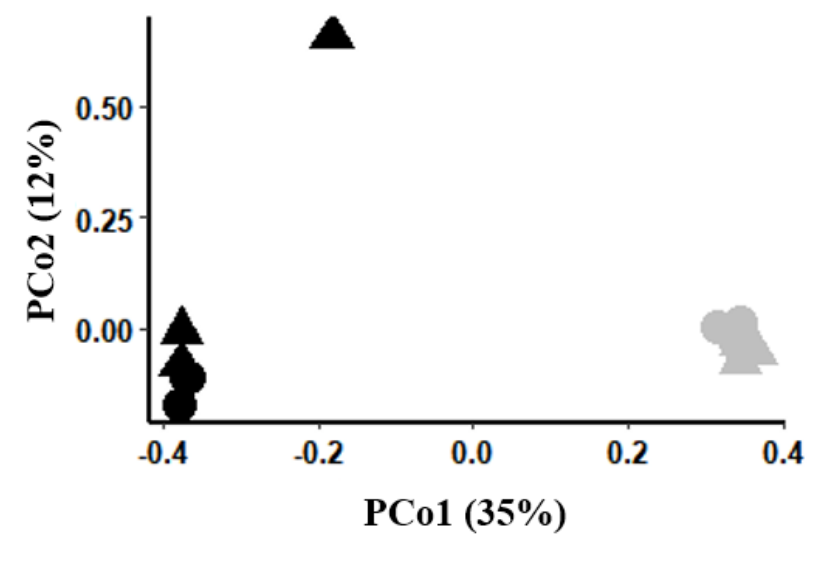

\section{Cultivar}

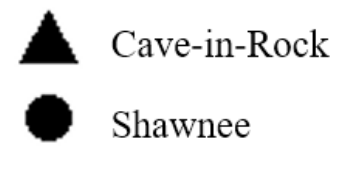

Figure 3: The effect of reclamation strategy on the (A) bacterial and (B) fungal community composition of the switchgrass microbiome. A principal coordinates analysis was conducted using the Bray-Curtis dissimilarity metric on OTU relative abundances. 
Actinobacteria

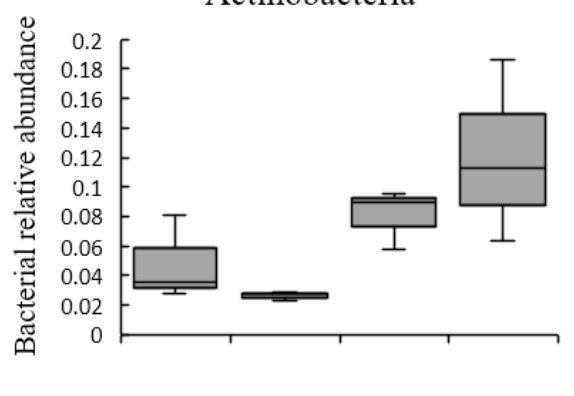

Chloroflexi

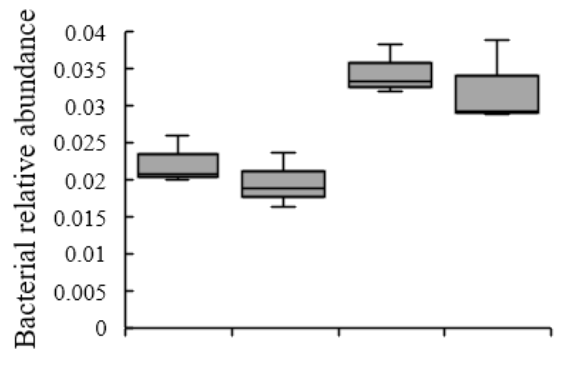

Gemmatimonadetes
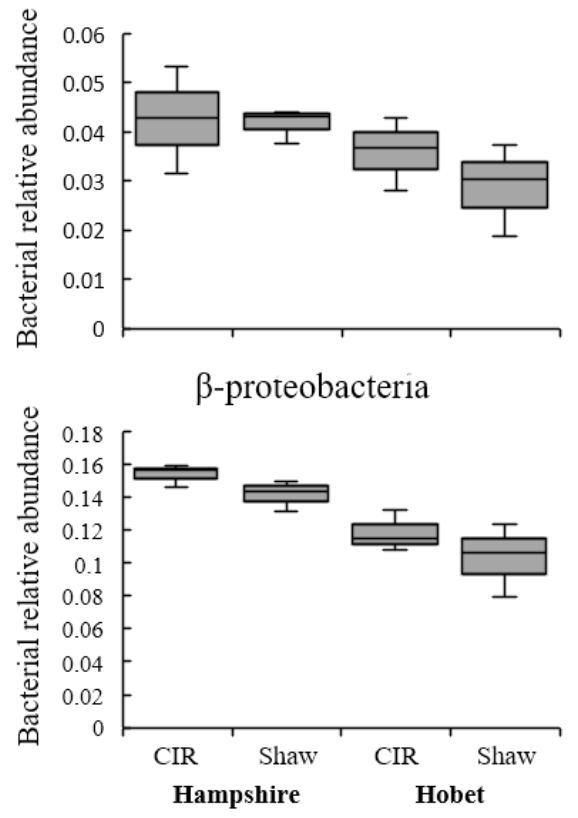

Armatimonadetes

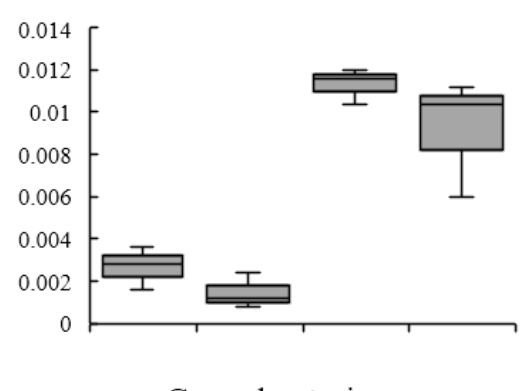

Cyanobacteria

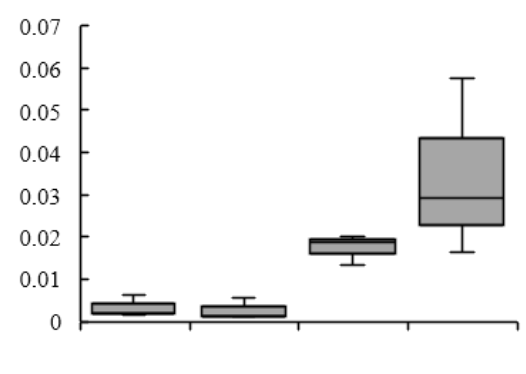

Nitrospirae
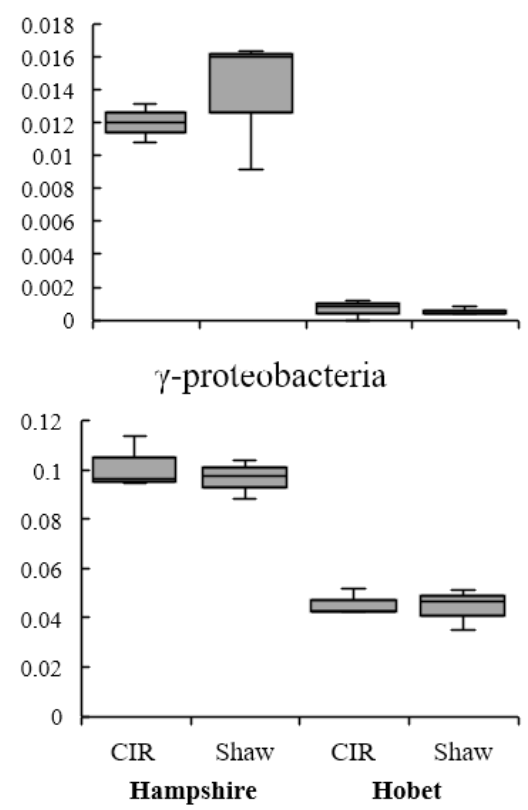

Bacteroidetes

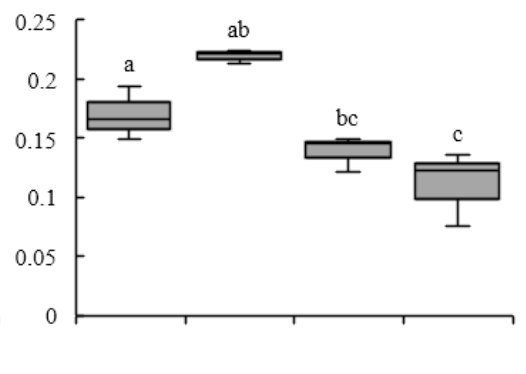

Firmicutes

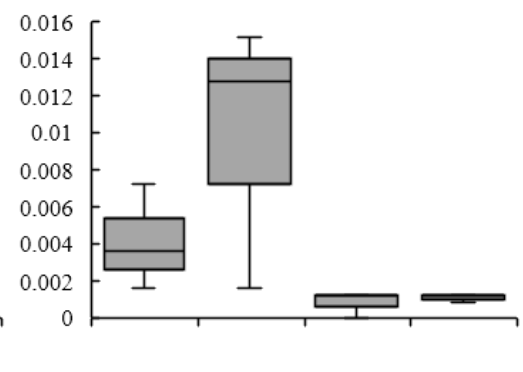

$\alpha$-proteobacteria

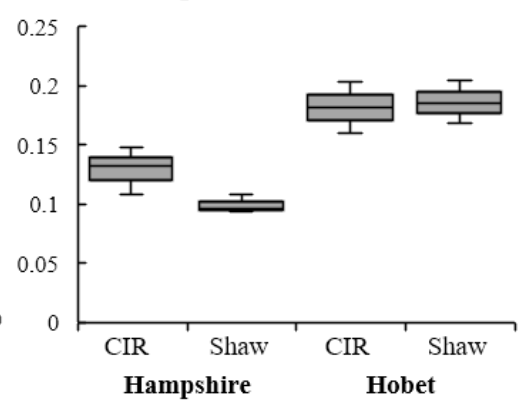

Figure 4: The effect of reclamation strategy on selected bacterial taxa. All induded bacterial phyla, with Proteobacteria divided into class, were significantly different between sites $(\mathrm{P}<0.05)$. Bacteriodetes was the only phyla that exhibited a site $\times$ cultivar interaction $(\mathrm{P}=0.01)$. CIR indicates the Cave-in-Rock cultivar and Shaw indicates the Shawnee cultivar. 
Agaricomycetes

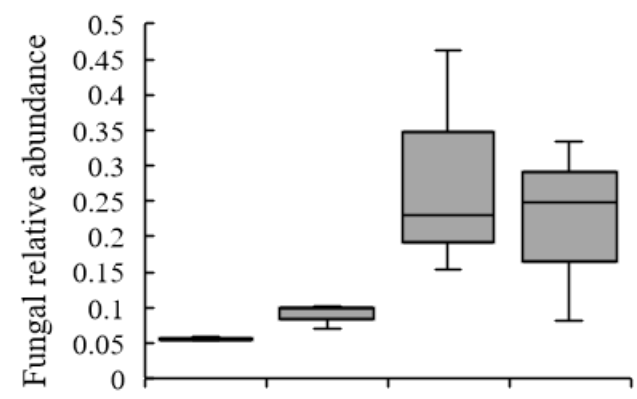

Eurotiomycetes

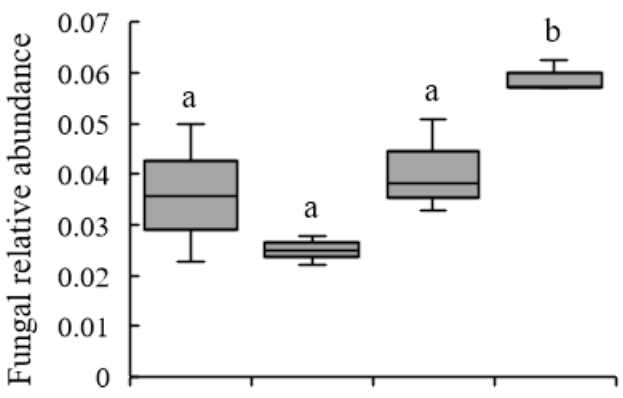

Microbotryomycetes

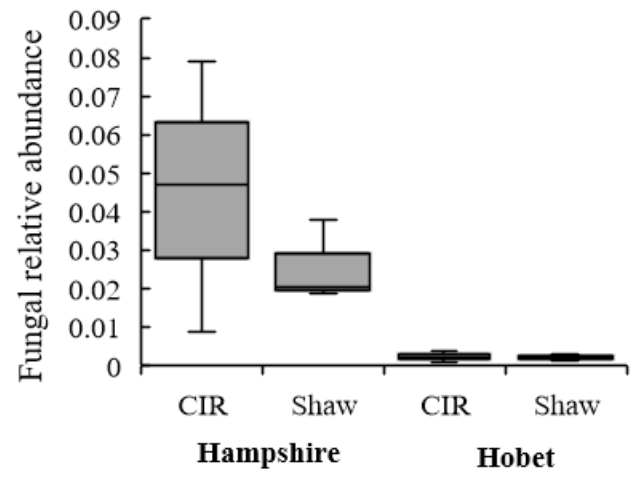

Chytridiomycetes

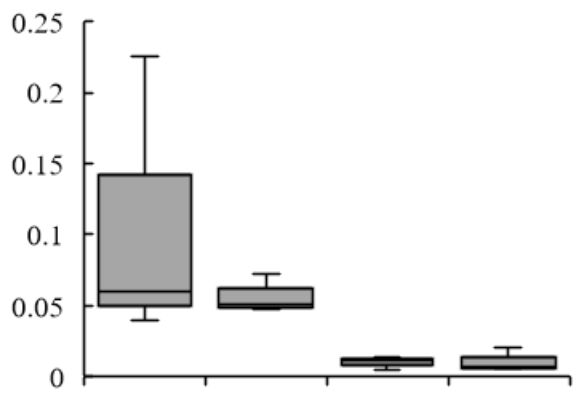

Lecanoromycetes

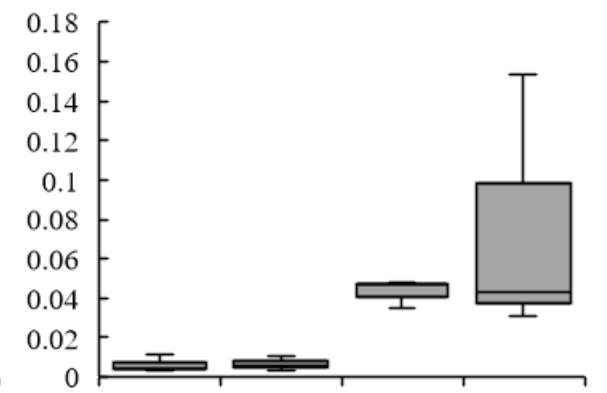

Saccharomycetes

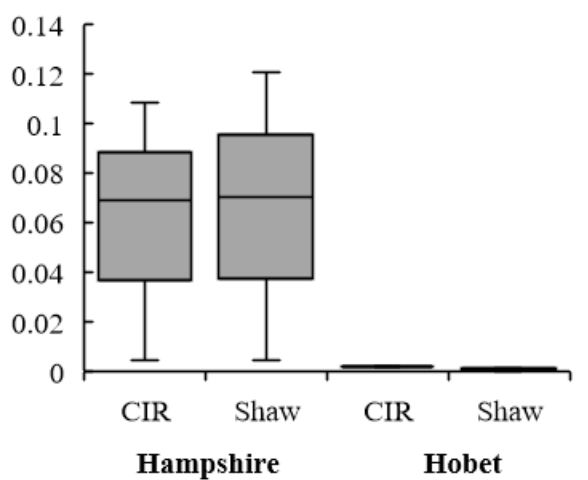

Figure 5: The effect of reclamation strategy on selected fungal taxa. Listed fungal classes were significantly different between sites $(\mathrm{P}<0.05)$. Eurotiomycetes was the only phyla that exhibited a site $\times$ cultivar interaction $(\mathrm{P}=0.01)$. CIR indicates the Cave-in-Rock cultivar and Shaw indicates the Shawnee cultivar. 


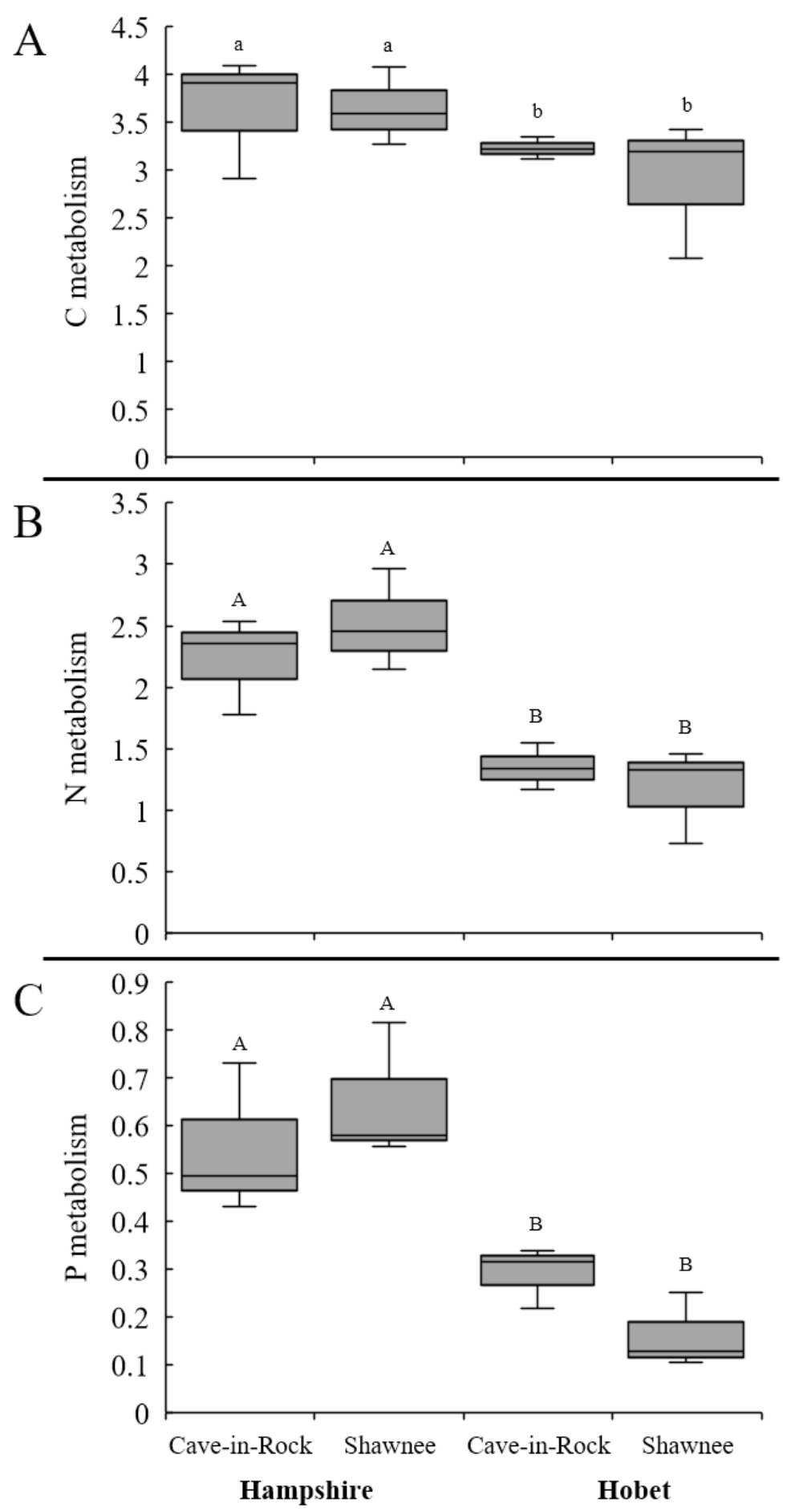

Figure 6: The effect of reclamation technique on the relative abundance of C-, N-, and P- metabolism associated genes through KEGG Orthology level 3. (A) The relative abundance of starch and sucrose metabolism-associated genes [PATH:ko00500]. (B) The relative abundance of nitrogen metabolismassociated genes [PATH:ko00910]. (C) The relative abundance of phosphonate and phosphinate metabolism-associated genes [PATH:ko00440]. Different capital and lowercase letters indicate statistically significant and marginally significant differences in means, respectively. Hits were normalized to total predicted proteins per sample and visualized as hits per 1,000 sequences. 


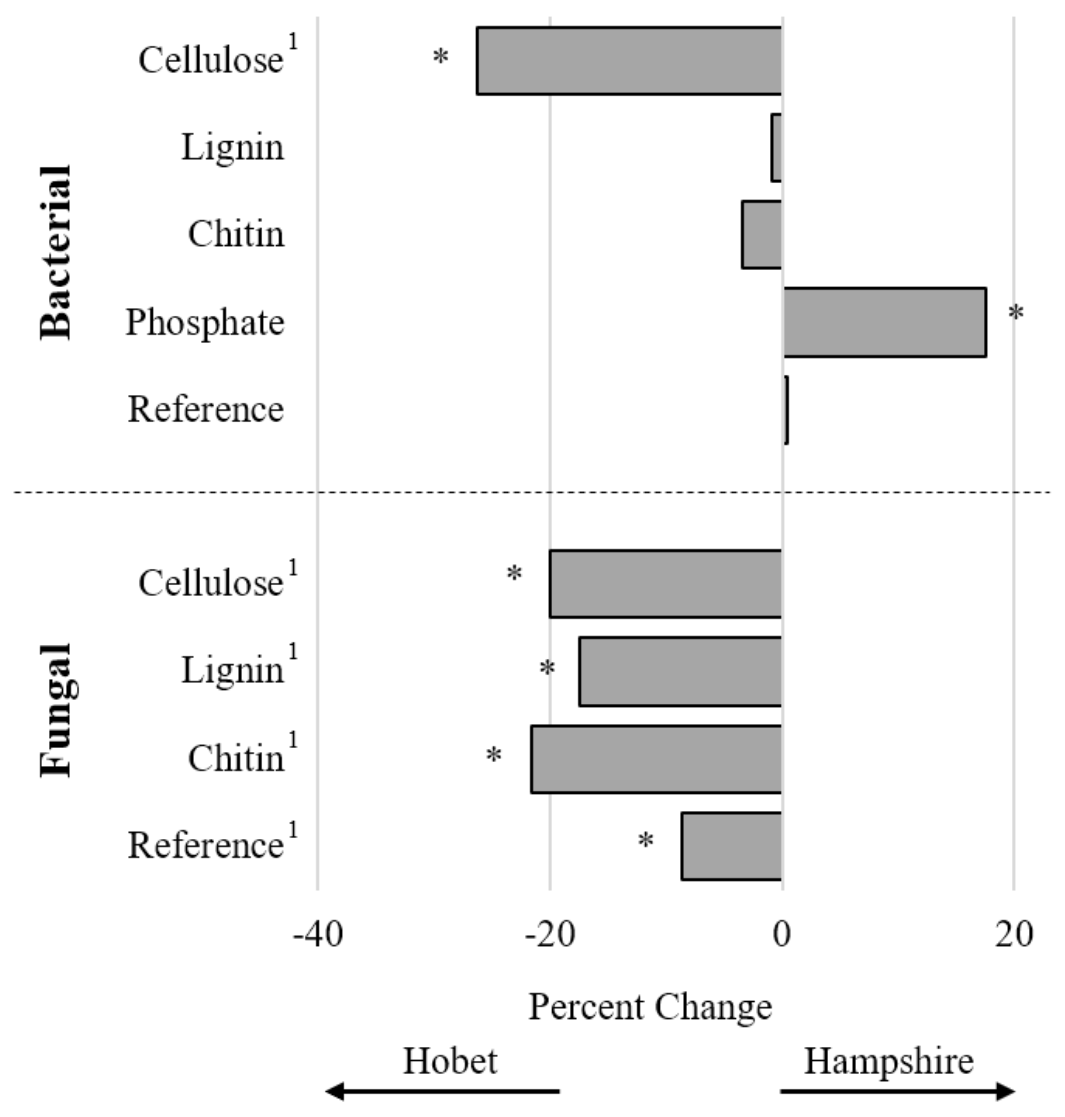

Figure 7: The effect of reclamation strategy on the relative abundances of C-, N-, and P- acquisition genes. Values are expressed as percent change, where positive values indicate a greater relative gene abundance at Hampshire and a negative value indicates greater relative gene abundance at Hobet. * indicates significance at $\mathrm{P}<0.05$. Substrate classes with a superscript 1 indicate nucleotide-curated functional gene databases instead of amino acid-curated databases. 


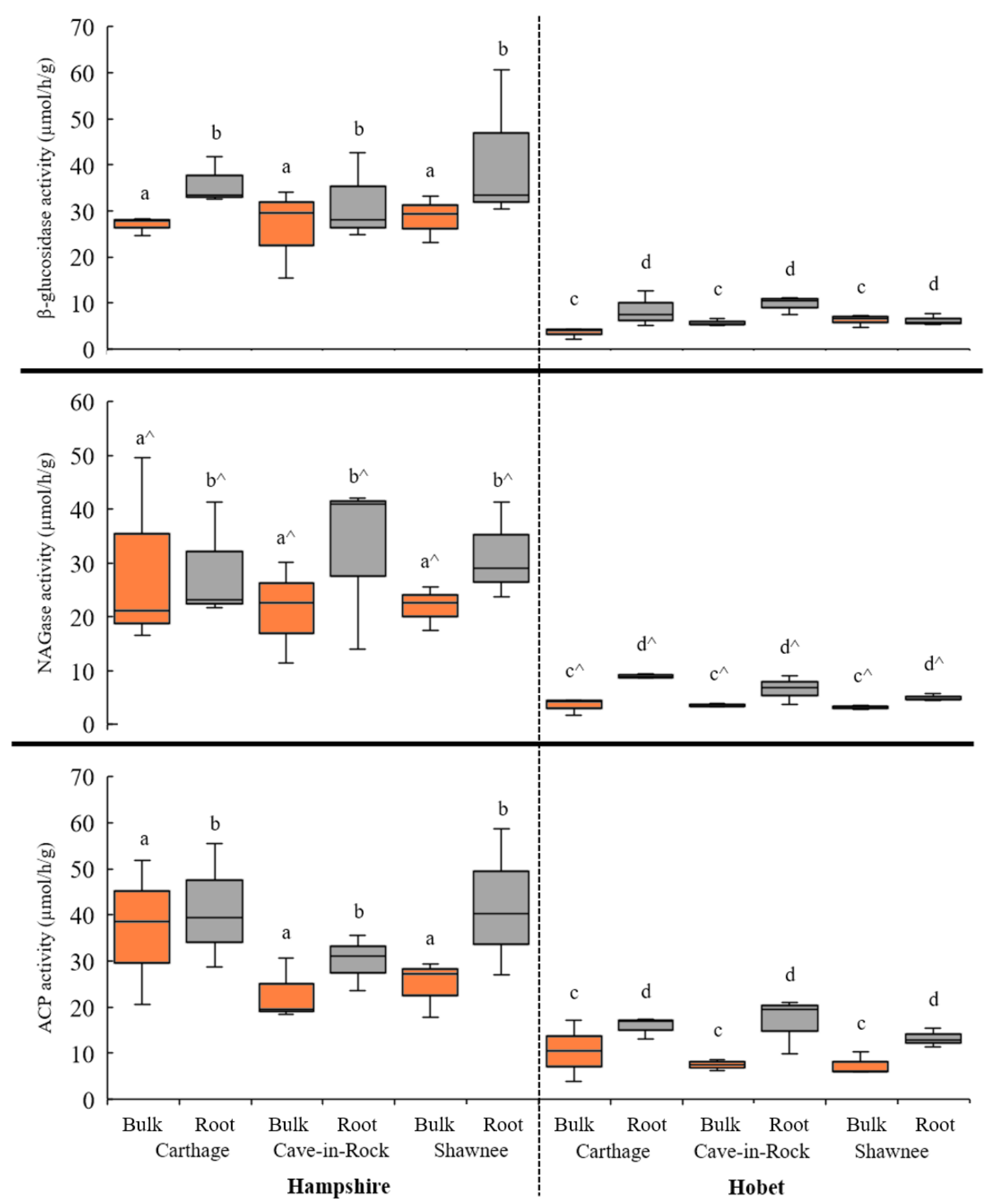

Figure 8: Extracellular enzyme activity responses of $\beta$-glucosidase, $\mathrm{N}$-acetyl-glucosaminidase (NAGase), and acid phosphatase (ACP) across switchgrass cultivars and soil types. Values expressed as mean \pm standard error $(\mathrm{n}=3)$ with eight analytical replicates. Different letters indicate significant differences in means at $\mathrm{P}<0.05$. ${ }^{\wedge}$ indicates marginal differences across soil types at $\mathrm{P}<0.1$. Orange boxes indicate bulk soil and gray boxes indicate root-associated soil. 
A
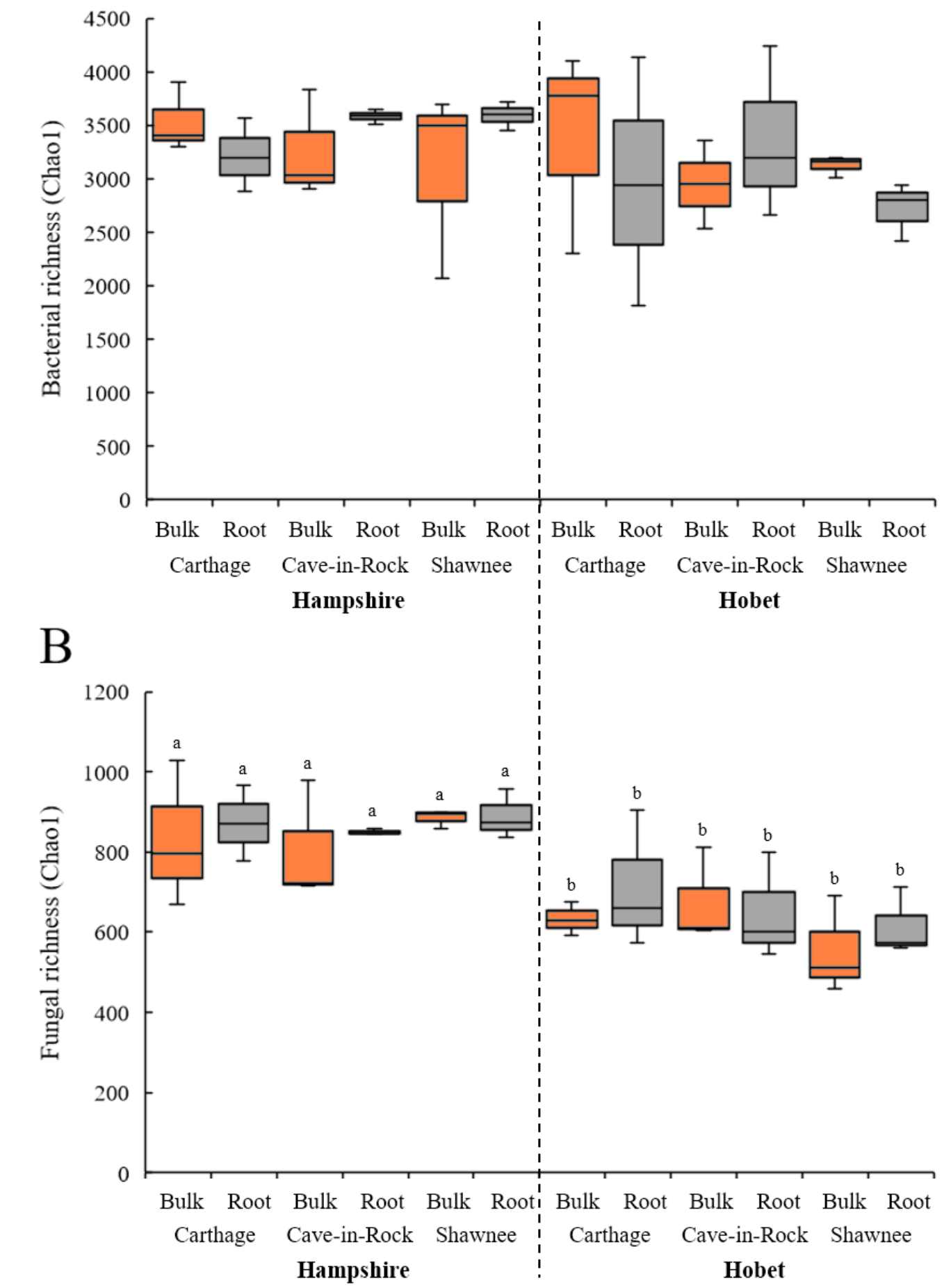

Figure 9: The effect of reclamation strategy on the (A) bacterial and (B) fungal richness of the switchgrass microbiome, as measured by Chaol index. Values expressed as mean \pm standard error $(\mathrm{n}=3)$. Different letters indicate significant differences in means at $\mathrm{P}<0.05$. Orange boxes indicate bulk soil and gray boxes indicate root-associated soil. 


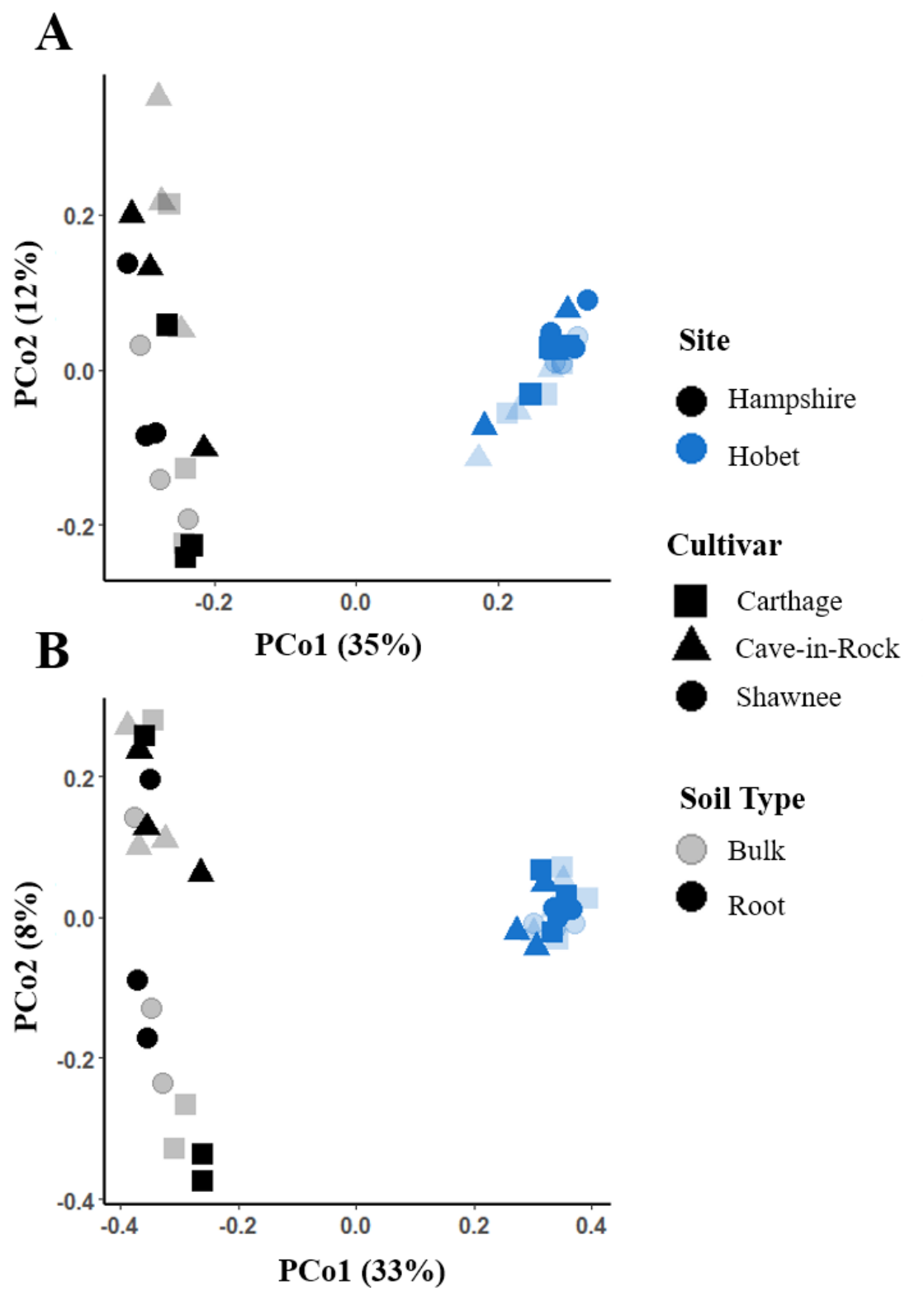

Figure 10: The effect of reclamation strategy on the (A) bacterial and (B) fungal community composition of the switchgrass microbiome. A principal coordinates analysis was conducted using the Bray-Curtis dissimilarity metric on OTU relative abundances. 


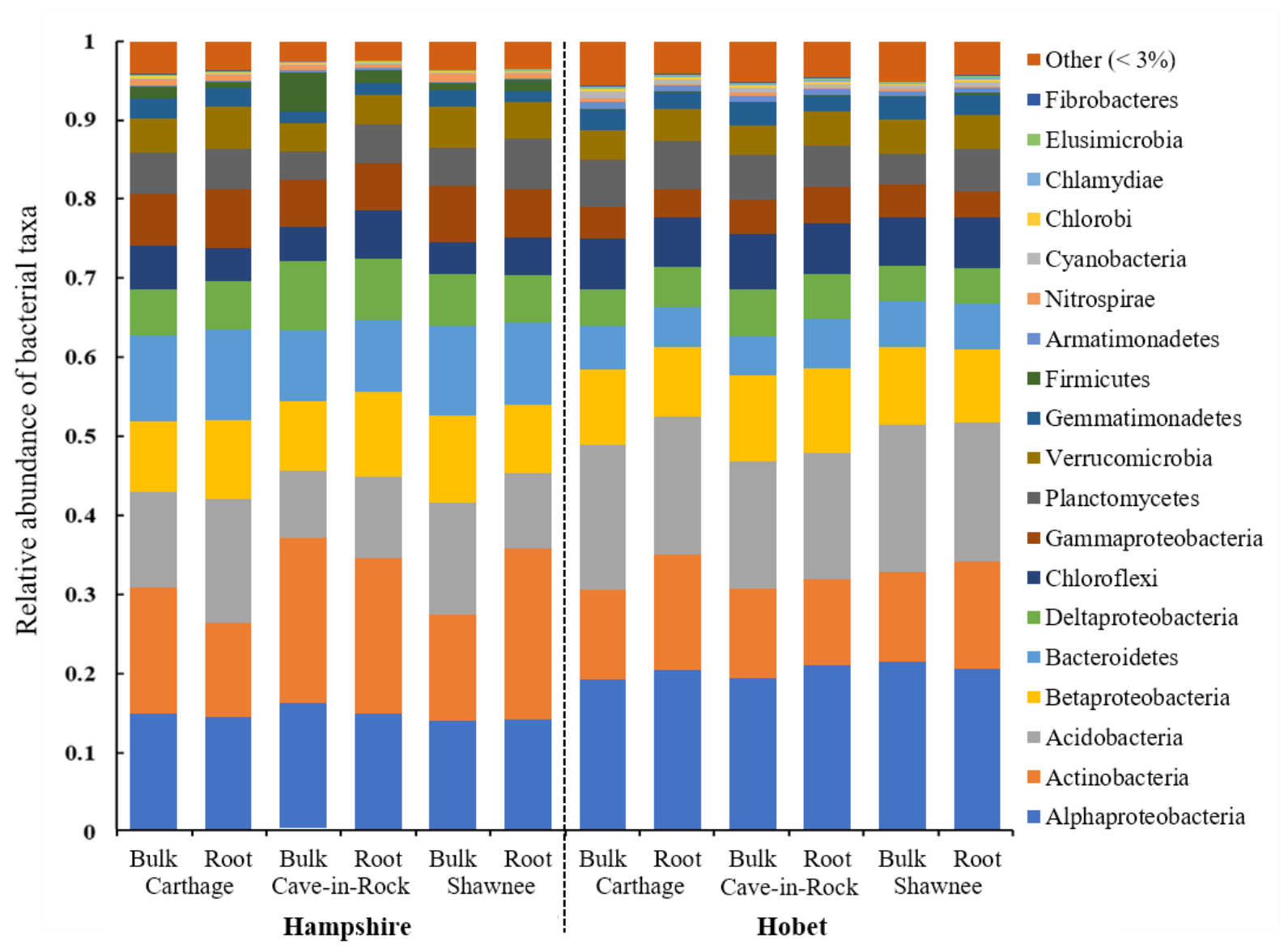

Figure 11: The effect of reclamation strategy on the relative abundance of bacterial taxa. Stacked bar charts include bacterial phyla, with Proteobacteria divided into class, and stacked from most abundant to least abundant. Statistical results using a 3-way ANOVA for each bacterial phylum are detailed in Table 4. 


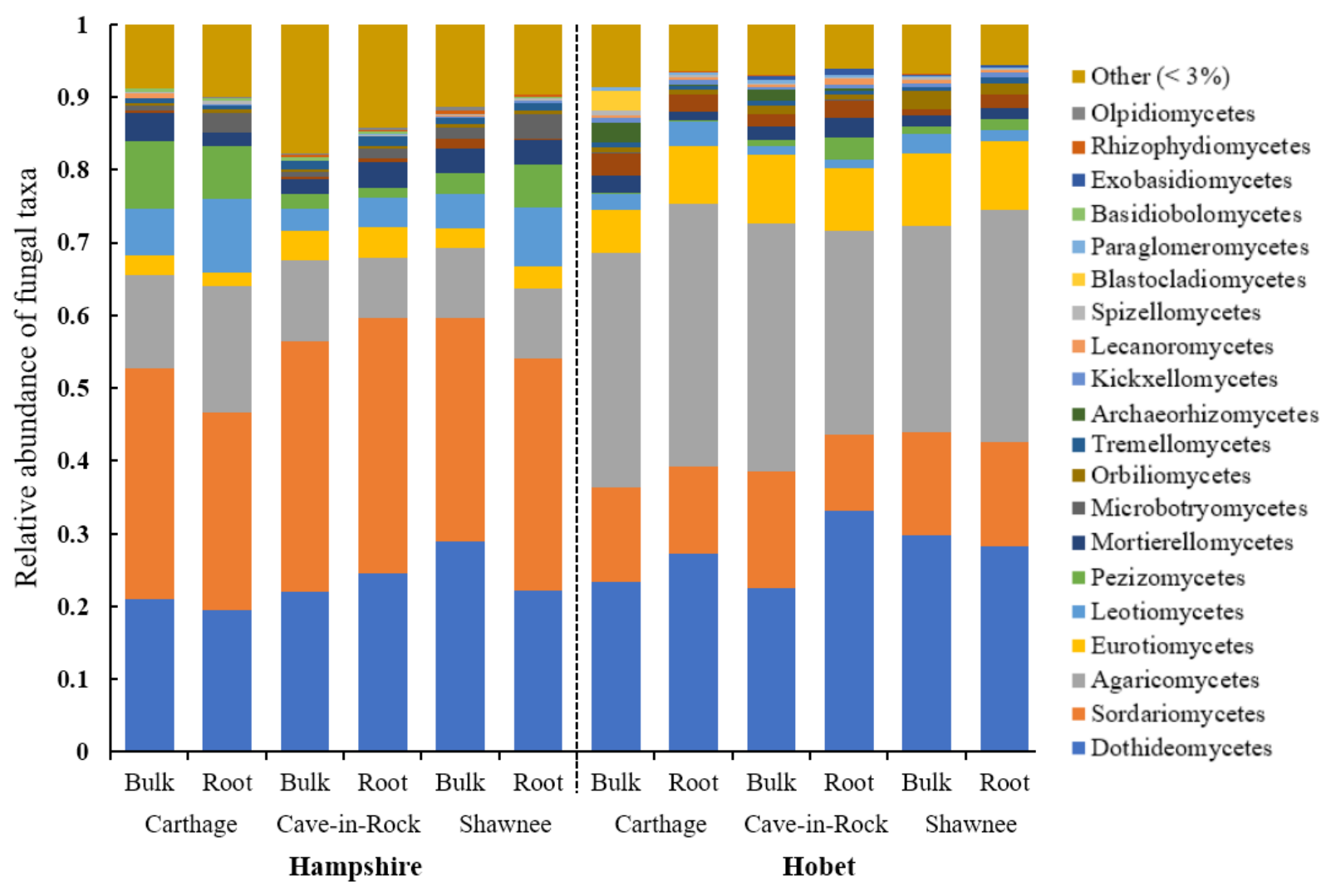

Figure 12: The effect of reclamation strategy on the relative abundance of fungal taxa. Stacked bar charts include fungal classes, stacked from most abundant to least abundant. Statistical results using a 3way ANOVA for each fungal phylum are detailed in Table 5. 


\section{References}

Abawi, G. .. and T. .. Widmer. 2000. "Impact of Soil Health Management Practices on Soilborne Pathogens, Nematodes and Root Diseases of Vegetable Crops." Applied Soil Ecology 15(1):37-47. Retrieved March 30, 2019 (https://www.sciencedirect.com/science/article/pii/S0929139300000706).

Abdullah, Rosazlin, Che Fauziah Ishak, Wan Rasidah Kadir, and Rosenani Abu Bakar. 2015. "Characterization and Feasibility Assessment of Recycled Paper Mill Sludges for Land Application in Relation to the Environment." International Journal of Environmental Research and Public Health 12(8):9314-29.

Altschul, Stephen F., Warren Gish, Webb Miller, Eugene W. Myers, and David J. Lipman. 1990. “Basic Local Alignment Search Tool.” Journal of Molecular Biology 215(3):403-10. Retrieved March 2, 2019 (https://www.sciencedirect.com/science/article/pii/S0022283605803602?via\%3Dihub).

American Society for Testing and Materials. 1985. Standard Test Method for Particle-Size Analysis of Soils D 422-63 (1972).

Anderson, Marti J. 2001. “A New Method for Non-Parametric Multivariate Analysis of Variance.” Austral Ecology 26(1):32-46. Retrieved February 23, 2019 (http://doi.wiley.com/10.1111/j.1442-9993.2001.01070.pp.x).

Anjembe, B., N. B. Ibrahim, and C. Kurayemen. 2016. "Phosphorus Adsorption Isotherms of Some Low Activity Clay Soils As Influenced By Soil Properties and Their Effect on Fertilizer P Recommendations and Yield of Soybean (Glycine Max (L.) Merr.) In Benue State, Nigeria." European Journal of Agricultire and Forestry Research 4(3):19-33. 
Antunes, Pedro M., Kim Schneider, Derek Hillis, and John N. Klironomos. 2007. "Can the Arbuscular Mycorrhizal Fungus Glomus Intraradices Actively Mobilize P from Rock Phosphates?" Pedobiologia 51(4):281-86. Retrieved (https://linkinghub.elsevier.com/retrieve/pii/S0031405607000315).

Apprill, Amy, S. McNally, Rachel Parsons, and Laura Weber. 2015. "Minor Revision to V4 Region SSU rRNA 806R Gene Primer Greatly Increases Detection of SAR11 Bacterioplankton.” Aquatic Microbial Ecology 75(2):129-37. Retrieved (http://www.intres.com/abstracts/ame/v75/n2/p129-137/).

Armesto, J. J. and S. T. A. Pickett. 1985. “Experiments on Disturbance in Old-Field Plant Communities: Impact on Species Richness and Abundance.” Ecology 66(1):230-40. Retrieved February 20, 2019 (http://doi.wiley.com/10.2307/1941323).

Badalucco, L. and P. J. Kuikman. 2001. "Mineralization and Immobilization in the Rhizosphere.” Pp. 159-96 in The rhizosphere; biochemistry and organic substances at the soil-plant interface, edited by R. Pinton, Z. Varanini, and P. Nannipieri. New York: Marcel Dekker.

Bahulikar, Rahul A., Ivone Torres-Jerez, Eric Worley, Kelly Craven, and Michael K. Udvardi. 2014. "Diversity of Nitrogen-Fixing Bacteria Associated with Switchgrass in the Native Tallgrass Prairie of Northern Oklahoma" edited by J. E. Kostka. Applied and Environmental Microbiology 80(18):5636-43. Retrieved September 28, 2018 (http://dx.doi.org/10.1128).

Barros, N., I. Gomez-Orellana, S. Feijóo, and R. Balsa. 1995. "The Effect of Soil Moisture on Soil Microbial Activity Studied by Microcalorimetry." Thermochimica Acta 249:161-68. Retrieved March 25, 2019 
(https://www.sciencedirect.com/science/article/abs/pii/004060319590686X).

Barwell, Louise J., Nick J. B. Isaac, and William E. Kunin. 2015. “Measuring $\beta$ - Diversity with Species Abundance Data" edited by T. Coulson. Journal of Animal Ecology 84(4):1112-22. Retrieved April 2, 2019 (http://doi.wiley.com/10.1111/1365-2656.12362).

Behie, Scott W. and Michael J. Bidochka. 2014. "Nutrient Transfer in Plant-fungal Symbioses." Trends in Plant Science 19(11):734-40. Retrieved March 30, 2019 (http://dx.doi.org/10.1016/j.tplants.2014.06.007).

Bendfeldt, Eric S., James A. Burger, and W.Lee Daniels. 2001. "Quality of Amended Mine Soils After Sixteen Years.” Soil Science Society of America Journal 65(6):1736. Retrieved (https://www.soils.org/publications/sssaj/abstracts/65/6/1736).

Benjamini, Yoav and Yosef Hochberg. 1995. "Controlling the False Discovery Rate: A Practical and Powerful Approach to Multiple Testing." Journal of the Royal Statistical Society. Series B (Methodological) 57(1):289-300. Retrieved (http://www.jstor.org/stable/2346101).

Berg, Björn. 2000. "Litter Decomposition and Organic Matter Turnover in Northern Forest Soils." Forest Ecology and Management 133(1-2):13-22. Retrieved April 1, 2019 (https://www.sciencedirect.com/science/article/pii/S0378112799002947).

Blanco-Canqui, Humberto. 2016. “Growing Dedicated Energy Crops on Marginal Lands and Ecosystem Services.” Soil Science Society of America Journal 80(4):845. Retrieved June 5, 2018 (https://dl.sciencesocieties.org/publications/sssaj/abstracts/80/4/845).

Boe, Arvid and Michael D. Casler. 2005. "Hierarchical Analysis of Switchgrass Morphology." Crop Science 45(6):2465. Retrieved 
(https://www.crops.org/publications/cs/abstracts/45/6/2465).

Boer, Wietse de, Larissa B. Folman, Richard C. Summerbell, and Lynne Boddy. 2005. "Living in a Fungal World: Impact of Fungi on Soil Bacterial Niche Development.” FEMS Microbiology Reviews 29(4):795-811. Retrieved March 30, 2019 (https://academic.oup.com/femsre/article-abstract/29/4/795/493265).

Boratyn, Grzegorz M., Jean Thierry-Mieg, Danielle Thierry-Mieg, Ben Busby, and Thomas L. Madden. 2018. "Magic-BLAST, an Accurate DNA and RNA-Seq Aligner for Long and Short Reads.” bioRxiv 390013. Retrieved March 19, 2019 (http://dx.doi.org/10.1101/390013).

Bowman, Shaun M. and Stephen J. Free. 2006. "The Structure and Synthesis of the Fungal Cell Wall.” BioEssays 28(8):799-808. Retrieved April 1, 2019 (http://doi.wiley.com/10.1002/bies.20441).

Bragazza, Luca et al. 2006. “Atmospheric Nitrogen Deposition Promotes Carbon Loss from Peat Bogs." Proceedings of the National Academy of Sciences 103(51):19386-89. Retrieved March 27, 2019 (www.pnas.orgcgidoi10.1073pnas.0606629104).

Bray, J.Roger and J. T. Curtis. 1957. “An Ordination of the Upland Forest Communities of Southern Wisconsin.” Ecological Monographs 27(4):325-49. Retrieved March 2, 2019 (http://cescos.fau.edu/gawliklab/papers/BrayJRandJTCurtis1957.pdf).

Brejda, John J., Lowell E. Moser, and Kennethp Vogel. 1998. "Evaluation of Switchgrass Rhizosphere Microflora for Enhancing Seedling Yield and Nutrient Uptake (AJ).” Agronomy Journal 90:753-58. Retrieved March 20, 2019 (https://pdfs.semanticscholar.org/2569/bb02a14c911ab964cf5c3f50945826d94417.pdf?_ga 
$=2.15492406 .1222757005 .1553127733-1589004648.1550977350)$.

Brown, Carol, Thomas Griggs, Travis Keene, Mike Marra, and Jeff Skousen. 2016. "Switchgrass Biofuel Production on Reclaimed Surface Mines: I. Soil Quality and Dry Matter Yield.” BioEnergy Research 9(1):31-39. Retrieved June 5, 2018 (https://link.springer.com/content/pdf/10.1007\%2Fs12155-015-9658-2.pdf).

Brzostek, Edward R., Alison Greco, John E. Drake, and Adrien C. Finzi. 2013. "Root Carbon Inputs to the Rhizosphere Stimulate Extracellular Enzyme Activity and Increase Nitrogen Availability in Temperate Forest Soils." Biogeochemistry 115(1-3):65-76. Retrieved March 24,2019 (https://harvardforest.fas.harvard.edu/sites/harvardforest.fas.harvard.edu/files/publications/p dfs/Brzostek_BioGeoChem_2013.pdf).

Buchfink, Benjamin, Chao Xie, and Daniel H. Huson. 2014. "Fast and Sensitive Protein Alignment Using DIAMOND." Nature Methods 12(1):59-60.

Bushnell, Brian. n.d. "BBTools Software Package.” Retrieved March 28, 2019 (http://sourceforge.net/projects/bbmap/).

Campbell, R. and M. P. Greaves. 1990. "Anatomy and Community Structure of the Rhizosphere." Pp. 11-34 in The Rhizosphere. John Wiley and Sons Ltd. Retrieved April 2, 2019 (https://www.cabdirect.org/cabdirect/abstract/19911951554).

Caporaso, J.Gregory et al. 2010. “QIIME Allows Analysis of High-Throughput Community Sequencing Data." Nature Methods 7(5):335-36. Retrieved February 23, 2019 (http://www.nature.com/articles/nmeth.f.303). 
Carvalhais, Lilia C. et al. 2011. "Root Exudation of Sugars, Amino Acids, and Organic Acids by Maize as Affected by Nitrogen, Phosphorus, Potassium, and Iron Deficiency." Journal of Plant Nutrition and Soil Science 174(1):3-11. Retrieved March 31, 2019 (http://doi.wiley.com/10.1002/jpln.201000085).

Casler, M. D. and A. R. Boe. 2003. "Cultivar X Environment Interactions in Switchgrass.” Crop Science 43(6):2226-33. Retrieved March 1, 2019 (https://www.ars.usda.gov/ARSUserFiles/50901500/publications/2003-Casler-CS-432226.pdf).

Casler, Michael D. et al. 2017. "Biomass Yield of Switchgrass Cultivars under High- versus Low-Input Conditions.” Crop Science 57(2):821. Retrieved June 5, 2018 (https://dl.sciencesocieties.org/publications/cs/pdfs/57/2/821).

Cenini, Valeria L. et al. 2016. "Linkages between Extracellular Enzyme Activities and the Carbon and Nitrogen Content of Grassland Soils.” Soil Biology and Biochemistry 96:198206. Retrieved March 25, 2019 (http://dx.doi.org/10.1016/j.soilbio.2016.02.015).

Chang, Ed-Haun, Ren-Shih Chung, and Yuong-How Tsai. 2007. "Effect of Different Application Rates of Organic Fertilizer on Soil Enzyme Activity and Microbial Population.” Soil Science and Plant Nutrition 53(2):132-40. Retrieved March 27, 2019 (https://www.tandfonline.com/action/journalInformation?journalCode=tssp20).

Chao, Anne. 1984. "Nonparametric Estimation of the Number of Classes in a Population." Scandinavian Journal of Statistics 11(4):265-70. Retrieved (http://www.jstor.org/stable/4615964).

Chapman, Samantha K., J. a Langley, S. C. Hart, and G. W. Koch. 2005. "Plants Actively 
Control Nitrogen Cycling: Uncorking the Microbail Bottleneck.” New Phytologist 169:2734.

Chaudhary, Doongar R., Jyotisna Saxena, Nicola Lorenz, Linda K. Dick, and Richard P. Dick. 2012. "Microbial Profiles of Rhizosphere and Bulk Soil Microbial Communities of Biofuel Crops Switchgrass (Panicum Virgatum L.) and Jatropha (Jatropha Curcas L.)." Applied and Environmental Soil Science 2012.

Chen, Xiangbi et al. 2018. "Lignin and Cellulose Dynamics with Straw Incorporation in Two Contrasting Cropping Soils." Scientific Reports 8(1):1633. Retrieved April 2, 2019 (www.nature.com/scientificreports).

Clark, R. B. 2002. "Differences among Mycorrhizal Fungi for Mineral Uptake per Root Length of Switchgrass Grown in Acidic Soil.” Journal of Plant Nutrition 25(8):1753-72. Retrieved March 5, 2019

(http://digitalcommons.unl.edu/usdaarsfacpubhttp://digitalcommons.unl.edu/usdaarsfacpub/ 524).

Clark, R. B., V. C. Baligar, and R. W. Zobel. 2005. "Response of Mycorrhizal Switchgrass to Phosphorus Fractions in Acidic Soil." Communications in Soil Science and Plant Analysis 36(9-10):1337-59. Retrieved (http://www.tandfonline.com/doi/abs/10.1081/CSS200056950).

Clark, R. B., R. W. Zobel, and S. K. Zeto. 1999. "Effects of Mycorrhizal Fungus Isolates on Mineral Acquisition by Panicum Virgatum in Acidic Soil.” Mycorrhiza 9(3):167-76. Retrieved April 18, 2019 (https://link.springer.com/content/pdf/10.1007\%2Fs005720050302.pdf). 
Clarke, KR and RN Gorley. 2015. "PRIMER v7: User Manual/Tutorial."

Cline, Lauren C. and Donald R. Zak. 2015. "Soil Microbial Communities Are Shaped by PlantDriven Changes in Resource Availability during Secondary Succession.” Ecology 96(12):3374-85. Retrieved March 2, 2019 (https://deepblue.lib.umich.edu/bitstream/handle/2027.42/116975/ecy201596123374.pdf?se quence $=1 \&$ isAllowed=y).

Dai, Zhongmin et al. 2016. "Sensitive Responders among Bacterial and Fungal Microbiome to Pyrogenic Organic Matter (Biochar) Addition Differed Greatly between Rhizosphere and Bulk Soils.” Scientific Reports 6(1):36101. Retrieved March 27, 2019 (www.nature.com/scientificreports).

Dalenberg, J. W. and G. Jager. 1989. "Priming Effect of Some Organic Additions to 14CLabelled Soil." Soil Biology and Biochemistry 21(3):443-48. Retrieved April 18, 2019 (https://www.sciencedirect.com/science/article/abs/pii/0038071789901570).

Darrah, P. R. 1993. "The Rhizosphere and Plant Nutrition: A Quantitative Approach.” Plant and Soil 155-156(1):1-20. Retrieved March 31, 2019 (https://www.jstor.org/stable/pdf/42939258.pdf?refreqid=excelsior\%3A8d7341760bc94fbb 2d5f1aa598e9cbc9).

Deng, Shiping, Matteo Lorito, Merja Penttilä, and Gary E. Harman. 2007. "Overexpression of an Endochitinase Gene (ThEn-42) in Trichoderma Atroviride for Increased Production of Antifungal Enzymes and Enhanced Antagonist Action Against Pathogenic Fungi." Applied Biochemistry and Biotechnology 142(1):81-94. Retrieved April 1, 2019 (http://link.springer.com/10.1007/s12010-007-0012-9). 
Dighton, J. 2016. Fungi in Ecosystem Processes. Taylor \& Francis Group. Retrieved (http://ir.obihiro.ac.jp/dspace/handle/10322/3933).

Edayilam, Nimisha et al. 2018. "Phosphorus Stress-Induced Changes in Plant Root Exudation Could Potentially Facilitate Uranium Mobilization from Stable Mineral Forms." Environmental Science \& Technology 52(14):7652-62. Retrieved March 31, 2019 (http://pubs.acs.org/doi/10.1021/acs.est.7b05836).

Edgar, Robert C. 2010. "Search and Clustering Orders of Magnitude Faster than BLAST." Bioinformatics 26(19):2460-61. Retrieved March 28, 2019 (http://www.drive5.com/usearch).

Edzwald, James K., Donald C. Toensing, and Michael Chi-Yew. Leung. 1976. "Phosphate Adsorption Reactions with Clay Minerals.” Environmental Science \& Technology 10(5):485-90. Retrieved March 30, 2019 (https://pubs.acs.org/sharingguidelines).

Egamberdieva, Dilfuza, Giancarlo Renella, Stephan Wirth, and Rafiq Islam. 2011. "Enzyme Activities in the Rhizosphere of Plants." in Soil Enzymology, vol. 22, Soil Biology, edited by G. Shukla and A. Varma. Springer Berlin Heidelberg. Retrieved (http://link.springer.com/10.1007/978-3-642-14225-3).

Eivazi, F. and M. Tabatabai. 1976. "Phosphatases in Soils." Soil Biology and Biochemistry 9:167-72. Retrieved March 13, 2019 (https://www.jstor.org/stable/pdf/2434888.pdf?refreqid=excelsior\%3Ad5a27b361bc976503 1889f13631d57d4).

Engelmann, Margaret H. and Thomas E. Weaks. 1985. "An Analysis of the Effects of StripMining Disturbance on Bryophyte Species Diversity.” The Bryologist 88(4):344-49. 
Retrieved March 30, 2019

(https://www.jstor.org/stable/pdf/3242670.pdf?refreqid=excelsior\%3Ad07f9b0bb5a500d18 bd9b874911a2547).

Environmental Protection Agency. 2007. Regulation of Fuels and Fuel Additives: Renewable Fuel Standard Program.

Fang, Shengzuo, Jiujun Liu, Dong Liu, and Baodong Xie. 2010. "Enzymatic Activity and Nutrient Availability in the Rhizosphere of Poplar Plantations Treated with Fresh Grass Mulch.” Soil Science and Plant Nutrition 56(3):483-91. Retrieved March 24, 2019 (https://www.tandfonline.com/action/journalInformation?journalCode=tssp20).

Fawal, Nizar et al. 2012. "PeroxiBase: A Database for Large-Scale Evolutionary Analysis of Peroxidases." Nucleic Acids Research 41(D1):D441-44. Retrieved March 28, 2019 (http://www.ncbi.nlm.nih.gov/pubmed/23180785).

Fierer, Noah et al. 2012. "Comparative Metagenomic, Phylogenetic and Physiological Analyses of Soil Microbial Communities across Nitrogen Gradients." The ISME Journal 6(5):100717. Retrieved February 16, 2019 (http://www.).

Fierer, Noah, Mark A. Bradford, and Robert B. Jackson. 2007. TOWARD AN ECOLOGICAL CLASSIFICATION OF SOIL BACTERIA. Retrieved September 4, 2018 (http://fiererlab.org/wp-content/uploads/2014/09/Fierer-Bradford-Jackson-Ecology20071.pdf).

Fierer, Noah and Robert B. Jackson. 2006. "The Diversity and Biogeography of Soil Bacterial Communities." Proceedings of the National Academy of Sciences 103(3):626-31. Retrieved (www.pnas.orgcgidoi10.1073pnas.0507535103). 
Fierer, Noah, Joshua P. Schimel, and Patricia A. Holden. 2003. "Variations in Microbial Community Composition through Two Soil Depth Profile.” Soil Biology and Biochemistry 35:167-76.

Fike, John H. et al. 2006. "Switchgrass Production for the Upper Southeastern USA: Influence of Cultivar and Cutting Frequency on Biomass Yields.” Biomass and Bioenergy 30(3):207-13.

Fish, Jordan A. et al. 2013. "FunGene: The Functional Gene Pipeline and Repository." Frontiers in Microbiology 4:291. Retrieved March 28, 2019 (http://journal.frontiersin.org/article/10.3389/fmicb.2013.00291/abstract).

Fog, Kare. 1988. "The Effect of Added Nitrogen on the Rate of Decomposition of Organic Matter.” Biological Reviews 63(3):433-62. Retrieved April 2, 2019 (http://doi.wiley.com/10.1111/j.1469-185X.1988.tb00725.x).

Fraser, Tandra D., Derek H. Lynch, Elizabeth Bent, Martin H. Entz, and Kari E. Dunfield. 2015. "Soil Bacterial phoD Gene Abundance and Expression in Response to Applied Phosphorus and Long-Term Management.” Soil Biology and Biochemistry 88:137-47. Retrieved (https://linkinghub.elsevier.com/retrieve/pii/S0038071715001649).

Freedman, Zachary B., Rima A. Upchurch, and Donald R. Zak. 2016. "Microbial Potential for Ecosystem N Loss Is Increased by Experimental N Deposition” edited by T. Miki. PLOS ONE 11(10):e0164531. Retrieved (http://dx.plos.org/10.1371/journal.pone.0164531).

Freedman, Zachary B., Rima A. Upchurch, Donald R. Zak, and Lauren C. Cline. 2016. “Anthropogenic N Deposition Slows Decay by Favoring Bacterial Metabolism: Insights from Metagenomic Analyses.” Frontiers in Microbiology 7(MAR):1-11. Retrieved (http://journal.frontiersin.org/Article/10.3389/fmicb.2016.00259/abstract). 
Galand, Pierre E. et al. 2016. "Disturbance Increases Microbial Community Diversity and Production in Marine Sediments.” Frontiers in Microbiology 7(DEC):1-11. Retrieved (http://journal.frontiersin.org/article/10.3389/fmicb.2016.01950/full).

George, Eckhard, Horst Marschner, and Iver Jakobsen. 1995. "Role of Arbuscular Mycorrhizal Fungi in Uptake of Phosphorus and Nitrogen From Soil.” Critical Reviews in Biotechnology 15(3-4):257-70. Retrieved April 18, 2019 (http://www.tandfonline.com/doi/full/10.3109/07388559509147412).

Gilbert, Clayton, Handelsman, and Parke. 1996. "Use of Cluster and Discriminant Analyses to Compare Rhizosphere Bacterial Communities Following Biological Perturbation." Microbial Ecology 32(2):123-47. Retrieved April 2, 2019

(http://www.ncbi.nlm.nih.gov/pubmed/8688005).

Glass, Jennifer B. et al. 2015. "Meta-Omic Signatures of Microbial Metal and Nitrogen Cycling in Marine Oxygen Minimum Zones.” Frontiers in Microbiology 6:998. Retrieved March 2, 2019 (www.frontiersin.org).

Gohl, Daryl M. et al. 2016. "Systematic Improvement of Amplicon Marker Gene Methods for Increased Accuracy in Microbiome Studies.” Nature Biotechnology 34(9):942-49. Retrieved March 23, 2019 (http://www.nature.com/articles/nbt.3601).

Goyal, Sneh, K. Chander, M. C. Mundra, and K. K. Kapoor. 1999. "Influence of Inorganic Fertilizers and Organic Amendments on Soil Organic Matter and Soil Microbial Properties under Tropical Conditions." Biology and Fertility of Soils 29(2):196-200. Retrieved March 27, 2019 (https://link-springercom.www.libproxy.wvu.edu/content/pdf/10.1007\%2Fs003740050544.pdf). 
de Graaff, Marie-Anne, Julie D. Jastrow, Shay Gillette, Aislinn Johns, and Stan D. Wullschleger. 2014. "Differential Priming of Soil Carbon Driven by Soil Depth and Root Impacts on Carbon Availability.” Soil Biology and Biochemistry 69:147-56. Retrieved March 5, 2019 (http://dx.doi.org/10.1016/j.soilbio.2013.10.047).

de Graaff, Marie Anne, Johan Six, Julie D. Jastrow, Christopher W. Schadt, and Stan D. Wullschleger. 2013. "Variation in Root Architecture among Switchgrass Cultivars Impacts Root Decomposition Rates.” Soil Biology and Biochemistry 58:198-206. Retrieved (http://dx.doi.org/10.1016/j.soilbio.2012.11.015).

Greaves, JE and EG Carter. 1920. "Influence of Moisture on the Bacterial Activities of the Soil." Soil Science 10(5):361-87. Retrieved March 25, 2019

(https://books.google.com/books?hl=en\&lr=\&id=jXQQAAAAIAAJ\&oi=fnd\&pg=PA361\& ots=5Rytcg019v\&sig=7vq3tqv_K2zVNnvPbgAHEX8QL28).

Haering, Kathryn C., W.Lee Daniels, and Jesse A. Roberts. 1993. "Changes in Mine Soil Properties Resulting from Overburden Weathering." Journal of Environmental Quality 22:194-200. Retrieved (http://dx.doi.org/10.2134/jeq1993.00472425002200010026x).

Hammer, Edith C., Jan Pallon, Håkan Wallander, and Pål Axel Olsson. 2011. “Tit for Tat? A Mycorrhizal Fungus Accumulates Phosphorus under Low Plant Carbon Availability.” FEMS Microbiology Ecology 76(2):236-44. Retrieved March 25, 2019 (https://academic.oup.com/femsec/article-abstract/76/2/236/697580).

Hartmann, Martin, Beat Frey, Jochen Mayer, Paul Mäder, and Franco Widmer. 2015. "Distinct Soil Microbial Diversity under Long-Term Organic and Conventional Farming.” The ISME Journal 9(5):1177-94. Retrieved March 27, 2019 (www.nature.com/ismej). 
Hartmann, Martin and Franco Widmer. 2006. "Community Structure Analyses Are More Sensitive to Differences in Soil Bacterial Communities than Anonymous Diversity Indices.” Applied and Environmental Microbiology 72(12):7804-12. Retrieved March 27, 2019 (http://www.ncbi.nlm.nih.gov/pubmed/17041161).

Hashem, Abeer, Elsayed Fathi Abd_Allah, Abdulaziz A. Alqarawi, and Dilfuza Egamberdieva. 2018. “Arbuscular Mycorrhizal Fungi and Plant Stress Tolerance.” Pp. 81-103 in Plant Microbiome: Stress Response. Microorganisms for Sustainability, edited by D.

Egamberdieva and P. Ahmad. Springer, Singapore. Retrieved March 27, 2019 (https://link.springer.com/chapter/10.1007/978-981-10-5514-0_4).

Helgason, Thorunn and Alastair H. Fitter. 2009. "Natural Selection and the Evolutionary Ecology of the Arbuscular Mycorrhizal Fungi (Phylum Glomeromycota).” Journal of Experimental Botany 60(9):2465-80. Retrieved March 5, 2019

(https://academic.oup.com/jxb/article-abstract/60/9/2465/513679).

Heuck, Christine, Alfons Weig, and Marie Spohn. 2015. “Soil Microbial Biomass C:N:P Stoichiometry and Microbial Use of Organic Phosphorus.” Soil Biology and Biochemistry 85:119-29. Retrieved March 30, 2019 (https://www.sciencedirect.com/science/article/pii/S0038071715000747).

Ho, Adrian, D. Paolo, Di Lonardo, and Paul L. E. Bodelier. 2017. "Revisiting Life Strategy Concepts in Environmental Microbial Ecology." FEMS Microbiology Ecology 93:6. Retrieved February 24, 2019 (https://academic.oup.com/femsec/articleabstract/93/3/fix006/2937747).

Hong, C. O. et al. 2014. "Switchgrass Response to Nitrogen Fertilizer Across Diverse 
Environments in the USA: A Regional Feedstock Partnership Report." BioEnergy Research 7(3):777-88. Retrieved March 31, 2019 (http://link.springer.com/10.1007/s12155-0149484-y).

Hong, Chen, Yanxiao Si, Yi Xing, and Yang Li. 2015. "Illumina MiSeq Sequencing Investigation on the Contrasting Soil Bacterial Community Structures in Different Iron Mining Areas." Environmental Science and Pollution Research 22(14):10788-99. Retrieved March 30, 2019 (https://link.springer.com/content/pdf/10.1007\%2Fs11356-015-41863.pdf).

Van Horn, David J. et al. 2014. "Soil Microbial Responses to Increased Moisture and Organic Resources along a Salinity Gradient in a Polar Desert" edited by J. E. Kostka. Applied and Environmental Microbiology 80(10):3034-43. Retrieved March 25, 2019 (http://dx.doi.org/10.1128).

Hu, Lingfei et al. 2018. "Root Exudate Metabolites Drive Plant-Soil Feedbacks on Growth and Defense by Shaping the Rhizosphere Microbiota.” Nature Communications 9(1):2738. Retrieved March 24, 2019 (www.nature.com/naturecommunications).

Huang, Xing-Feng et al. 2014. "Rhizosphere Interactions: Root Exudates, Microbes, and Microbial Communities.” Botany 92(4):267-75. Retrieved (http://www.nrcresearchpress.com/doi/10.1139/cjb-2013-0225).

Huntemann, Marcel et al. 2016. "The Standard Operating Procedure of the DOE-JGI Metagenome Annotation Pipeline (MAP v.4)." Standards in Genomic Sciences 11(1):17. Retrieved February 23, 2019 (https://environmentalmicrobiome.biomedcentral.com/track/pdf/10.1186/s40793-016-0138- 
$\mathrm{X})$.

Hyatt, D. et al. 2010. "Prodigal: Prokaryotic Gene Recognition and Translation Initiation Site Identification." BMC Bioinformatics 11:119.

Ishida, Yuzaburo and Hajime Kadota. 1981. Growth Patterns and Substrate Requirements of Naturally Occurring Obligate Oligotrophs. Retrieved March 5, 2019 (https://www-jstororg.www.libproxy.wvu.edu/stable/pdf/4250653.pdf?refreqid=excelsior\%3A9d87fb684fac3 9fd9676073d5541254b).

Javaid, Arshad. 2009. “Arbuscular Mycorrhizal Mediated Nutrition in Plants.” Journal of Plant Nutrition 32(10):1595-1618. Retrieved (http://www.tandfonline.com/doi/abs/10.1080/01904160903150875).

Jesus, Ederson da C. et al. 2016. "Influence of Corn, Switchgrass, and Prairie Cropping Systems on Soil Microbial Communities in the Upper Midwest of the United States." $G C B$ Bioenergy 8(2):481-94.

Kanehisa, Minoru and Susumu Goto. 2000. “KEGG: Kyoto Encyclopedia of Genes and Genomes.” Nucleic Acids Research 28(1):27-30. Retrieved February 18, 2019 (http://www.genome.ad.jp/kegg/).

Ker, Keomany, Philippe Seguin, Brian T. Driscoll, James W. Fyles, and Donald L. Smith. 2012. "Switchgrass Establishment and Seeding Year Production Can Be Improved by Inoculation with Rhizosphere Endophytes.” Biomass \& Bioenergy 47:295-301. Retrieved July 17, 2018 (https://www.sciencedirect.com/science/article/pii/S0961953412003716).

Kering, M. K., J. T. Biermacher, T. J. Butler, J. Mosali, and J. A. Guretzky. 2012. "Biomass 
Yield and Nutrient Responses of Switchgrass to Phosphorus Application.” BioEnergy Research 5(1):71-78. Retrieved March 30, 2019

(https://link.springer.com/content/pdf/10.1007\%2Fs12155-011-9174-y.pdf).

Kering, Maru K., Twain J. Butler, Jon T. Biermacher, Jagadeesh Mosali, and John A. Guretzky. 2013. "Effect of Potassium and Nitrogen Fertilizer on Switchgrass Productivity and Nutrient Removal Rates under Two Harvest Systems on a Low Potassium Soil." BioEnergy Research 6(1):329-35. Retrieved June 5, 2018 (http://link.springer.com/10.1007/s12155012-9261-8).

Kim-Dura, S., S. Lowman, S. Zhang, and C. Mei. 2016. "Growth Promotion of Switchgrass by Bacterial Endophyte Pantoea Agglomerans Strain PaKM Isolated from Seeds.” Journal of Pathology \& Microbiology 1(2):1-9.

Kim, Seonhwa et al. 2012. "Growth Promotion and Colonization of Switchgrass (Panicum Virgatum) Cv. Alamo by Bacterial Endophyte Burkholderia Phytofirmans Strain PsJN.” Biotechnology for Biofuels 5(1):37. Retrieved March 31, 2019 (http://www.biotechnologyforbiofuels.com/content/5/1/37).

van der Klei, Ida et al. 2011. "Cytology, Cell Walls and Septa." Pp. 111-28 in The Yeasts. Elsevier. Retrieved March 26, 2019 (https://www.sciencedirect.com/science/article/pii/B9780444521491000082).

Kloepper, J. W. 1980. "Effects of Rhizosphere Colonization by Plant Growth-Promoting Rhizobacteria on Potato Plant Development and Yield.” Phytopathology 70(11):1078-82. Retrieved (http://www.apsnet.org/publications/phytopathology/backissues/Documents/1980Abstracts/ 
Phyto70_1078.htm).

Köberl, Martina, Miguel Dita, Alfonso Martinuz, Charles Staver, and Gabriele Berg. 2017. "Members of Gammaproteobacteria as Indicator Species of Healthy Banana Plants on Fusarium Wilt-Infested Fields in Central America.” Scientific Reports 7(1):45318. Retrieved March 30, 2019 (www.nature.com/scientificreports).

Koh, Lian Pin and Jaboury Ghazoul. 2008. "Biofuels, Biodiversity, and People: Understanding the Conflicts and Finding Opportunities." Biological Conservation 141(10):2450-60. Retrieved February 23, 2019 (https://ac-els-cdncom.www.libproxy.wvu.edu/S0006320708002954/1-s2.0-S0006320708002954main.pdf?_tid=26af30e6-8584-4a8b-818407a570726fc1\&acdnat=1550944158_35374f13974a46f0881476861b2db4db).

Kuznetsov, S. I., G. A. Dubinina, and N. A. Lapteva. 1979. "Biology of Oligotrophic Bacteria." Annual Review of Microbiology 33(1):377-87. Retrieved March 5, 2019 (www.annualreviews.org).

Larney, Francis J. and Denis A. Angers. 2012. "The Role of Organic Amendments in Soil Reclamation: A Review." Canadian Journal of Soil Science 92(1):19-38. Retrieved March 1, 2019 (www.nrcresearchpress.com).

Lasudee, Krisana, Shinji Tokuyama, Saisamorn Lumyong, and Wasu Pathom-aree. 2018. "Actinobacteria Associated With Arbuscular Mycorrhizal Funneliformis Mosseae Spores, Taxonomic Characterization and Their Beneficial Traits to Plants: Evidence Obtained From Mung Bean (Vigna Radiata) and Thai Jasmine Rice (Oryza Sativa)." Frontiers in Microbiology 9:1247. Retrieved April 2, 2019 
(https://www.frontiersin.org/article/10.3389/fmicb.2018.01247/full).

Lazarovits, George. 2001. "Management of Soil-Borne Plant Pathogens with Organic Soil Amendments: A Disease Control Strategy Salvaged from the Past." Canadian Journal of Plant Pathology 23(1):1-7. Retrieved March 30, 2019 (http://www.tandfonline.com/doi/abs/10.1080/07060660109506901).

Lemus, R. et al. 2002. "Biomass Yield and Quality of 20 Switchgrass Populations in Southern Iowa, USA.” Biomass and Bioenergy 23(6):433-42. Retrieved March 24, 2019 (https://pdf.sciencedirectassets.com/271477/1-s2.0-S0961953400X00852/1-s2.0S0961953402000739/main.pdf?x-amz-securitytoken=FQoGZXIvYXdzECcaDIjKY1AysRcgqVNG9SK3A\%2B2CPTVobqZqKLW3RaO1 Y\%2B96nUuDCWjtHsD2yNVulrcPHOHwRvmEyqykI9zQ\%2BBiv\%2FQaix9X8dW8Km qZQYihlKlKO).

De León-Lorenzana, Arit S. et al. 2018. "Soil Salinity Controls Relative Abundance of Specific Bacterial Groups Involved in the Decomposition of Maize Plant Residues." Frontiers in Ecology and Evolution 6:51. Retrieved March 19, 2019 (http://journal.frontiersin.org/article/10.3389/fevo.2018.00051/full).

Letcher, Peter M., Martha J. Powell, Perry F. Churchill, and James G. Chambers. 2006. "Ultrastructural and Molecular Phylogenetic Delineation of a New Order, the Rhizophydiales (Chytridiomycota).” Mycological Research 110(8):898-915. Retrieved March 27, 2019 (http://www.biology.duke.edu/fungi/mycolab/).

Li, Heng. 2015. "BFC: Correcting Illumina Sequencing Errors." Bioinformatics 31(17):2885-87. Retrieved March 28, 2019 (https://academic.oup.com/bioinformatics/article- 
lookup/doi/10.1093/bioinformatics/btv290).

Li, Hui et al. 2018. "Soil Microbial Beta-Diversity Is Linked with Compositional Variation in Aboveground Plant Biomass in a Semi-Arid Grassland.” Plant and Soil 423(1-2):465-80. Retrieved April 2, 2019 (http://link.springer.com/10.1007/s11104-017-3524-2).

Liebig, M. A., H. A. Johnson, J. D. Hanson, and A. B. Frank. 2005. “Soil Carbon under Switchgrass Stands and Cultivated Cropland." Biomass and Bioenergy 28:347-54. Retrieved February 28, 2019 (www.elsevier.com/locate/biombioe).

Liu, Jiali, Lu Tang, Hong Gao, Miao Zhang, and Changhong Guo. 2019. "Enhancement of Alfalfa Yield and Quality by Plant Growth-promoting Rhizobacteria under Saline-alkali Conditions." Journal of the Science of Food and Agriculture 99(1):281-89. Retrieved March 31, 2019 (https://onlinelibrary.wiley.com/doi/abs/10.1002/jsfa.9185).

Lombard, Vincent, Hemalatha Golaconda Ramulu, Elodie Drula, Pedro M. Coutinho, and Bernard Henrissat. 2014. "The Carbohydrate-Active Enzymes Database (CAZy) in 2013." Nucleic Acids Research 42(D1):D490-95. Retrieved March 28, 2019 (https://academic.oup.com/nar/article-lookup/doi/10.1093/nar/gkt1178).

Lukashin, AV and M. Borodovsky. 1998. "GeneMark.hmm: New Solutions for Gene Finding." Nucleic Acids Research 26(4):1107-15.

Lundell, Taina K., Miia R. Mäkelä, Ronald P. de Vries, and Kristiina S. Hildén. 2014. "Genomics, Lifestyles and Future Prospects of Wood-Decay and Litter-Decomposing Basidiomycota." Pp. 329-70 in Fungi, vol. 70. Retrieved March 26, 2019 (http://dx.doi.org/10.1016/B978-0-12-397940-7.00011-2). 
Ma, B. L., Lianne M. Dwyer, and Edward G. Gregorich. 1999. "Soil Nitrogen Amendment Effects on Seasonal Nitrogen Mineralization and Nitrogen Cycling in Maize Production.” Agronomy Journal 91(6):1003. Retrieved March 31, 2019 (https://www.agronomy.org/publications/aj/abstracts/91/6/1003).

Ma, Z., C. W. Wood, and D. I. Bransby. 2000. "Impacts of Soil Management on Root Characteristics of Switchgrass.” Biomass and Bioenergy 18(2):105-12.

Manzoni, Stefano, Joshua P. Schimel, and Amilcare Porporato. 2012. "Responses of Soil Microbial Communities to Water Stress: Results from a Meta-Analysis.” Ecology 93(4):930-38. Retrieved March 25, 2019 (http://doi.wiley.com/10.1890/11-0026.1).

Mao, Yuejian, Xiangzhen Li, Eoghan M. Smyth, Anthony C. Yannarell, and Roderick I. Mackie. 2014. "Enrichment of Specific Bacterial and Eukaryotic Microbes in the Rhizosphere of Switchgrass ( Panicum Virgatum L.) through Root Exudates.” Environmental Microbiology Reports 6(3):293-306. Retrieved March 20, 2019 (http://doi.wiley.com/10.1111/17582229.12152).

Maron, Pierre-Alain et al. 2018. "High Microbial Diversity Promotes Soil Ecosystem Functioning" edited by H. L. Drake. Applied and Environmental Microbiology 84(9):e02738-17. Retrieved April 2, 2019 (http://www.ncbi.nlm.nih.gov/pubmed/29453268).

Marra, Michael, Travis Keene, Jeff Skousen, and Thomas Griggs. 2013. "Switchgrass Yield on Reclaimed Surface Mines for Bioenergy Production.” Journal of Environment Quality 42(3):696. Retrieved June 5, 2018 (https://www.agronomy.org/publications/jeq/abstracts/42/3/696). 
McDonald, Daniel et al. 2012. “An Improved Greengenes Taxonomy with Explicit Ranks for Ecological and Evolutionary Analyses of Bacteria and Archaea." The ISME Journal 6(3):610-18. Retrieved March 13, 2019 (http://www.cyanodb.cz).

McGuire, Krista L., Steven D. Allison, Noah Fierer, and Kathleen K. Treseder. 2013. "Ectomycorrhizal-Dominated Boreal and Tropical Forests Have Distinct Fungal Communities, but Analogous Spatial Patterns across Soil Horizons" edited by J. Thioulouse. PLoS ONE 8(7):e68278. Retrieved March 28, 2019 (http://dx.plos.org/10.1371/journal.pone.0068278).

McLaughlin, Samuel B. and Lynn Adams Kszos. 2005. "Development of Switchgrass (Panicum Virgatum) as a Bioenergy Feedstock in the United States.” Biomass and Bioenergy 28(6):515-35. Retrieved (http://linkinghub.elsevier.com/retrieve/pii/S0961953404001904).

Meentemeyer, Vernon. 1978. "Macroclimate and Lignin Control of Litter Decomposition Rates." Ecology 59(3):465-72. Retrieved April 2, 2019 (http://doi.wiley.com/10.2307/1936576).

Mendes, Rodrigo et al. 2011. "Deciphering the Rhizosphere Microbiome for DiseaseSuppressive Bacteria.” Science 332(6033):1097-1100. Retrieved March 30, 2019 (www.sciencemag.org/cgi/content/full/science.1202007/DC1).

Mendes, Rodrigo, Paolina Garbeva, and Jos M. Raaijmakers. 2013. “The Rhizosphere Microbiome: Significance of Plant Beneficial, Plant Pathogenic, and Human Pathogenic Microorganisms." FEMS Microbiology Reviews 37(5):634-63. Retrieved March 31, 2019 (https://academic.oup.com/femsre/article-abstract/37/5/634/540803).

Menkis, Audrius et al. 2012. "Occurrence and Impact of the Root-Rot Biocontrol Agent Phlebiopsis Gigantea on Soil Fungal Communities in Picea Abies Forests of Northern 
Europe.” FEMS Microbiology Ecology 81(2):438-45. Retrieved February 23, 2019

(https://academic.oup.com/femsec/article-abstract/81/2/438/504793).

Merino, C., R. Godoy, and F. Matus. 2016. "Soil Microorganisms and Enzyme Activity at Different Levels of Organic Matter Stability.” Journal of Soil Science and Plant Nutrition 16(ahead):0-0. Retrieved February 23, 2019 (https://pdfs.semanticscholar.org/14ed/6b7ff6f352999b83efa4e3a92a82acf0bc1c.pdf?_ga=2 $.142556018 .1710508271 .1550977350-1589004648.1550977350)$.

Meyer, F. et al. 2008. "The Metagenomics RAST Server - a Public Resource for the Automatic Phylogenetic and Functional Analysis of Metagenomes." BMC Bioinformatics 9(1):386. Retrieved February 12, 2019 (http://www.theseed.org).

Mueller, Rebecca C., Jayne Belnap, and Cheryl R. Kuske. 2015. "Soil Bacterial and Fungal Community Responses to Nitrogen Addition across Soil Depth and Microhabitat in an Arid Shrubland." Frontiers in Microbiology 6:891. Retrieved March 25, 2019 (www.frontiersin.org).

Mummey, Daniel L., Peter D. Stahl, and Jeffrey S. Buyer. 2002. "Microbial Biomarkers as an Indicator of Ecosystem Recovery Following Surface Mine Reclamation.” Applied Soil Ecology 21(3):251-59. Retrieved July 16, 2018 (https://www.sciencedirect.com/science/article/pii/S0929139302000902).

Naveed, Muhammad et al. 2016. "Spatial Variability of Microbial Richness and Diversity and Relationships with Soil Organic Carbon, Texture and Structure across an Agricultural Field.” Applied Soil Ecology 103:44-55. Retrieved March 27, 2019 (https://www.sciencedirect.com/science/article/pii/S092913931630066X?via\%3Dihub). 
Ndakidemi, P. A. 2006. "Manipulating Legume/cereal Mixtures to Optimize the above and below Ground Interactions in the Traditional African Cropping Systems." African Journal of Biotechnology 5(25):2526-33. Retrieved (http://www.scopus.com/inward/record.url?eid=2-s2.033846277212\&partnerID=40\&md5=505b64a394ea167a678911e620cf909f).

Nguyen, Nhu H. et al. 2016a. "FUNGuild: An Open Annotation Tool for Parsing Fungal Community Datasets by Ecological Guild." Fungal Ecology 20:241-48. Retrieved February 18, 2019 (https://www.sciencedirect.com/science/article/abs/pii/S1754504815000847).

Nguyen, Nhu H. et al. 2016b. "FUNGuild: An Open Annotation Tool for Parsing Fungal Community Datasets by Ecological Guild.” Fungal Ecology 20(13):241-48. Retrieved February 18, 2019 (www.elsevier.com/locate/soilbio).

Noguchi, H., T. Taniguchi, and T. Itoh. 2008. "MetaGeneAnnotator: Detecting Species-Specific Patterns of Ribosomal Binding Site for Precise Gene Prediction in Anonymous Prokaryotic and Phage Genomes." DNA Research 15:387-96.

Nurk, Sergey, Dmitry Meleshko, Anton Korobeynikov, and Pavel A. Pevzner. 2017. "metaSPAdes: A New Versatile Metagenomic Assembler." Genome Research 27(5):82434. Retrieved March 28, 2019 (https://genome.cshlp.org/content/27/5/824).

O’Leary, Nuala A. et al. 2016. "Reference Sequence (RefSeq) Database at NCBI: Current Status, Taxonomic Expansion, and Functional Annotation.” Nucleic Acids Research 44(D1):D73345. Retrieved March 28, 2019 (http://www.ncbi.nlm.nih.gov/pubmed/26553804).

Oksanen, Jari et al. 2019. "Package 'Vegan': Community Ecology Package.” http://vegan.rforge.r-project.org/. Retrieved February 23, 2019 (https://cran.r- 
project.org/web/packages/vegan/vegan.pdf).

Ouyang, Yang, Sarah E. Evans, Maren L. Friesen, and Lisa K. Tiemann. 2018. "Effect of Nitrogen Fertilization on the Abundance of Nitrogen Cycling Genes in Agricultural Soils: A Meta-Analysis of Field Studies.” Soil Biology and Biochemistry 127:71-78. Retrieved March 31, 2019 (https://linkinghub.elsevier.com/retrieve/pii/S0038071718302864).

Owens, V. N. N. et al. 2013. "Nitrogen Use in Switchgrass Grown for Bioenergy across the USA.” Biomass and Bioenergy 58:286-93. Retrieved June 5, 2018 (https://www.sciencedirect.com/science/article/pii/S0961953413003401).

Parada, Alma E., David M. Needham, and Jed A. Fuhrman. 2016. "Every Base Matters: Assessing Small Subunit rRNA Primers for Marine Microbiomes with Mock Communities, Time Series and Global Field Samples.” Environmental Microbiology 18(5):1403-14. Retrieved February 23, 2019 (http://doi.wiley.com/10.1111/1462-2920.13023).

Pedroso, Gabriel M. et al. 2013. "Yield and Nitrogen Management of Irrigated Switchgrass Systems in Diverse Ecoregions.” Agronomy Journal 105(2):311-20. Retrieved June 5, 2018 (https://www.agronomy.org/publications/aj/abstracts/105/2/311).

R., Yadav and Tarafdar J. 2001. "Influence of Organic and Inorganic Phosphorus Supply on the Maximum Secretion of Acid Phosphatase by Plants.” Biology and Fertility of Soils 34(3):140-43. Retrieved (http://link.springer.com/10.1007/s003740100376).

R Core Team. 2013. "R: A Language and Environment for Statistical Computing." Retrieved (http://www.r-project.org/).

Rajagopal, D., S. E. Sexton, D. Roland-Holst, and D. Zilberman. 2007. “Challenge of Biofuel: 
Filling the Tank without Emptying the Stomach?" Environmental Research Letters 2(4):44004. Retrieved (http://stacks.iop.org/17489326/2/i=4/a=044004?key=crossref.fba50ea732136d067e1f9900ac42e22f).

Rayment, GE and FR Higginson. 1992. "Australian Laboratory Handbook of Soil and Water Chemical Methods." Australian Soil and Land Survey Handbook 3. Retrieved February 11, 2019 (https://www.environment.nsw.gov.au/resources/soils/testmethods/phca.pdf).

Rho, M., H. Tang, and Y. Ye. 2010. "FragGeneScan: Predicting Genes in Short and Error-Prone Reads." Nucleic Acids Research 38(20):191.

Rinkes, Zachary L., Michael N. Weintraub, Jared L. DeForest, and Daryl L. Moorhead. 2011. "Microbial Substrate Preference and Community Dynamics during Decomposition of Acer Saccharum.” Fungal Ecology 4(6):396-407. Retrieved April 1, 2019 (https://www.sciencedirect.com/science/article/abs/pii/S1754504811000171).

Rinnan, Riikka and E. Baath. 2009. "Differential Utilization of Carbon Substrates by Bacteria and Fungi in Tundra Soil.” Applied and Environmental Microbiology 75(11):3611-20. Retrieved March 25, 2019 (http://aem.asm.org/).

Roosendaal, Damaris et al. 2016. "Switchgrass Ecotypes Alter Microbial Contribution to DeepSoil C.” Soil 2(2):185-97. Retrieved March 5, 2019 (www.soil-journal.net/2/185/2016/).

Rousk, Johannes et al. 2010. "Soil Bacterial and Fungal Communities across a pH Gradient in an Arable Soil.” The ISME Journal 4(10):1340-51. Retrieved March 13, 2019 (www.nature.com/ismej).

Rovira, Albert D. 1969. "Plant Root Exudates.” The Botanical Review 35(1):35-57. Retrieved 
March 31, 2019 (http://link.springer.com/10.1007/BF02859887).

Ryals, Rebecca, Michael Kaiser, Margaret S. Torn, Asmeret Asefaw Berhe, and Whendee L. Silver. 2014. "Impacts of Organic Matter Amendments on Carbon and Nitrogen Dynamics in Grassland Soils.” Soil Biology and Biochemistry 68:52-61. Retrieved March 27, 2019 (http://dx.doi.org/10.1016/j.soilbio.2013.09.011).

Saiya-Cork, K. .., R. .. Sinsabaugh, and D. .. Zak. 2002. "The Effects of Long Term Nitrogen Deposition on Extracellular Enzyme Activity in an Acer Saccharum Forest Soil.” Soil Biology and Biochemistry 34(9):1309-15.

Saravesi, Karita et al. 2015. "Moth Outbreaks Alter Root-Associated Fungal Communities in Subarctic Mountain Birch Forests.” Microbial Ecology 69(4):788-97. Retrieved March 28, 2019 (http://link.springer.com/10.1007/s00248-015-0577-8).

Sathya, Arumugam, Rajendran Vijayabharathi, and Subramaniam Gopalakrishnan. 2017. "Plant Growth-Promoting Actinobacteria: A New Strategy for Enhancing Sustainable Production and Protection of Grain Legumes.” 3 Biotech 7(2):102. Retrieved March 27, 2019 (http://www.ncbi.nlm.nih.gov/pubmed/28560641).

Sato, Takumi, Tatsuhiro Ezawa, Weiguo Cheng, and Keitaro Tawaraya. 2015. "Release of Acid Phosphatase from Extraradical Hyphae of Arbuscular Mycorrhizal Fungus Rhizophagus Clarus." Soil Science and Plant Nutrition 61(2):269-74. Retrieved March 13, 2019 (https://www.tandfonline.com/action/journalInformation?journalCode=tssp20).

Sawyer, Anne et al. 2019. "Cultivar and Phosphorus Effects on Switchgrass Yield and Rhizosphere Microbial Diversity.” Applied Microbiology and Biotechnology 103(4):197387. Retrieved March 30, 2019 (http://link.springer.com/10.1007/s00253-018-9535-y). 
Schachtman, Daniel P., Robert J. Reid, and S. M. Ayling. 1998. "Phosphorus Uptake by Plants: From Soil to Cell.” Plant Physiology 116(2):447-53. Retrieved March 5, 2019 (www.plantphysiol.org).

Schimel, Joshua, Teri C. Balser, and Matthew Wallenstein. 2007. "Microbial Stress Response Physiology and Its Implications for Ecosystem Function.” Ecology 88(6):1386-94. Retrieved March 25, 2019 (http://doi.wiley.com/10.1890/06-0219).

Shrestha, Raj K., Rattan Lal, and Pierre-Andre Jacinthe. 2009. "Enhancing Carbon and Nitrogen Sequestration in Reclaimed Soils through Organic Amendments and Chiseling." Soil Science Society of America Journal 73(3):1004. Retrieved (https://www.soils.org/publications/sssaj/abstracts/73/3/1004).

Siciliano, Steven D. et al. 2014. "Soil Fertility Is Associated with Fungal and Bacterial Richness, Whereas pH Is Associated with Community Composition in Polar Soil Microbial Communities.” Soil Biology and Biochemistry 78:10-20. Retrieved March 13, 2019 (http://dx.doi.org/10.1016/j.soilbio.2014.07.005).

Sinsabaugh, Robert L. et al. 2008. "Stoichiometry of Soil Enzyme Activity at Global Scale." Ecology Letters 11(11):1252-64. Retrieved (http://doi.wiley.com/10.1111/j.14610248.2008.01245.x).

Skousen, Jeff, Travis Keene, Mike Marra, and Brady Gutta. 2013. "Reclamation of Mined Land With Switchgrass, Miscanthus, and Arundo for Biofuel Production.” Journal American Society of Mining and Reclamation 2(1):177-91. Retrieved (http://www.asmr.us/Publications/Journal/Vol 2 Issue 1/Skousen-WV.pdf).

Smith, S. E., Iver Jakobsen, M. Gronlund, and F.Andrew Smith. 2011. "Roles of Arbuscular 
Mycorrhizas in Plant Phosphorus Nutrition: Interactions between Pathways of Phosphorus Uptake in Arbuscular Mycorrhizal Roots Have Important Implications for Understanding and Manipulating Plant Phosphorus Acquisition.” Plant Physiology 156(3):1050-57. Retrieved March 5, 2019 (www.plantphysiol.org/cgi/doi/10.1104/pp.111.174581).

Sokka, Laura, Riina Antikainen, and Pekka Kauppi. 2004. "Flows of Nitrogen and Phosphorus in Municipal Waste: A Substance Flow Analysis in Finland.” Progress in Industrial Ecology, An International Journal 1(1/2/3):165. Retrieved March 31, 2019 (http://hdl.handle.net/1975/285).

Stark, J. M. and Mary K. Firestone. 1995. "Mechanisms for Soil Moisture Effects on Activity of Nitrifying Bacteria." Applied and Environmental Microbiology 61(1):218-21. Retrieved March 25, 2019 (https://www.ncbi.nlm.nih.gov/pmc/articles/PMC1388328/pdf/hw0218.pdf).

Stone, A. G. et al. 2003. "Effect of Organic Amendments on Soilborne and Foliar Diseases in Field-Grown Snap Bean and Cucumber.” Plant Disease 87(9):1037-42. Retrieved March 30,2019 (https://pdfs.semanticscholar.org/ede8/56eb6e932f81793de938e4797f2e9529fe23.pdf).

Stott, D. E., S. S. Andrews, M. A. Liebig, Brian J. Wienhold, and D. L. Karlen. 2010. "Evaluation of $\beta$-Glucosidase Activity as a Soil Quality Indicator for the Soil Management Assessment Framework.” Soil Science Society of America Journal 74(1):107. Retrieved February 23, 2019 (http://digitalcommons.unl.edu/usdaarsfacpubhttp://digitalcommons.unl.edu/usdaarsfacpub/ 1222). 
Swedrzyńska, Dorota, Irena Małecka, Andrzej Blecharczyk, Arkadiusz Swedrzyński, and Justyna Starzyk. 2013. “Effects of Various Long-Term Tillage Systems on Some Chemical and Biological Properties of Soil." Polish Journal of Environmental Studies 22(6):1835-44. Retrieved April 19, 2019 (https://www.researchgate.net/publication/286015857).

Tabatabai, M. 1994. "Soil Enzymes." Pp. 775-833 in Methods of Soil Analysis. Part 2: Microbiological and biochemical properties. Madison, WI.

Tang, Ya, Jia-Sui Xie, and Shu Geng. 2010. "Marginal Land-Based Biomass Energy Production in China." Journal of Integrative Plant Biology 52(1):112-21. Retrieved September 28, 2018 (http://doi.wiley.com/10.1111/j.1744-7909.2010.00903.x).

Tarafdar, J. C. and Norbert Claassen. 1988. “Organic Phosphorus Compounds as a Phosphorus Source for Higher Plants through the Activity of Phosphatases ..." Biology and Fertility of Soils 5(October 2016):308-12.

Terrat, Sébastien et al. 2017. "Mapping and Predictive Variations of Soil Bacterial Richness across France” edited by X. Li. PLOS ONE 12(10):e0186766. Retrieved March 27, 2019 (https://dx.plos.org/10.1371/journal.pone.0186766).

Tharanathan, Rudrapatnam N. and Farooqahmed S. Kittur. 2003. "Chitin — The Undisputed Biomolecule of Great Potential." Critical Reviews in Food Science and Nutrition 43(1):6187. Retrieved April 1, 2019 (http://www.ncbi.nlm.nih.gov/pubmed/12587986).

Tilman, David, Christian Balzer, Jason Hill, and Belinda L. Befort. 2011. "Global Food Demand and the Sustainable Intensification of Agriculture." Proceedings of the National Academy of Sciences 108(50):20260-64. Retrieved March 11, 2019 (https://www-ncbi-nlm-nihgov.www.libproxy.wvu.edu/pmc/articles/PMC3250154/pdf/pnas.201116437.pdf). 
Treseder, Kathleen K. and Alison Cross. 2006. "Global Distributions of Arbuscular Mycorrhizal Fungi." Ecosystems 9(2):305-16. Retrieved (https://doi.org/10.1007/s10021-005-0110-x).

Tukey, John W. 1949. "Comparing Individual Means in the Analysis of Variance Author ( S ): John W . Tukey Published by : International Biometric Society Stable URL : http://www.jstor.org/stable/3001913.” International Biometric Society 5(2):99-114. Retrieved February 23, 2019 (https://pdfs.semanticscholar.org/392f/58ba40429bd2fdcc24e54bf0c07a99b02dab.pdf).

U.S. Department of the Interior. 1977. The Surface Mining Control and Reclamation Act (SMCRA). Retrieved February 16, 2019 (https://www.doi.gov/ocl/hearings/110/SMCRA_072507).

U.S. Energy Information Administration. 2019. Monthly Energy Review - January 2019. Retrieved February 16, 2019 (https://www.eia.gov/totalenergy/data/monthly/pdf/sec1_7.pdf).

UNITE Community. 2019. “UNITE QIIME Release for Fungi.” Retrieved (https://plutof.ut.ee/\#/doi/10.15156/BIO/786334).

United Nations Department of Economic and Social Affairs. 2017. World Population Prospects: The 2017 Revision, Key Findings and Advance Tables. edited by Intergovernmental Panel on Climate Change. Cambridge: Cambridge University Press. Retrieved March 11, 2019 (https://population.un.org/wpp/Publications/Files/WPP2017_KeyFindings.pdf).

United States 102d Congress. 1992. Energy Policy Act of 1992. Retrieved November 12, 2018 (https://afdc.energy.gov/files/pdfs/2527.pdf). 
Varvel, G. E., K. P. Vogel, R. B. Mitchell, R. F. Follett, and J. M. Kimble. 2008. "Comparison of Corn and Switchgrass on Marginal Soils for Bioenergy.” Biomass and Bioenergy 32(1):1821. Retrieved September 28, 2018 (http://www.elsevier.com/locate/biombioe).

van der Wal, Annemieke, Thomas D. Geydan, Thomas W. Kuyper, and Wietse de Boer. 2013.

“A Thready Affair: Linking Fungal Diversity and Community Dynamics to Terrestrial Decomposition Processes.” FEMS Microbiology Reviews 37(4):477-94. Retrieved March 26, 2019 (https://academic.oup.com/femsre/article-abstract/37/4/477/2398950).

Walker, Travis S., Harsh Pal Bais, Erich Grotewold, and Jorge M. Vivanco. 2003. "Root Exudation and Rhizosphere Biology Root Exudation and Rhizosphere Biology.” Plant Physiology 132(1):44-51.

Wang, Fenghua et al. 2018. "Long-Term Nitrogen Fertilization Elevates the Activity and Abundance of Nitrifying and Denitrifying Microbial Communities in an Upland Soil: Implications for Nitrogen Loss From Intensive Agricultural Systems.” Frontiers in Microbiology 9:2424. Retrieved March 31, 2019

(https://www.frontiersin.org/article/10.3389/fmicb.2018.02424/full).

Warren, Melissa J. et al. 2017. "Molybdenum-Based Diazotrophy in a Sphagnum Peatland in Northern Minnesota” edited by A. J. M. Stams. Applied and Environmental Microbiology 83(17). Retrieved March 2, 2019 (http://aem.asm.org/).

West, A. W. and G. P. Sparling. 1986. Modifications to the Substrate-Induced Respiration Method to Permit Measurement of Microbial Biomass in Soils of Differing Water Contents. Retrieved March 11, 2019 (https://ac-els-cdncom.www.libproxy.wvu.edu/0167701286900126/1-s2.0-0167701286900126- 
main.pdf?_tid=182ed5a5-b4c8-42a3-b215-

1da1a450e630\&acdnat=1552326083_ee580128c52e0a7fe8e496543515b85f).

White, T. J., T. Bruns, S. Lee, and J. Taylor. 1990. “Amplification and Direct Sequencing of Fungal Ribosomal RNA Genes for Phylogenetics.” Pp. 315-22 in In:PCR protocols: a guide to methods and applications. Retrieved February 23, 2019 (https://nature.berkeley.edu/brunslab/papers/white1990.pdf).

Wolkowski, Richard P. 2003. "Nitrogen Management Considerations for Landspreading Municipal Solid Waste Compost." Journal of Environment Quality 32(5):1844. Retrieved (https://www.agronomy.org/publications/jeq/abstracts/32/5/1844).

Wolna-Maruwka, A., J. Klama, and A. Niewiadomska. 2007. "Effect of Fertilization Using Communal Sewage Sludge on Respiration Activity and Counts of Selected Microorganisms in the Grey Brown Podzolic Soil.” Polish Journal of Environmental Studies 16(6):899.907. Retrieved April 19, 2019 (http://www.pjoes.com/Effect-of-Fertilization-Using-CommunalSewage-r-nSludge-on-Respiration-Activity-and,88064,0,2.html).

Xia, Ye, Amna Amna, and Stephen Obol Opiyo. 2018. "The Culturable Endophytic Fungal Communities of Switchgrass Grown on a Coal-Mining Site and Their Effects on Plant Growth" edited by R. Aroca. PLOS ONE 13(6):e0198994. Retrieved April 16, 2019 (https://www.npr.org/templates/story/story.php?storyId=9966084).

Xia, Ye, Eliana Greissworth, Curtis Mucci, Mark A. Williams, and Seth De Bolt. 2013. "Characterization of Culturable Bacterial Endophytes of Switchgrass ( Panicum Virgatum L.) and Their Capacity to Influence Plant Growth.” GCB Bioenergy 5(6):674-82. Retrieved (http://doi.wiley.com/10.1111/j.1757-1707.2012.01208.x). 
Xue, Kai et al. 2018. "Functional Activity and Functional Gene Diversity of a Cu-Contaminated Soil Remediated by Aided Phytostabilization Using Compost, Dolomitic Limestone and a Mixed Tree Stand.” Environmental Pollution 242:229-38. Retrieved April 1, 2019 (https://doi.org/10.1016/j.envpol.2018.06.057).

Xue, Pei-Pei, Yolima Carrillo, Vanessa Pino, Budiman Minasny, and Alex. B. McBratney. 2018. "Soil Properties Drive Microbial Community Structure in a Large Scale Transect in South Eastern Australia.”Scientific Reports 8(1):11725. Retrieved March 25, 2019 (www.nature.com/scientificreports/).

Zhang, Tao, Neng-Fei Wang, Hong-Yu Liu, Yu-Qin Zhang, and Li-Yan Yu. 2016. "Soil pH Is a Key Determinant of Soil Fungal Community Composition in the Ny-Ålesund Region, Svalbard (High Arctic)." Frontiers in Microbiology 7. Retrieved March 13, 2019 (www.frontiersin.org).

Zhang, Yulan, Lijun Chen, Zhijie Wu, and Caixia Sun. 2011. "Kinetic Parameters of Soil BetaGlucosidase Response to Environmental Temperature and Moisture Regimes." R. Bras. Ci. Solo. 35:1285-91. Retrieved February 23, 2019 (http://www.scielo.br/pdf/rbcs/v35n4/a22v35n4.pdf). 